\title{
CÁLCULO DE ESFORÇOS E DESLOCAMENTOS EM ESTRUTURAS RETICULADAS CONSIDERANDO-SE A MECÂNICA DO DANO PARA A MODELAGEM DO CONCRETO ARMADO
}

\section{Alexandre Sampaio Botta}

Dissertação apresentada à Escola de Engenharia de São Carlos da Universidade de São Paulo, como parte dos requisitos para obtenção do título de Mestre em Engenharia de Estruturas

ORIENTADOR: Prof. Dr. Wilson Sergio Venturini

São Carlos

1998 


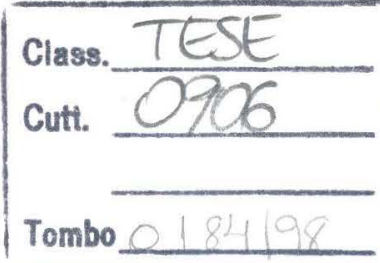

B751c Cálculo de esforços e deslocamentos em estruturas reticuladas considerando-se a mecânica do dano para a modelagem do concreto armado / Alexandre Sampaio Botta. -- São Carlos, 1998.

Dissertação (Mestrado) -- Escola de Engenharia de São Carlos-Universidade de São Paulo, 1998. Área: Engenharia de Estruturas.

Orientador: Prof. Dr. Wilson Sergio Venturini.

1. Análise não-linear. 2. Mecânica do dano. 3. Concreto armado. I. Título. 


\section{FOLHA DE APROVAC̄̃̃}

Candidato: Engenheiro ALEXANDRE SAMPAIO BOTTA

Dissertação defendida e aprovada em 13-05-1998 pela Comissão Julgadora:

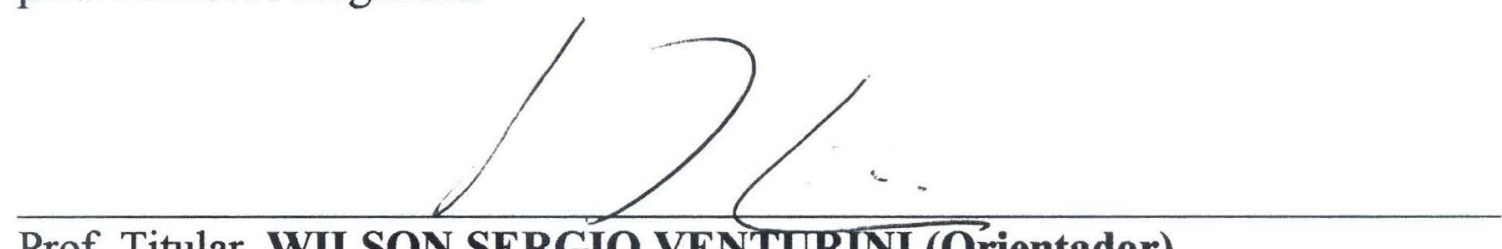

Prof. Titular WILSON SERGIO VENTURINI (Orientador)

(Escola de Engenharia de São Carlos - Universidade de São Paulo)

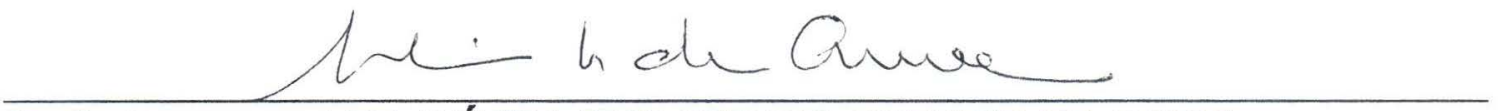

Profa. Doutora ANA LÚCIA HOMCE DE CRESCE EL DEBS

(Escola de Engenharia de São Carlos - Universidade de São Paulo)

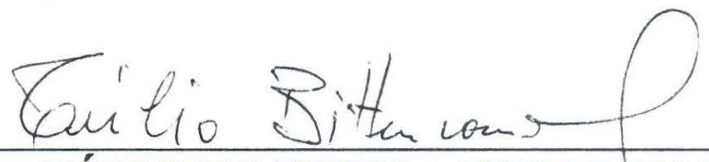

Prof. Doutor TÚLIO NOGUEIRA BITTENCOURT

(Escola Politécnica - Universidade de São Paulo)

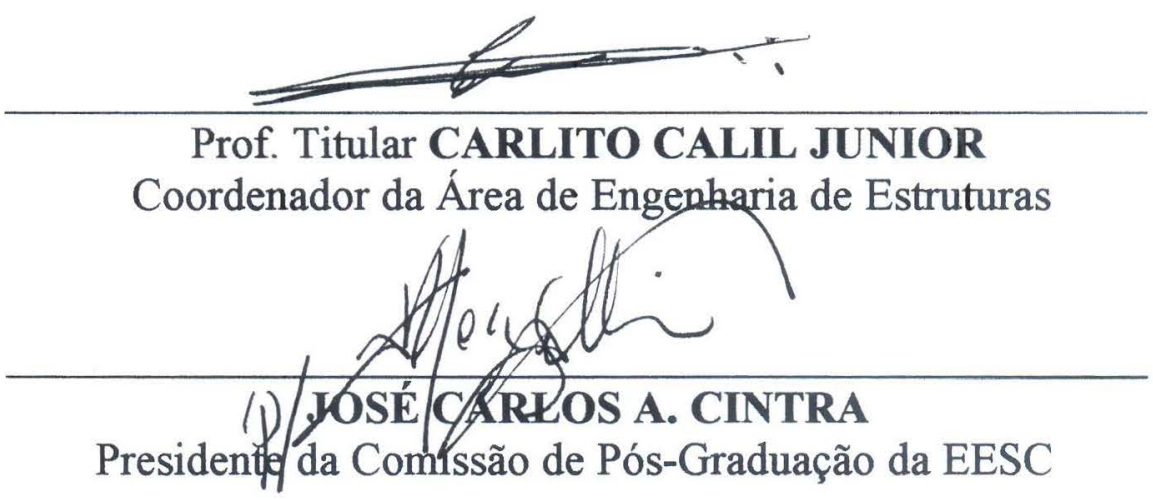




\section{Dedico aos meus pais,}

aos meus avós e ao meu irmão. 


\section{AGRADECIMENTOS}

\section{À Deus, por tudo.}

Ao meu orientador Wilson Sergio Venturini pelo apoio, pelos ensinamentos e pela amizade conquistados ao longo do período de desenvolvimento do trabalho.

Aos colegas do departamento de estruturas pela amizade, troca de conhecimentos e agradável convivência.

Aos funcionários do departamento pela atenção e ajuda que puderam dar durante o período de desenvolvimento do trabalho.

Ao CNPq pelo apoio financeiro. 


\section{SUMÁRIO}

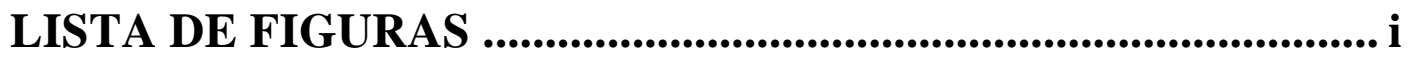

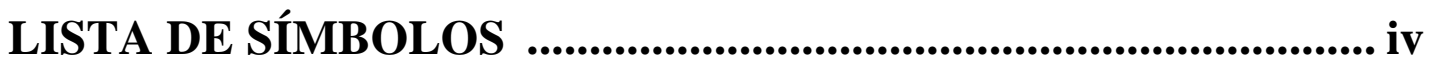

RESUMO ........................................................................................ vii

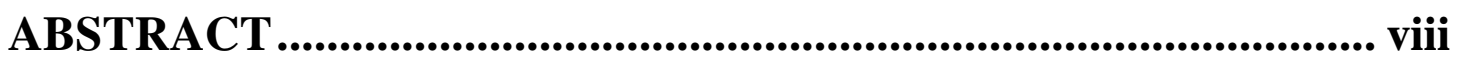

\section{1 - INTRODUÇÃ̂̃}

1.1- Generalidades e síntese do conteúdo da dissertação ........................1

1.2- Comportamento experimental do concreto à compressão e à tração .. 3

1.3- Modelos de previsão para o comportamento dos materiais estruturais 7

1.4- Análise estrutural de pavimentos de edifícios de concreto armado .....8 8

2.1- Contribuição do concreto entre fissuras na resistência à tração .........10

2.2- Conceito de estados limites e verificação da segurança estrutural ...... 12 
2.3- Modelo elasto-plástico para as barras de aço da armadura

3 - MODELOS CONSTITUTIVOS DE DANO PARA O CONCRETO

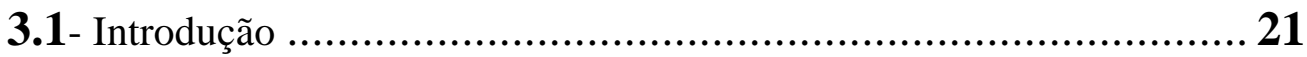

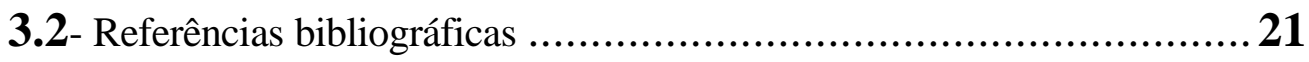

3.3- Hipóteses e definições básicas dos modelos de dano isótropos .......... 25

3.4- Modelo de dano de Mazars ........................................................ 28

3.5- Modelo de dano proposto por Cervera et. alli ............................. 36

3.6- Representação geométrica dos critérios de dano ............................ 41

3.7- Influência dos parâmetros de dano à tração na resposta numérica ......45

\section{4 - APLICAÇÃO NUMÉRICA DOS MODELOS DE DANO À .... ANÁLISE DE PAVIMENTOS DE CONCRETO ARMADO ........ 51}

4.1- Elementos finitos lineares de barra para modelagem de grelhas .........51

4.2- Modelos de dano escritos em variáveis generalizadas .....................53

4.3- Procedimento para cálculo da linha neutra de uma seção ................ 58

4.4- Procedimento incremental-iterativo de resolução numérica .............. 61

4.5- Solução do problema de valor de contorno com modelos de dano .......

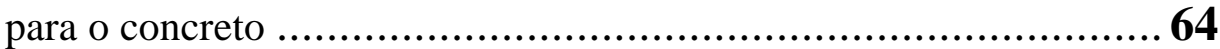


5 - EXEMPLOS DE APLICAÇÃO ...................................................... 69

- Exemplo 01 - Vigas em concreto armado com cargas concentradas ..70

- Exemplo 02 - Pavimento de edifício em concreto armado ...................78

- Exemplo 03 - Comparação entre modelos de dano e modelo do ...........

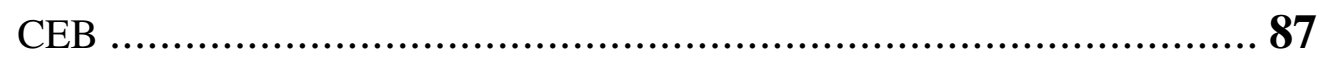

6 - CONCLUSÕES ..............................................................93

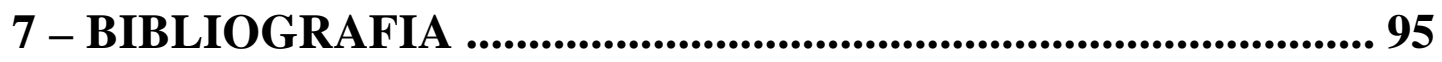




\section{LISTA DE FIGURAS}

Figura 1.1 - Fissuração inicial do concreto ....................................................... 4

Figura 1.2 - Modos básicos de solicitação de uma fissura ........................................ 4

Figura 1.3 - Curva típica tensão-deformação do concreto à compressão .................. 5

Figura 1.4 - Curva típica tensão-deformação do concreto à tração............................. 6

Figura 1.5 - Fissuração do concreto à compressão e à tração..................................... 6

Figura 2.1 - Estádios de comportamento de peças de concreto armado..................... 10

Figura 2.2 - Tensões no concreto e na armadura entre fissuras ................................ 11

Figura 2.3 - Diagrama momento-curvatura proposto pelo CEB/158 ……………... 12

Figura 2.4 - Diagrama de tensões no concreto da NBR-6118 ................................ 13

Figura 2.5 - Ciclos de deformação e de tensão na plasticidade ................................. 15

Figura 2.6 - Curva tensão-deformação do modelo elasto-plástico unidimensional .. 16

Figura 2.7 - Modelo elasto-plástico perfeito e com encruamento ............................. 17

Figura 2.8 - Variação do limite elástico para encruamento isótropo e cinemático .... 18

Figura 2.9 - Situações teóricas possíveis do modelo com encruamento isótropo ..... 20

Figura 3.1 - Mecânica do Dano e Mecânica da Fratura …………………………... 25

Figura 3.2 - Elemento de volume de um sólido danificado ...................................... 26

Figura 3.3 - Hipótese da deformação equivalente ………………………………... 27

Figura 3.4 - Comportamento unilateral do concreto.............................................. 29

Figura 3.5 - Diagramas do concreto à tração ........................................................... 30

Figura 3.6 - Representação esquemática das variáveis de dano em função de $\widetilde{\varepsilon}$..... 32

Figura 3.7 - Diagramas experimental e teórico para o concreto à tração e à

compressão 
Figura 3.8 - Superfície de dano no espaço das deformações principais .................. 42

Figura 3.9 - Superfície inicial para estados biaxiais de tensões principais efetivas .... 43

Figura 3.10 - Critério de Drucker-Prager para um material isótropo ..................... 44

Figura 3.11 - Energia dissipada na tração no modelo de Cervera .......................... 45

Figura 3.12 - Trecho softening linear do concreto na tração uniaxial...................... 47

Figura 3.13 - Trecho softening exponencial do concreto na tração uniaxial ............. 49

Figura 4.1 - Sistemas de coordenadas locais para o elemento finito de grelha.......... 52

Figura 4.2 - Relações entre curvaturas e deformações ........................................ 55

Figura 4.3 - Diagrama de tensões no concreto e na armadura .............................. 56

Figura 4.4 - Características geométricas de seções retangulares .............................. 57

Figura 4.5 - Diagrama momento-curvatura de uma seção de concreto armado........ 58

Figura 4.6 - Deformações específicas em função da posição da linha neutra............ 59

Figura 4.7 - Procedimento numérico de aproximações sucessivas para busca de raízes de funções

Figura 4.8 - Deformação angular constante para diferentes valores da LN ............. 61

Figura 4.9 - Procedimento de Newton-Raphson para caso unidimensional .............. 63

Figura 4.10 - Rigidez secante da curva "momento-curvatura".............................. 64

Figura 5.1 - Geometria das vigas em concreto armado .................................. 70

Figura 5.2 - Distribuição das armaduras nas vigas.......................................... 71

Figura 5.3 - Diagrama tensão-deformação uniaxial para carregamento cíclico......... 72

Figura 5.4 - Discretização das vigas em elementos de barra para análise numérica .. 74

Figura 5.5 - Diagrama carga x deslocamento para viga pouco armada .................. 75

Figura 5.6 - Diagrama carga x deslocamento para viga normalmente armada .......... 75

Figura 5.7 - Diagrama carga x deslocamento para viga super armada.................... 76

Figura 5.8 - Forma do pavimento do pilotis .............................................. 80

Figura 5.9 - Metade do pavimento simétrico............................................... 81

Figura 5.10 - Numeração de nós e elementos da malha de elementos finitos ........... 82

Figura 5.11 - Carregamento de serviço distribuído nas vigas do pavimento............. 83

Figura 5.12 - Diagrama carga x deslocamento do nó 29 ................................... 84 
Figura 5.13 - Diagrama carga x deslocamento do nó 56 .................................. 84

Figura 5.14 - Diagrama carga x deslocamento do nó 83 ..................................... 85

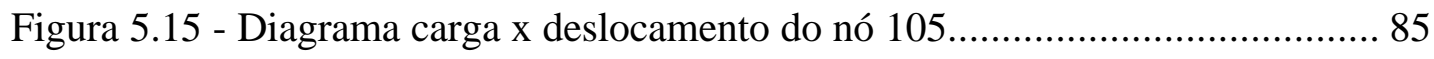

Figura 5.16 - Distribuição dos momentos fletores nas vigas do pavimento .............. 86

Figura 5.17 - Viga solicitada a momento fletor constante ................................. 87

Figura 5.18 - Diagramas "momento-curvatura" para viga com momento constante. 88

Figura 5.19 - Diagramas "momento-curvatura" ajustados pelo modelo do CEB ..... para viga com momento constante ......................................... 89

Figura 5.20 - Diagrama carga x deslocamento do nó 29 para parâmetros de dano ... ajustados pelo modelo do CEB ............................................. 90

Figura 5.21 - Diagrama carga x deslocamento do nó 56 para parâmetros de dano ... ajustados pelo modelo do CEB ............................................... 90

Figura 5.22 - Diagrama carga x deslocamento do nó 83 para parâmetros de dano ... ajustados pelo modelo do CEB ............................................... 91

Figura 5.23 - Diagrama carga x deslocamento do nó 105 para parâmetros de dano .. ajustados pelo modelo do CEB 91 


\section{LISTA DE SÍMBOLOS}

\section{Gregos}

$\alpha$

$\alpha_{C}$

$\alpha_{T}$

$\varepsilon$

$\widetilde{\varepsilon}$

$\varepsilon^{\mathrm{e}}$

$\varepsilon^{p}$

$\varepsilon_{\mathrm{d} 0}$

$\underline{\varepsilon}$

$\underline{\varepsilon}_{C}$

$\underline{\varepsilon} \mathrm{T}$

$\dot{\lambda}$

$\sigma$

$\underline{\sigma}$
Variável interna do modelo elasto-plástico

Coeficiente que multiplica o parâmetro de dano à compressão no modelo de Mazars

Coeficiente que multiplica o parâmetro de dano à tração no modelo de Mazars

Deformação uniaxial total do modelo elasto-plástico

Deformação equivalente

Deformação uniaxial elástica do modelo elasto-plástico

Deformação uniaxial plástica do modelo elasto-plástico

Deformação correspondente ao pico de tensão de um ensaio de tração uniaxial no concreto

Tensor das deformações

Parte negativa do tensor de deformações

Parte positiva do tensor de deformações

Valor absoluto da velocidade de deformação plástica do modelo elastoplástico

Tensão uniaxial do modelo elasto-plástico

Tensor de tensões 
б $\quad$ Tensão efetiva unidimensional

$\underline{\tilde{\sigma}} \quad$ Tensor de tensões efetivas

$\langle\underline{\sigma}\rangle_{+} \quad$ Parte positiva do tensor de tensões efetivas

$\langle\underline{\sigma}\rangle_{-} \quad$ Parte negativa do tensor de tensões efetivas

$\sigma_{\mathrm{Ct}} \quad$ Tensão de tração no concreto

$\sigma_{y} \quad$ Tensão limite de plastificação do aço

$\bar{\tau}^{+} \quad$ Norma equivalente de tração efetiva

$\bar{\tau}^{-} \quad$ Norma equivalente de compressão efetiva

\section{Romanos}

$\mathrm{A}_{\mathrm{C}}, \mathrm{B}_{\mathrm{C}} \quad$ Parâmetros de dano à compressão do modelo de Mazars

$\mathrm{A}_{\mathrm{T}}, \mathrm{B}_{\mathrm{T}} \quad$ Parâmetros de dano à tração do modelo de Mazars

$\mathrm{A}^{+} \quad$ Parâmetro de dano à tração do modelo de Cervera

$\mathrm{A}^{-}, \mathrm{B}^{-} \quad$ Parâmetros de dano à compressão do modelo de Cervera

$\mathrm{d}^{+} \quad$ Variável escalar de dano à tração do modelo de Cervera

$\mathrm{d}^{-} \quad$ Variável escalar de dano à compressão do modelo de Cervera

D Variável escalar de dano do modelo de Mazars

D $\quad$ Variável escalar de dano à compressão do modelo de Mazars

$\mathrm{D}_{\mathrm{T}} \quad$ Variável escalar de dano à tração do modelo de Mazars

$\underline{\underline{D}}_{0} \quad$ Tensor elástico linear do material íntegro

E Módulo de elasticidade longitudinal

E Módulo de elasticidade do material com dano

f Critério de plastificação ou critério de dano

$\mathrm{f}_{\mathrm{Ct}} \quad$ Resistência à ruptura do concreto à tração 
$\mathrm{F}_{\mathrm{C}}(\tilde{\varepsilon}) \quad$ Função contínua e positiva da deformação equivalente do modelo de Mazars

$\mathrm{F}_{\mathrm{T}}(\tilde{\varepsilon}) \quad$ Função contínua e positiva da deformação equivalente do modelo de Mazars

H Módulo plástico do aço com encruamento isótropo

$\mathrm{g}^{+} \quad$ Critério de dano à tração do modelo de Cervera

$\mathrm{g}^{-} \quad$ Critério de dano à compressão do modelo de Cervera

$\mathrm{r}_{0}^{+} \quad$ Parâmetro de dano à tração do modelo de Cervera

$\mathrm{r}^{+}, \mathrm{r}^{-} \quad$ Variáveis que controlam o tamanho das superfícies de danificação do modelo de Cervera

$\mathrm{r}_{0}{ }^{-} \quad$ Parâmetro de dano à compressão do modelo de Cervera

So Área danificada de uma superfície

S Área total de uma superfície

S $\quad$ Área resistente efetiva de uma superfície 


\section{RESUMO}

O trabalho tem o objetivo de contribuir no avanço das metodologias de cálculo de esforços e deslocamentos em serviço das estruturas de pavimentos de edifícios a partir da consideração de modelos não-lineares que representam com mais fidelidade o comportamento real do concreto armado.

A forte não-linearidade física revelada nas curvas tensão-deformação obtidas de ensaios de corpos de prova de concreto atesta a exigência crescente de sua consideração nos modelos matemáticos de previsão do comportamento das estruturas usuais de concreto armado.

Os modelos fundamentados na Mecânica do Dano Contínuo aplicam-se à previsão do comportamento do concreto por ser este um material que apresenta degradação de suas propriedades mecânicas em função do crescimento de microfissuras continuamente distribuídas na massa do material.

O trabalho consta da implementação de dois algoritmos que descrevem os modelos de dano para o concreto propostos por Mazars e Cervera et. alli. que tem por finalidade a determinação de esforços e deslocamentos em grelhas de pavimentos de concreto armado supondo a armadura concentrada em uma única camada e obedecendo a um regime de comportamento elasto-plástico com encruamento.

O método dos elementos finitos é aplicado e o modelo é transformado da relação escrita em termos de "tensão X deformação" para "momento X curvatura". 


\begin{abstract}
This work aims to contribute with the displacement and effort evaluation methodology for building floor structures in service, by taking into consideration nonlinear models that can better represent the actual reinforced concrete behaviour.

The strong physical non-linearities shown by the stress $\times$ strain curves built from concrete testing samples emphasise the necessity of considering them to write the mathematical models used to simulate usual reinforced concrete structures.

Models based on the continuum damage mechanics are applied to evaluate the concrete behaviour, due to be that material susceptible to mechanical property degradation achieved due to the growth of microfissures continually distributed inside the body.

The work consists on the implantation of two algorithms based on the damage models proposed by Mazars and Cervera et alli, aiming to find displacements and efforts in reinforced concrete floor grids, assuming that the reinforcement is concentrated at a single layer and follows an elasto-plastic relationship.

The classical stress $\times$ strain relationship is transformed into a relation given in terms of moment $\times$ curvature to be implemented together a non-linear finite element approach.
\end{abstract}




\section{CAPÍTULO 1}

\section{INTRODUÇÃO}

\section{1 - Generalidades e síntese do conteúdo da dissertação}

A análise estrutural de pavimentos de edifícios de concreto armado sofreu significativas mudanças no formato do tratamento a eles dispensado nas últimas décadas. Profissionais projetistas das estruturas usuais de edifícios passaram a automatizar os cálculos que são requeridos para o bom funcionamento das estruturas. Isso se deveu principalmente à acessibilidade dos microprocessadores junto aos engenheiros projetistas.

Paralelamente aos esforços do meio técnico em adquirir rotinas de cálculo cada vez mais automatizadas, o meio científico e acadêmico buscava entender melhor o comportamento do concreto e do aço e, dessa forma, tentar previsões mais verdadeiras do comportamento das estruturas de concreto armado.

Em particular, o estudo de mecanismos físicos de deformação e ruptura de materiais como o concreto e o aço levou pesquisadores a se interessarem pelas análises fenomenológicas a nível de micro-estrutura dos materiais com o intuito de buscarem relações entre esses fenômenos e as curvas típicas tensão-deformação apresentadas pelos ensaios uni e multiaxiais de corpos de prova padronizados.

Este trabalho tem como objetivo apresentar resultados obtidos da análise estrutural de grelhas de pavimentos de edifícios de concreto armado considerando-se para o concreto modelos fundamentados na teoria da Mecânica do Dano Contínuo e para as barras de aço da armadura modelos elasto-plásticos com 
encruamento. Para tanto foi desenvolvido um código de cálculo em linguagem FORTRAN empregando-se a técnica dos elementos finitos para a interpolação das funções deslocamento do problema.

A análise estrutural aqui referenciada trata da verificação das peças em estado de serviço, onde exigências como a limitação de flechas e verificação da abertura de fissuras são de suma importância. Os modelos de dano se enquadram nesse tipo de análise porque levam em conta a perda da linearidade apresentada pelo concreto inclusive a baixas deformações. Mesmo com as hipóteses admitidas para os modelos de dano ainda se obtêm respostas mais confiáveis do que as obtidas pelos modelos simplificados como por exemplo aquele que considera peças no estádio II (resistência à tração desprezada) para solicitações de serviço.

Ainda no capítulo 1 algumas evidências experimentais do comportamento do concreto solicitado à compressão e à tração são relatadas. A seguir, fazem-se comentários sobre modelos mecânicos de previsão do comportamento de materiais estruturais. Ao final, tratam-se aspectos gerais da análise estrutural de pavimentos de edifícios de concreto armado.

No capítulo 2 discute-se a utilização dos modelos usuais e clássicos do concreto armado. Conceitos como início de fissuração, contribuição da resistência do concreto à tração entre fissuras e estados limites estão abordados. Ao final encontra-se uma descrição da formulação do modelo elasto-plástico com encruamento positivo para as barras de aço da armadura.

No capítulo 3 procura-se apresentar alguns conceitos centrais sobre os modelos de dano isótropos como o importante conceito de "deformação equivalente". Em seguida, apresentam-se os modelos constitutivos de dano de Mazars e de Cervera et. alli. Alguns aspectos particulares dos modelos isótropos e a questão da influência dos parâmetros de dano à tração na resposta numérica estão descritos ao final.

O quarto capítulo trata das aplicações dos modelos de dano descritos no capítulo 3 para análise de grelhas de pavimentos. Discute-se então a técnica dos elementos finitos, a utilização simplificada do elemento finito de barra ao invés do de chapa, a transformação dos modelos para variáveis generalizadas "momento $\mathrm{X}$ curvatura", os procedimentos incrementais-iterativos de resolução de problemas não- 
lineares, o procedimento de busca da linha neutra das seções transversais para posterior integração das tensões por quadratura de Gauss e, por fim, passos simplificados do algoritmo numérico.

No capítulo 5, são descritos um exemplo numérico de viga, um de pavimento de edifício de concreto armado e um com comparação entre modelos de dano e modelos usuais de normas com resultados comparativos entre os modelos implementados e com observações quanto à identificação paramétrica e sua influência nos resultados.

O trabalho ainda reúne as conclusões finais do estudo no capítulo 6 e a bibliografia consultada no capítulo 7. Em anexo encontram-se tabelas dos exemplos.

\section{2 - Comportamento experimental do concreto à compressão e à tração}

Sabe-se que o concreto antes mesmo de ser carregado apresenta fissuras distribuídas em seu volume e encontradas com predominância na interface entre agregados e massa cimentícia.

BUSSAMRA [6] cita que, sob condições corretas de umidade durante a cura, as micro-fissuras se dispõem tangencialmente à referida interface. Em condições diversas de cura, a retração da argamassa provoca aparecimento de microrachaduras perpendiculares à interface e, portanto, na própria argamassa. Além disso, cita que a danificação inicial do concreto pode ter como causa a formação de "filmes" de água acumulados ao redor dos agregados durante a cura. Isso explica a maior densidade de fissuras encontradas nos planos horizontais normais à direção da ação das forças gravitacionais.

$\mathrm{O}$ aspecto geral da micro-fissuração do concreto, antes de serem aplicadas cargas externas, pode ser visualizado na figura 1.1 . 


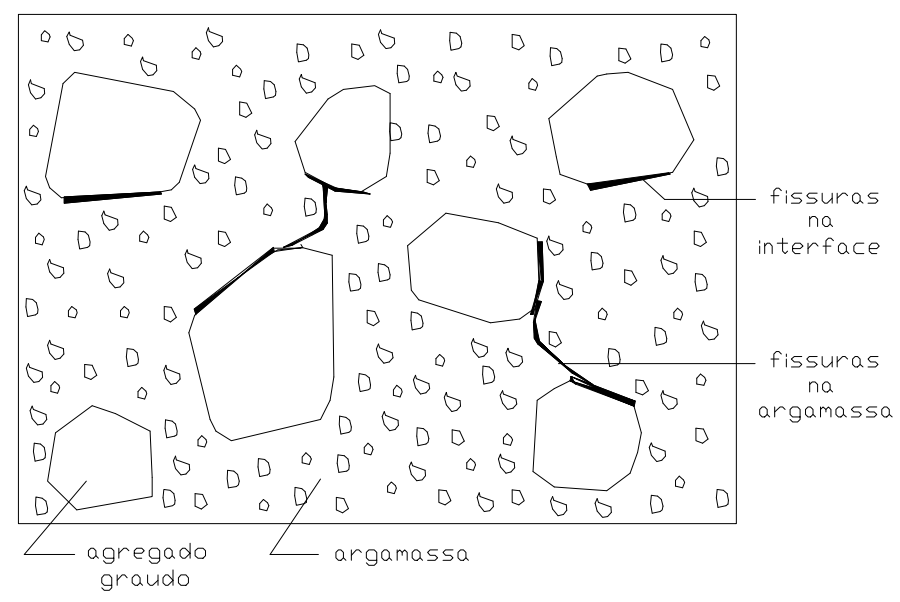

Figura 1.1 - Fissuração inicial do concreto.

Em um estado de compressão uniaxial as fissuras ocorrem preferencialmente numa direção paralela à da carga. Na tração uniaxial as fissuras se distribuem perpendicularmente à direção do carregamento. Fissuras encontradas na interface agregado-argamassa são denominadas primárias e aquelas situadas na massa de cimento e areia são ditas secundárias.

Uma importante classificação para o estudo de uma fissura ou trinca é o modo como essa é solicitada. Existem três modos possíveis. Qualquer outro constitui superposição desses. O modo I é caracterizado por um esforço de tração unidirecional, com a fissura se desenvolvendo num plano perpendicular ao do carregamento. O modo II caracteriza-se por um escorregamento entre as faces da fissura, com esforço cisalhante aplicado na direção paralela ao defeito. O modo III também carateriza-se por escorregamento entre as faces, porém com esforço cisalhante atuando na direção perpendicular à da fissura. A figura 1.2 apresenta o esquema geral dos três modos básicos.

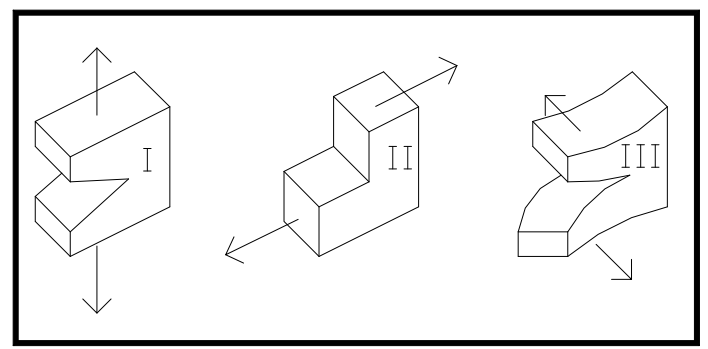

Figura 1.2 - Modos básicos de solicitação de uma fissura. 
Análises da danificação do concreto sob compressão permitem concluir que de 0 a $30 \%$ ou $40 \%$ da tensão máxima do ensaio uniaxial as fissuras permanecem estáveis na região da interface. Desse ponto até $70 \%$ ou $80 \%$ da carga máxima as fissuras se desenvolvem segundo os modos II (fissuras a $45^{\circ}$ em relação à direção da carga) e I ainda na região da interface agregado-argamassa. A partir daí ocorre instabilidade e rupturas locais na argamassa conduzindo o material à iminente ruptura devida a intensa degradação.

Os fenômenos observados microscopicamente se traduzem na forma apresentada pela curva tensão-deformação do ensaio de compressão uniaxial. Como se observa da figura 1.3, o material tem comportamento que se pode admitir linear até cerca de $30 \%$ da tensão de pico do ensaio, trecho que corresponde ao crescimento estável das micro-fissuras. A partir daí ocorre a crescente perda de rigidez proveniente da formação de novas fissuras e crescimento das já existentes.

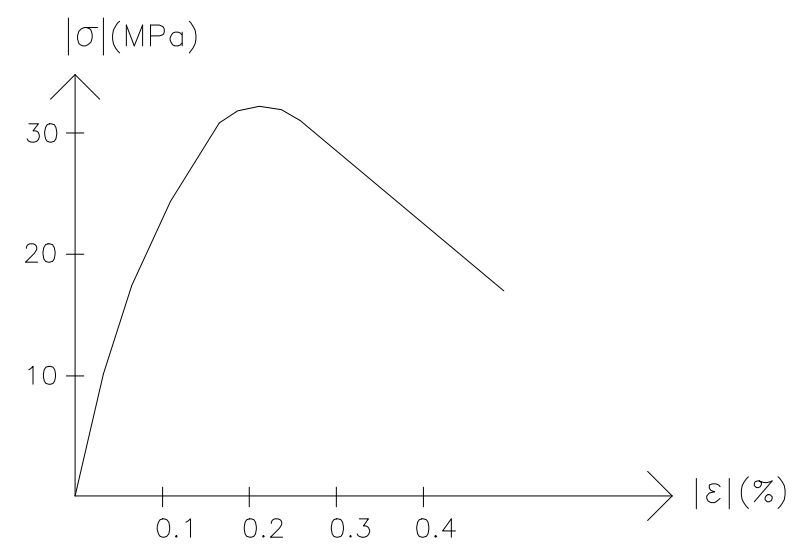

Figura 1.3 - Curva típica tensão-deformação do concreto à compressão

A perda de rigidez com carregamento crescente é facilmente observável nas curvas obtidas para carregamentos e descarregamentos sucessivos a diferentes níveis de tensão, verificando-se, então, uma proporcionalidade entre deformações residuais e nível de carga máxima dos diferentes recarregamentos.

$\mathrm{Na}$ tração uniaxial o comportamento do concreto é significativamente diferenciado. O material apresenta forte tendência à linearidade até cerca de $80 \%$ da tensão de pico. Após esse patamar surgem características de plasticidade e, atingida a 
máxima tensão, verifica-se uma queda abrupta do desenvolvimento da curva tensãodeformação, conforme pode ser observado na figura 1.4.

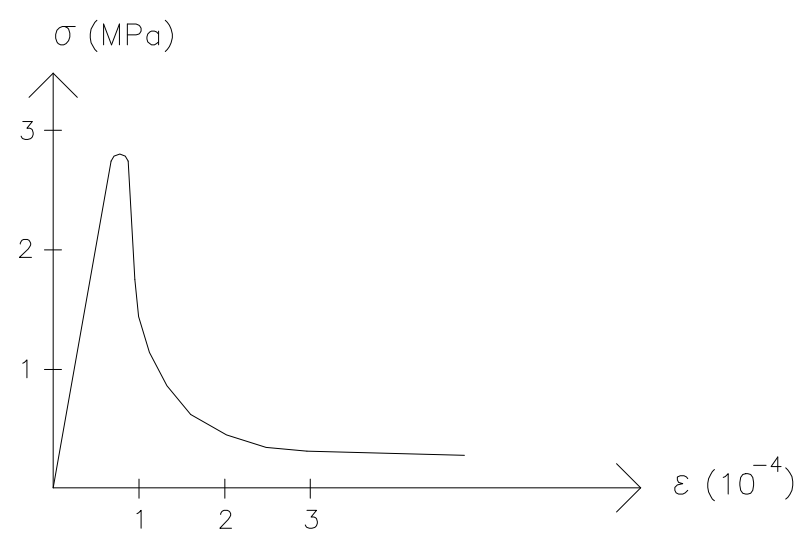

Figura 1.4 - Curva típica tensão-deformação do concreto à tração.

O modo I de fraturamento predomina para estados uniaxiais de tração. As fissuras primárias crescem com o aumento de carga caracterizando os modos I e II de solicitação. Posteriormente, propagam-se na argamassa (modo I) interligando-se umas às outras, podendo ocorrer inclusive uma danificação com instabilidade.

A figura 1.5 mostra a representação esquemática da evolução das microfissuras no concreto solicitado à compressão e à tração.

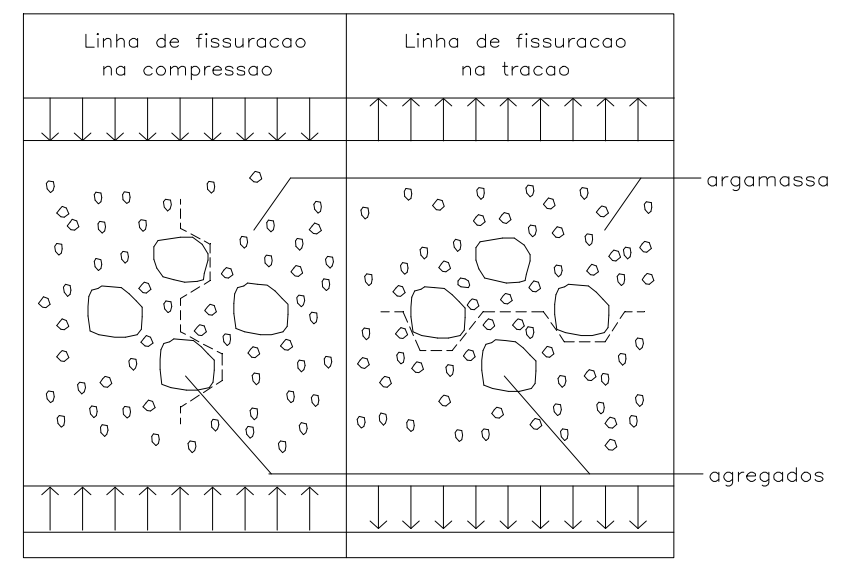

Figura 1.5 - Fissuração do concreto à compressão e à tração (linha pontilhada).

As fissuras ao redor dos agregados (fissuras primárias), tanto na compressão quanto na tração se desenvolvem segundo os modos I e II de solicitação. Com cargas próximas da máxima, em ambos os casos predomina modo I de 
fraturamento da argamassa (fissuras secundárias). Na compressão o modo II também acontece nessa região.

\section{3 - Modelos de previsão para o comportamento dos materiais estruturais}

As evidências experimentais do comportamento do concreto atestam que o engenheiro de estruturas tem que trabalhar com um material de alta complexidade. Além de sua constituição heterogênea, o concreto possui evidenciada diferença de comportamento à tração e à compressão, respostas distintas quando solicitado por ações estáticas ou dinâmicas, uni ou multiaxiais. A isso ainda acrescem-se os efeitos da retração, fluência e expansibilidade, que são, em geral, de difícil modelagem.

A procura por melhores modelos mecânicos que possam representar o comportamento do concreto sempre foi um tema de interesse para os pesquisadores. Ao mesmo tempo, o meio técnico sempre buscou agilidade e praticidade para a resolução dos problemas práticos de análise estrutural. Antes da difusão no mercado dos microcomputadores pessoais a técnica do meio contínuo (resolução dos problemas a partir do conhecimento da solução das equações diferenciais regentes) para a análise, por exemplo, de pórticos bi e tridimensionais de edifícios foi bastante utilizada.

Os métodos discretos, tais como diferenças finitas, elementos finitos e elementos de contorno, passaram a ter acentuada aplicação na pesquisa científica e na prática da engenharia a partir da evolução dos microprocessadores. Esse fato contribuiu para o tratamento mais refinado dos problemas planos e tridimensionais, cujas soluções anteriores provinham de simplificadas aproximações.

Com as técnicas numéricas disponíveis atualmente e com a velocidade de processamento dos computadores sempre crescente, a incorporação de modelos matemáticos cada vez mais sofisticados, que representem o comportamento mecânico dos materiais constituintes das estruturas encontradas na prática da engenharia, tem constituído campo de pesquisa amplo e de bastante interesse. 
Pesquisadores têm procurado encontrar respostas quanto ao porque das leis constitutivas serem da forma como reveladas dos ensaios de corpos-de-prova dos materiais a partir da constatação dos mecanismos físicos elementares de deformação e ruptura. O inverso também é válido, ou seja, elaborar modelos mecânicos para os materiais com base no estudo da micro-estrutura dos mesmos.

Percebe-se, portanto, o campo de pesquisa daí decorrente. Trata-se de estabelecer uma ponte entre conhecimento fenomenológico da micro-estrutura dos materiais estruturais e leis constitutivas macroscópicas expressas nas relações entre tensões e deformações. Entre essas duas extremidades está o modelo mecânico, ou seja, a aproximação matemática que efetivamente conduzirá à resposta da análise numérica das estruturas.

Dentro desse contexto se enquadra o presente trabalho. A teoria da Mecânica do Dano Contínuo não trata em específico do concreto. Porém, se aplica com razoável precisão a esse material, porque ele possui a característica de se degradar pelo aparecimento e crescimento de micro-fissuras continuamente distribuídas no seu volume. Pode-se dizer que foi a partir do entendimento desse mecanismo elementar de degradação do material que foi possível elaborar modelos mecânicos fundamentados na teoria do dano contínuo confiando-se que possivelmente se chegaria a bons resultados.

\section{4 - Análise estrutural de pavimentos de edifícios de concreto armado}

A técnica da subestruturação dos sistemas na análise estrutural de edifícios já vem sendo empregada há tempos. Essa técnica permite que o edifício seja subdividido em sistemas estruturais mais simples, como vigas isoladas ou trabalhando em conjunto, pórticos planos ou mesmo tridimensionais. Em geral, as lajes são consideradas diafragmas horizontais rígidos que compatibilizam as deformações numa mesma cota. Enfim, a técnica da sub-estruturação visa tornar o cálculo mais expedito. 
Esse trabalho terá sua aplicação na análise dos subsistemas horizontais formados pelas grelhas de pavimentos de concreto armado, ou seja, vigas trabalhando em conjunto sem a contribuição das lajes no cômputo das deformações dos pavimentos. A análise restringe-se às verificações de esforços e deslocamentos das peças estruturais em serviço, onde vislumbra-se maior campo de aplicabilidade da análise não-linear.

A implementação de modelos não-lineares para análise de edifícios de concreto vem ao longo do tempo merecendo destaque. Dentro da EESC-USP já foram e tem sido desenvolvidos diversos trabalhos na área. Um dos trabalhos pioneiros de programação em computador foi o de RAMALHO [30], que fez análises elásticas diversas de edifícios. CORRÊA [14] continuou na mesma linha incorporando então um modelo plástico para as lajes de edifícios.

CILONI [13] apresenta mais tarde um trabalho que já incorpora modelos constitutivos não-lineares na análise de pórticos deslocáveis de concreto armado e também faz uso da não-linearidade geométrica. MACHADO [23], da EPUSP, apresenta modelos para o cálculo de deslocamentos em estruturas de concreto armado e protendido.

Os modelos colocados nesse trabalho têm aplicações a pavimentos de edifícios, onde os elementos estruturais tem baixa rigidez à torção. Significa admitir que as tensões oriundas dos esforços de flexão são as que praticamente contribuem na totalidade da energia interna absorvida pelo sistema. Verifica-se que, nesse caso, mesmo com a consideração nos modelos de dano das tensões tangenciais provenientes da força cortante e do momento torçor, o resultado pouco seria alterado.

Procura-se com esse trabalho fomentar a questão da aplicabilidade dos modelos não-lineares na análise de estruturas usuais de concreto armado. Ao mesmo tempo, pretende-se mostrar que os modelos fundamentados na Mecânica do Dano Contínuo são factíveis de uso quando aplicados à previsão do comportamento das estruturas de concreto armado em serviço, em vista da proximidade das respostas numéricas com outras obtidas de modelos usuais encontrados nas recentes normas internacionais. 


\section{CAPÍTULO 2}

\section{MODELOS USUAIS PARA O CONCRETO ARMADO}

\section{1 - Contribuição do concreto entre fissuras na resistência à tração}

Nas barras fletidas, na presença de baixas solicitações, o concreto ainda resiste aos esforços de tração. Para que isso ocorra, basta que a tensão de tração na fibra mais solicitada da peça não supere o valor da resistência à ruptura do concreto à tração $\left(\sigma_{\mathrm{ct}} \leq \mathrm{f}_{\mathrm{ct}}\right)$. Diz-se, então, que a peça se encontra no estádio I de comportamento. Quando os dois valores se igualam, ocorre a formação da primeira fissura. A partir daí, pode-se dizer, grosseiramente, que a peça se encontra no estádio II de comportamento, cabendo somente à armadura resistir aos esforços de tração.

A diferença entre o mecanismo resistente do concreto armado no estádio I e II pode ser visualizada através dos diagramas de tensões da figura 2.1.

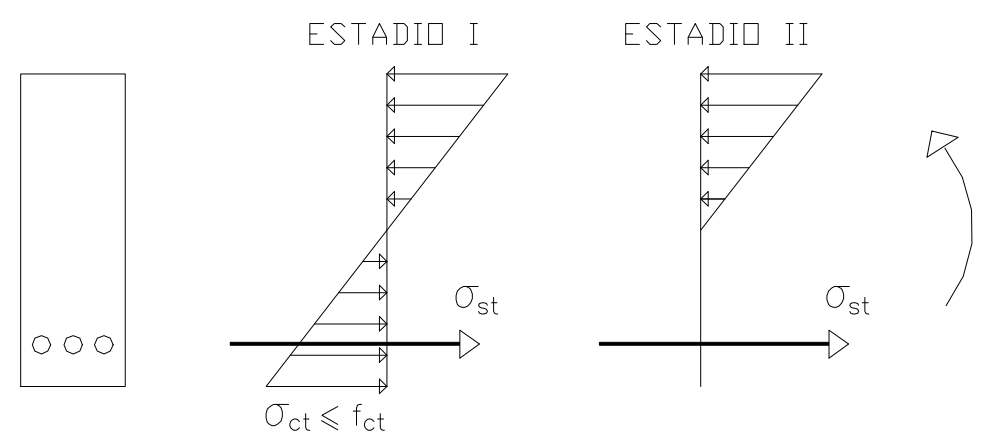

Figura 2.1 - Estádios de comportamento de peças de concreto armado.

Nas seções transversais onde há uma fissura, pode-se dizer que a tensão de tração no concreto na fibra correspondente à da armadura é nula. Em 
contrapartida, o aço passa a receber um incremento de esforço de tração não mais absorvido pelo concreto. Nas seções entre duas fissuras consecutivas os diagramas de tensões no concreto e na armadura apresentam particularidades.

À medida que se afasta de uma seção fissurada a tensão do aço diminui e aumenta-se, via transferência de tensões por aderência, a tensão de tração no concreto. Os diagramas da figura 2.2 mostram a distribuição das tensões entre duas fissuras.

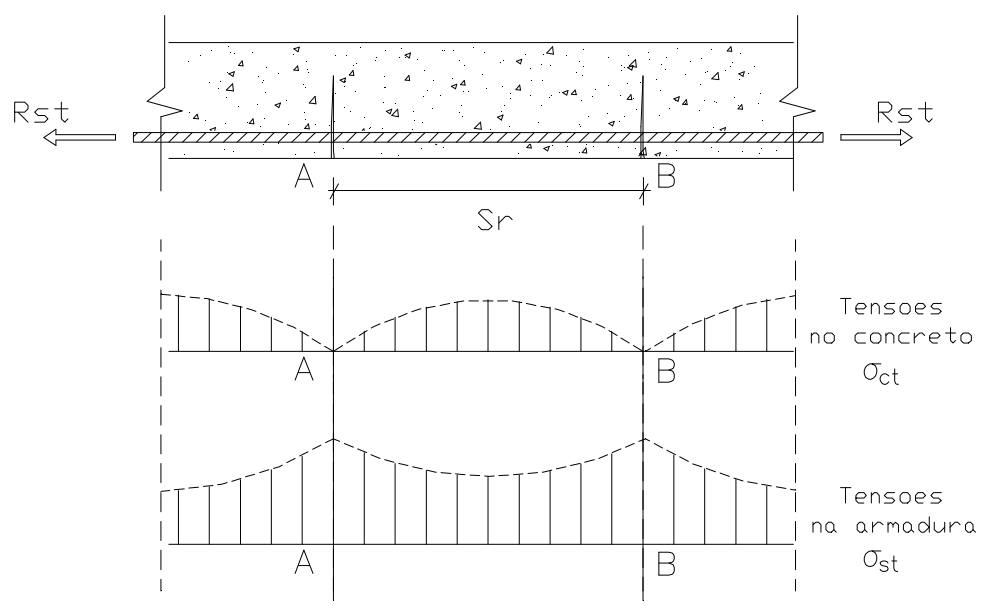

Figura 2.2 - Tensões no concreto e na armadura entre fissuras.

Em vista da distribuição de tensões no concreto entre fissuras cada seção se encontra em um estádio de comportamento diferente. Em geral, numa situação intermediária entre os estádios I e II. Algumas das normas internacionais propõem funções interpoladoras de curvaturas. É o caso do CEB (boletim 158) que assume como aproximação um diagrama teórico (figura 2.3) momento-curvatura que deixa de ser linear após atingido o momento de fissuração da peça.

A NBR-6118 sugere, para os cálculos de verificação de peças de concreto armado em serviço, estádio II de comportamento. Pelo que foi exposto anteriormente, o cálculo recomendado pela norma brasileira está demasiadamente a favor da segurança. 


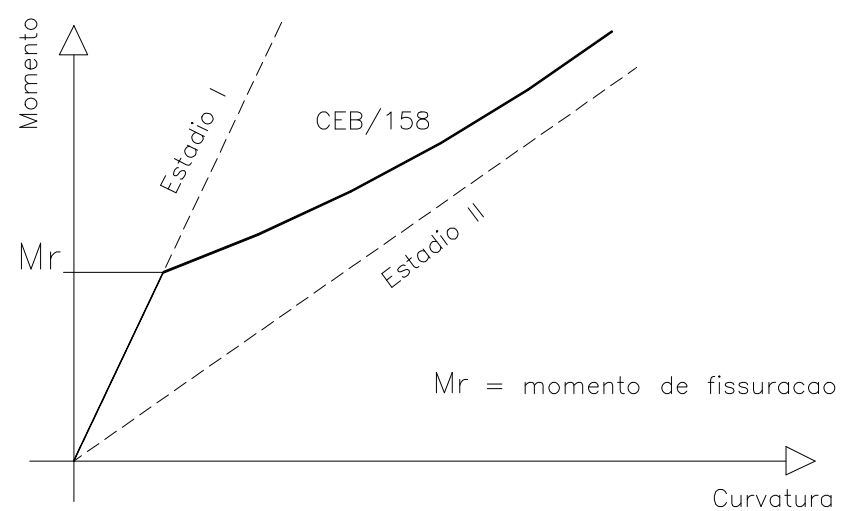

Figura 2.3 - Diagrama momento-curvatura proposto pelo CEB/158.

Os modelos mecânicos apropriados para o cálculo em serviço de peças de concreto armado são aproximações válidas para todo o contínuo dos sólidos. Ou seja, a natureza discreta dos fenômenos, tais como a existência de fissuras localizadas, espaçamento mínimo entre elas e distribuições particulares das tensões e deformações no concreto e no aço entre defeitos, passa a ser modelada como se o material fosse contínuo e obedecesse a leis constitutivas que melhor representem a somatória dos efeitos causados pelas falhas discretas.

Assim como o modelo do CEB/158 da figura 2.3, os modelos de dano para o concreto também são aproximações formuladas sob a hipótese da continuidade e que representam comportamentos médios de um processo inerentemente discreto.

\section{2 - Conceito de estados limites e verificação da segurança estrutural}

Estados a partir dos quais a estrutura apresenta desempenhos inadequados às finalidades da construção são ditos estados limites. A verificação da segurança estrutural deve manter afastada a possibilidade de uma seção qualquer da estrutura atingir um estado limite.

O estado limite último é atingido quando ocorre ruptura do concreto ou deformação plástica excessiva da armadura. Essas duas situações são definidas em função de um valor último de deformação para cada caso. Para flexão simples de barras de concreto armado, as maiores deformações de encurtamento do concreto e 
alongamento da armadura não devem ultrapassar valores especificados em normas para que não seja atingido o estado limite último.

O estado limite de utilização é atingido quando ocorrem flechas excessivas ou aberturas de fissuras muito grandes que comprometam a função para a qual a estrutura foi projetada ou a durabilidade dos elementos estruturais. Cada norma estabelece critérios próprios de verificação do estado limite de utilização. As ações que devem ser consideradas são as de serviço. Essas ações são ponderadas por coeficientes que levam em conta a probabilidade de ocorrência

Para a verificação da ruptura de elementos estruturais de concreto armado desprezam-se tensões resistentes de tração no concreto. Assim sendo, para o dimensionamento deve-se adotar um diagrama de tensões para o concreto comprimido e outro para o aço tracionado. Utilizando-se de convenientes limites máximos para as deformações das fibras das seções é possível dimensionar os elementos estruturais sob diversos tipos de solicitações. A NBR-6118, por exemplo, permite a adoção do diagrama parábola-retângulo (figura 2.4) para as tensões de compressão no concreto.

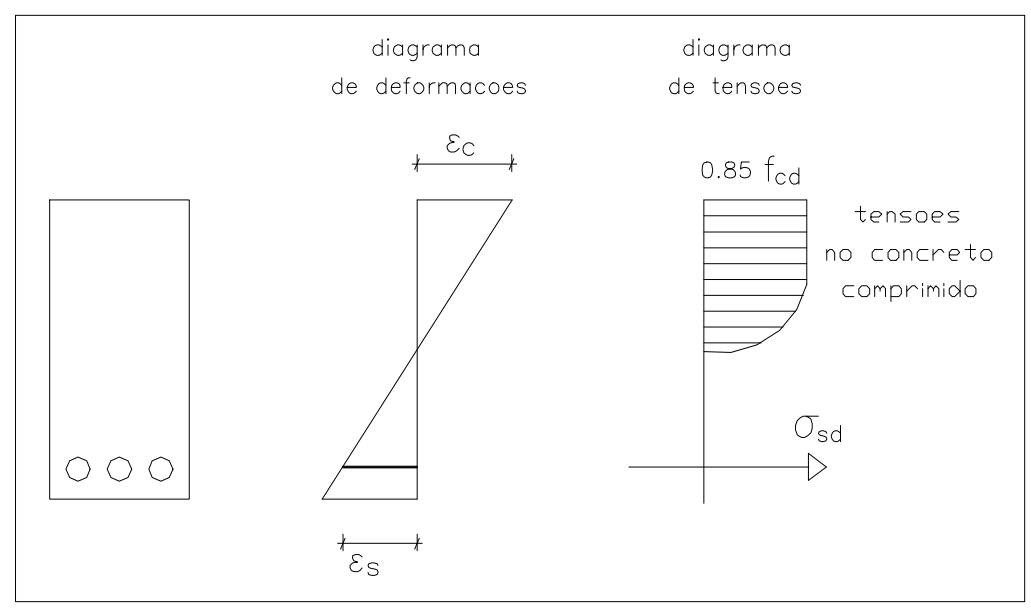

Figura 2.4 - Diagrama de tensões no concreto da NBR-6118.

A verificação do comportamento das peças estruturais em serviço pressupõem que elas já estejam dimensionadas segundo algum modelo mecânico, como o da figura 2.4, onde há limites de deformação que não devem ser ultrapassados com esforços internos calculados a partir de diagramas tensão- 
deformação definidos. Os modelos de dano podem ser utilizados com a finalidade de dimensionamento de peças de concreto armado. Para tanto, basta impor deformações limites para o encurtamento do concreto e para o alongamento do aço, e utilizar os diagramas tensão-deformação dos modelos na integração final das tensões para cálculo dos esforços solicitantes. Deve-se desconsiderar a resistência à tração do concreto nos cálculos de dimensionamento.

Em função da perda de linearidade entre tensões e deformações no concreto a níveis baixos de solicitação, torna-se necessária a utilização de modelos mecânicos não-lineares para o concreto para verificação da segurança quanto aos estados limites de utilização. A simplificação de se admitir comportamento de peças em serviço no estádio II com diagrama linear de tensões no concreto comprimido já caracteriza um modelo mecânico.

Com a redução dos custos computacionais e a evolução tecnológica dos microprocessadores, modelos simplificados tendem a ser abandonados nas análises mais rigorosas. A literatura apresenta modelos para o concreto fundamentados nas teorias da plasticidade, mecânica do dano, mecânica da fratura, consideração de efeitos viscosos e que, com o emprego de adequadas técnicas numéricas, leva a respostas mais confiáveis e precisas.

Os exemplos do capítulo 5 são aplicações dos modelos de dano descritos no capítulo 3 na análise de pavimentos de edifícios de concreto armado quanto à segurança em relação ao estado limite de deformação excessiva. Sendo, portanto, um estado limite de utilização, deverão ser consideradas ações ponderadas quanto à probabilidade de ocorrência (ações de serviço).

\section{3 - Modelo elasto-plástico para as barras de aço da armadura}

A plastificação é uma das características mecânicas mais evidentes no comportamento dos metais. O que a caracteriza é a existência de deformações ou tensões residuais verificadas nos ciclos de tensão ou deformação (figura 2.5), respectivamente. 
Os modelos elasto-plásticos são simplificações matemáticas dos fenômenos observados na figura 2.5. Em geral, as curvas tensão-deformação dos modelos são simplificações bilineares, como se verá adiante. Admitir-se-á, nesse trabalho, comportamento elasto-plástico para as barras de aço da armadura de peças de concreto armado.

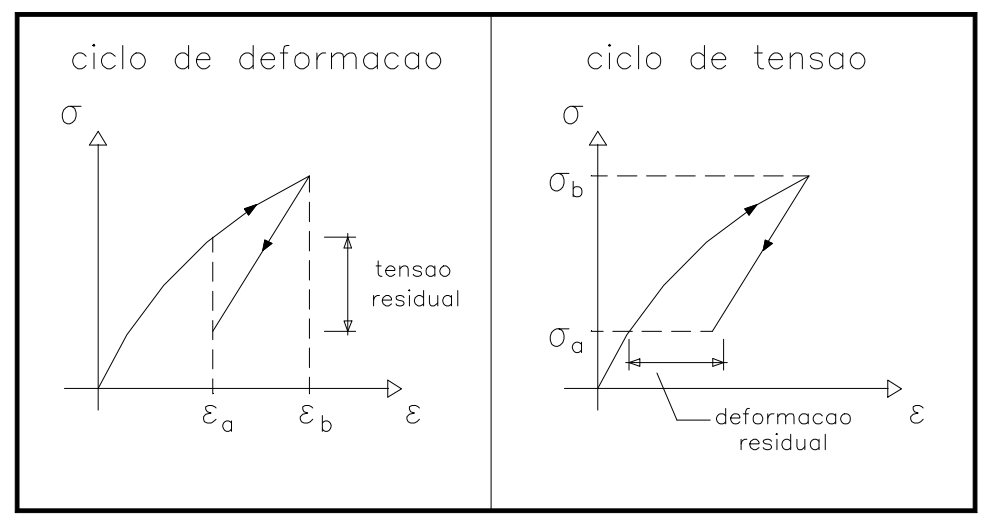

Figura 2.5 - Ciclos de deformação e de tensão na plasticidade.

Diversos textos tratam dos modelos elasto-plásticos em função de sua ampla aplicabilidade a muitos dos materiais utilizados na prática da engenharia. Em OWEN [27] o assunto é tratado relacionando-o com a técnica dos elementos finitos.

A aplicação dos modelos elasto-plásticos, por exemplo, ao concreto, fornece dentro de alguns limites bons resultados. Porém, sabe-se que a deformação do concreto é apenas em parte ocasionada por características internas de plasticidade e que o modo de ruptura preponderante do material é do tipo frágil.

Nos metais, ao contrário, observa-se comportamento plástico em função, principalmente, do movimento de "discordâncias" na estrutura cristalina interna do material. DRIEMEIER [16] apresenta o assunto com mais exatidão.

De um modo geral, os modelos elasto-plásticos são caracterizados por um trecho inicialmente elástico linear e um segundo trecho elasto-plástico, onde se acumulam deformações plásticas e cujo início ocorre quando se supera uma tensão limite, também denominada tensão de plastificação (figura 2.6). 


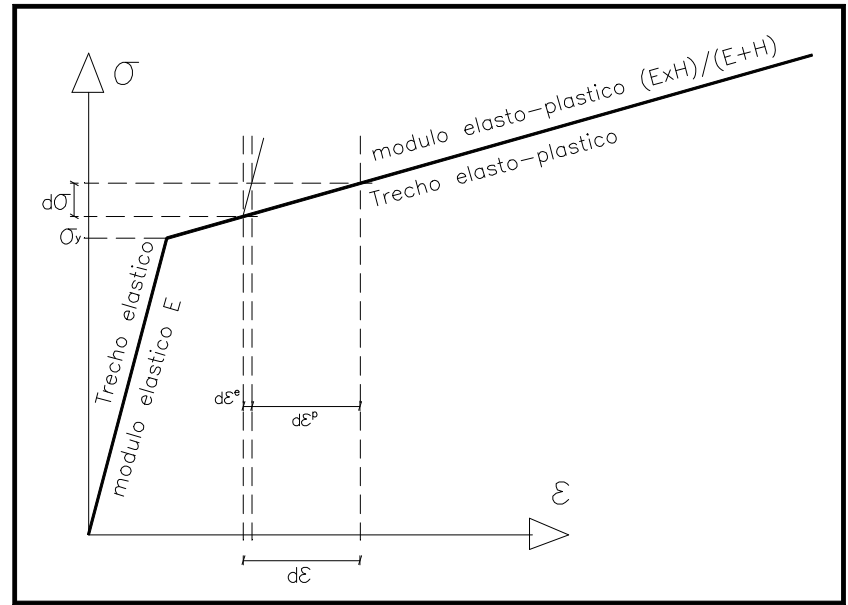

Figura 2.6 - Curva tensão-deformação do modelo elasto-plástico unidimensional.

Pode-se afirmar, em vista do diagrama da figura 2.6, que a deformação total é composta de uma parcela de deformação elástica e outra plástica (relação válida em teoria de pequenas deformações e pequenos deslocamentos). Temse assim as relações 2.1 e 2.2 .

$$
\begin{aligned}
& \varepsilon=\varepsilon^{e}+\varepsilon^{p} \\
& \sigma=E \varepsilon^{e}=E\left(\varepsilon-\varepsilon^{p}\right)
\end{aligned}
$$

De um trecho a outro, o material perde rigidez passando de um módulo elástico E que relaciona tensão e deformação para outro $(\mathrm{E} . \mathrm{H}) /(\mathrm{E}+\mathrm{H})$, onde $\mathrm{H}$, para o caso do encruamento isótropo, é o denominado módulo plástico, definido como a razão entre o acréscimo de tensão e o correspondente acréscimo de deformação plástica.

$$
\mathrm{H}=\frac{\mathrm{d} \sigma}{\mathrm{d} \varepsilon^{\mathrm{p}}}
$$

Se as variáveis do modelo são admitidas funções do tempo, num intervalo de variação $[0, \mathrm{~T}]$ contido no conjunto de números reais, pode-se escrever a relação 2.2 em termos de taxas (variações no tempo) resultando 2.4. 


$$
\dot{\sigma}=\mathrm{E} \dot{\varepsilon}^{\mathrm{e}}=\mathrm{E}\left(\dot{\varepsilon}-\dot{\varepsilon}^{\mathrm{p}}\right)
$$

onde definem-se:

$$
\begin{aligned}
& \dot{\varepsilon}=\frac{\mathrm{d} \varepsilon}{\mathrm{dt}} \\
& \dot{\varepsilon}^{\mathrm{p}}=\frac{\mathrm{d} \varepsilon^{\mathrm{p}}}{\mathrm{dt}} \\
& \dot{\sigma}=\frac{\mathrm{d} \sigma}{\mathrm{dt}}
\end{aligned}
$$

As deformações plásticas irreversíveis ocorrem quando se verifica a desigualdade $\dot{\varepsilon}^{\mathrm{p}} \neq 0$. No denominado modelo elasto-plástico perfeito, atingida a tensão $\sigma_{y}$, a taxa de deformação total coincide com a taxa de deformação plástica, ou seja, $\dot{\sigma}=0$. O trecho elasto-plástico do diagrama tensão-deformação, para esse caso, seria horizontal.

No modelo com encruamento positivo, a parcela de deformação plástica se soma a outra elástica, no trecho elasto-plástico. Conforme se vê na figura 2.6, a um acréscimo d $\sigma$ de tensão nesse trecho, correspondem as parcelas $d \varepsilon^{\mathrm{e}} \mathrm{e}$ $\mathrm{d}^{\mathrm{p}}$. Um descarregamento total (figura 2.7) revelaria cada uma das quantidades.

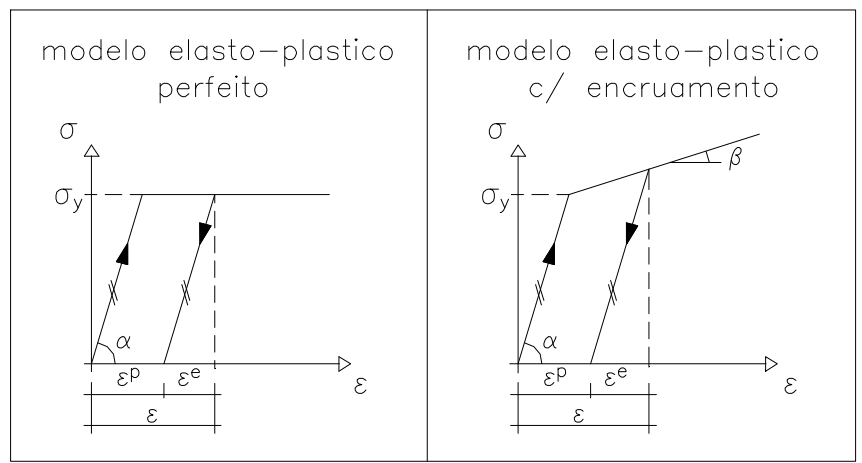

Figura 2.7 - Modelo elasto-plástico perfeito e com encruamento. 
A tangente do ângulo $\alpha$ da figura 2.7 é numericamente igual ao módulo de elasticidade longitudinal E do material. No modelo com encruamento isótropo a tangente do ângulo $\beta$ equivale à relação $(\mathrm{E} . \mathrm{H}) /(\mathrm{E}+\mathrm{H})$ vista anteriormente. A reta do descarregamento, em qualquer dos modelos, é sempre paralela à do carregamento.

A tensão limite elástica inicial $\sigma_{\mathrm{y}}$ se modifica quando se trata do modelo elasto-plástico com encruamento positivo à medida que se processa a plastificação. No encruamento isótropo o intervalo do domínio elástico expande, porém permanece simétrico em relação ao centro do intervalo do domínio elástico inicial. No encruamento cinemático o intervalo elástico permanece de tamanho constante, porém seu centro translada na direção correspondente à do sinal da deformação plástica a cada instante de tempo.

Na figura 2.8 tem-se a representação de um ciclo de tensão completo para os dois tipos de encruamento definidos.

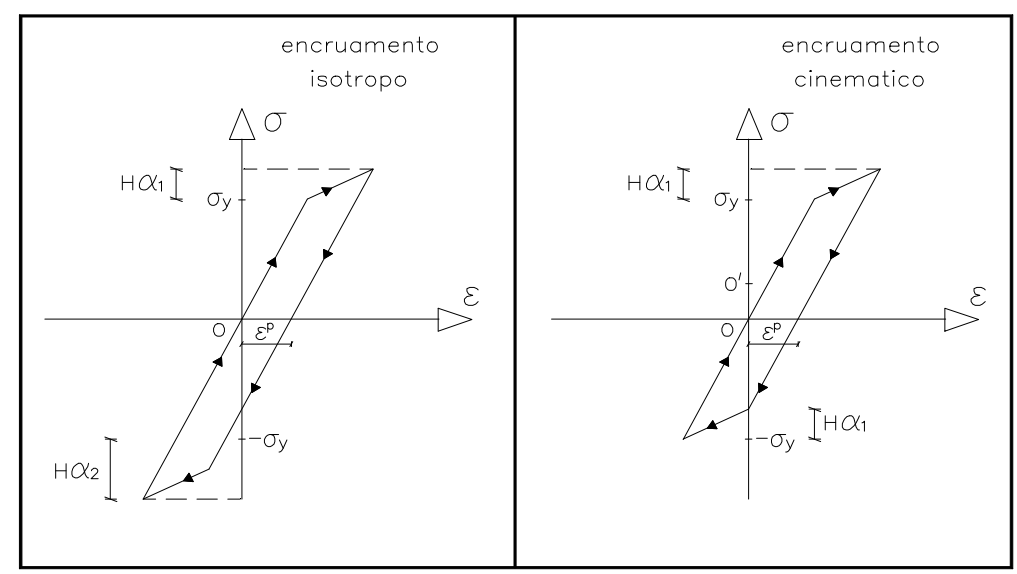

Figura 2.8 - Variação do limite elástico para encruamento isótropo e cinemático.

Para o encruamento positivo isótropo (diagrama à esquerda na figura 2.8) define-se a variável interna $\alpha \geq 0$ que controla a expansão da região elástica com a plastificação. Como o encruamento é por deformação define-se $\dot{\alpha}=\left|\dot{\varepsilon}^{\mathrm{p}}\right|$, de modo que ao final de um ciclo de tensão, mesmo $\operatorname{com} \varepsilon^{\mathrm{p}}=0$ tem-se a tensão limite 
de plastificação aumentada de um valor H. $\alpha$. Sendo assim, conclui-se que $\alpha_{1}=\varepsilon^{p}$ e $\alpha_{2}=2 . \varepsilon^{\mathrm{p}}$, na figura 2.8 .

Admitindo-se resposta simétrica do material à tração e à compressão, define-se critério de plastificação como uma relação que define estados de tensão admissíveis no modelo. Para o encruamento isótropo tem-se o critério:

$$
\mathrm{f}(\sigma, \alpha)=|\sigma|-\left(\sigma_{\mathrm{y}}+\mathrm{H} . \alpha\right) \leq 0
$$

com $\alpha \geq 0$ e as constantes do material $\sigma_{\mathrm{y}}>0$ e $\mathrm{H}>0$.

$\mathrm{O}$ critério de plastificação f é uma função das variáveis $\sigma$ e $\alpha$. Ele define um conjunto convexo e fechado de tensões admissíveis que varia de amplitude à medida que $\alpha=\int_{\mathrm{t}_{1}}^{\mathrm{t}_{2}}\left|\dot{\varepsilon}^{\mathrm{p}}\right| \mathrm{dt}$ também varia.

Percebe-se pela relação 2.8 que a igualdade $f(\sigma, \alpha)=0$ deve ser verificada para que ocorra deformação plástica. Define-se $\dot{\lambda} \geq 0$ como o valor absoluto da velocidade de deformação plástica que poderá ocorrer quando $\mathrm{f}(\sigma, \alpha)$ for igual a zero. Desse modo, têm-se as relações:

$$
\begin{aligned}
& \dot{\varepsilon}^{\mathrm{p}}=\dot{\lambda}>0 \text { se } \sigma=\sigma_{\mathrm{y}}+\mathrm{H} . \alpha \\
& \dot{\varepsilon}^{\mathrm{p}}=-\dot{\lambda}<0 \text { se } \sigma=-1 .\left[\sigma_{\mathrm{y}}+\text { H. } \alpha\right]
\end{aligned}
$$

que podem ser reunidas na relação 2.11.

$$
\dot{\varepsilon}^{\mathrm{p}}=\dot{\lambda} \sin (\sigma) \text { se } \mathrm{f}(\sigma, \alpha)=0
$$

onde vale: 


$$
\sin (\sigma)=\left\{\begin{array}{lll}
+1 & \text { se } & \sigma>0 \\
-1 & \text { se } & \sigma<0
\end{array}\right.
$$

Perante as condições unilaterais de contorno $\mathrm{f}(\sigma, \alpha) \leq 0$ e $\dot{\lambda} \geq 0$, pode-se dizer que se $\dot{\lambda}>0$ então necessariamente $\mathrm{f}(\sigma, \alpha)=0$ e que se $\mathrm{f}(\sigma, \alpha)<0$, tem-se $\dot{\lambda}=0$. Assim sendo, vale a relação:

$$
\dot{\lambda} \mathrm{f}(\sigma, \alpha)=0
$$

denominada de condição de complementaridade ou condição de Kuhn-Tucker.

Considerando uma situação em que se tem $\mathrm{f}(\sigma, \alpha)=0$, deve-se verificar a desigualdade $\dot{\mathrm{f}}(\sigma, \alpha) \leq 0$, porque em caso contrário a condição unilateral $\mathrm{f}(\sigma, \alpha) \leq 0$ deixaria de ser respeitada. Para $\dot{\mathrm{f}}(\sigma, \alpha)<0$ tem-se uma situação de descarregamento e, portanto, $\dot{\lambda}=0$. Para que se verifique $\dot{\lambda}>0$, são necessárias as condições: $f(\sigma, \alpha)=0$ e $\dot{\mathrm{f}}(\sigma, \alpha)=0$. Daí decorre:

$$
\dot{\lambda} \dot{\mathrm{f}}(\sigma, \alpha)=0
$$

denominada condição de consistência.

As situações teóricas possíveis de carregamento, descarregamento ou recarregamento do modelo com encruamento isótropo estão analisadas na figura 2.9

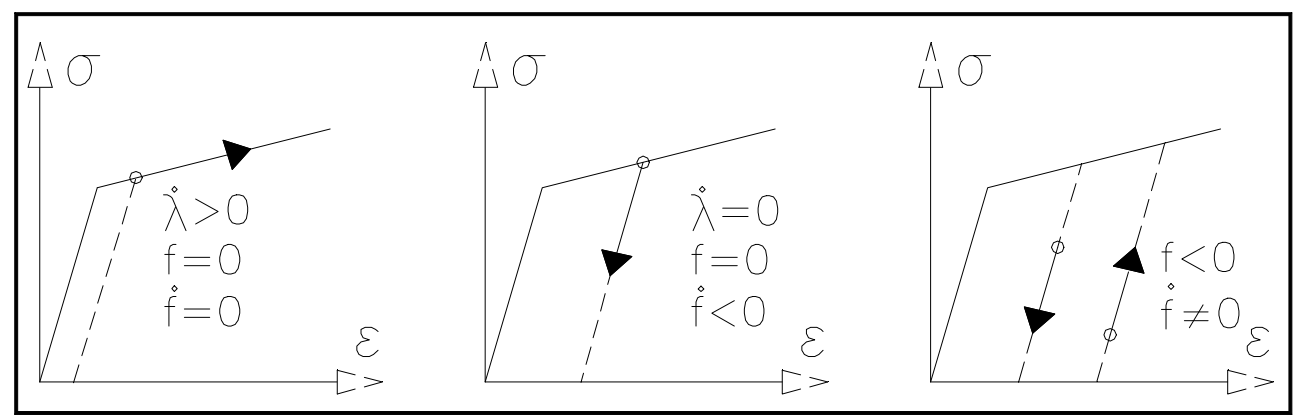

Figura 2.9 - Situações teóricas possíveis do modelo com encruamento isótropo. 


\section{CAPÍTULO 3}

\section{MODELOS CONSTITUTIVOS DE DANO PARA O CONCRETO}

\section{1 - Introdução}

Neste capítulo é tratada a formulação matemática dos modelos fundamentados na teoria da Mecânica do Dano Contínuo que serão aplicados, posteriormente, à análise de pavimentos de edifícios de concreto armado.

De início, faz-se uma descrição das principais referências bibliográficas de interesse sobre modelos de dano para o concreto. A seguir, expõemse as hipóteses básicas dos modelos de dano isótropos, tendo-se sempre em vista o comportamento micro-estrutural do concreto (capítulo 1).

$\mathrm{Na}$ sequência, descrevem-se dois modelos de dano para o concreto. $\mathrm{O}$ primeiro proposto por MAZARS [25] e outro proposto por CERVERA et. alli. [7], ambos isótropos. Alguns aspectos particulares dos modelos, como a representação geométrica dos critérios de dano, são tratados a seguir. Ao final, comenta-se a influência dos parâmetros de dano à tração na resposta numérica.

\section{2 - Referências bibliográficas}

Conforme anteriormente comentado, são muitos os modelos nãolineares que se aplicam à previsão do comportamento do concreto e que apresentam bons resultados. Uma boa coletânea desses modelos bem como suas formulações matemáticas pode ser encontrada em PROENÇA [29]. No trabalho são discutidos procedimentos de resolução incrementais-iterativos do tipo Newton-Raphson, 
aspectos da teoria da plasticidade, modelo de fraturamento através de uma formulação variacional e ao final algumas sugestões para a linha de pesquisa.

Em ÁLVARES [2] encontra-se uma classificação dos modelos constitutivos para o concreto dividida em três partes: modelos que não consideram variação de propriedades no tempo, modelos que consideram tais variações e modelos de dano. No trabalho tem-se mais detalhes sobre a referida classificação.

A Mecânica do Dano Contínuo foi desenvolvida com o objetivo de analisar o efeito da deterioração do material nas propriedades dos sólidos solicitados por ações mecânicas ou térmicas. A Mecânica do Dano Contínuo difere da Mecânica da Fratura na medida em que essa última lida com defeitos discretos do material, enquanto a outra considera microdefeitos continuamente distribuídos no sólido ou em regiões dele.

HULT [18] cita que, em um trabalho pioneiro, Kachanov (1958) propôs descrever o efeito coletivo da deterioração por uma variável do campo escalar. Assim, um processo inerentemente discreto foi modelado então por uma variável contínua. Da mesma forma que somente foi possível o desenvolvimento da teoria da elasticidade depois que foi desconsiderada a natureza discreta da estrutura dos materiais, a concepção básica de Kachanov fez sucesso e instigou posteriores desenvolvimentos no mesmo campo de análise.

O modelo de dano de Kachanov foi desenvolvido para descrever ruptura frágil por fluência em metais solicitados uniaxialmente à tração para elevadas temperaturas. O trabalho de HULT descreve toda a formulação matemática utilizada por Kachanov. Em KACHANOV [19] pode-se encontrar o próprio artigo que deu início à teoria do dano.

Depois de outros pesquisadores, ainda que de maneira tímida, terem inserido alguns avanços nas formulações fundamentadas na teoria do dano, foi apenas recentemente que a Mecânica do Dano Contínuo foi formalizada com base na termodinâmica dos processos irreversíveis. O trabalho de LEMAITRE \& CHABOCHE [22] descreve a evolução do dano em termos da termodinâmica.

Afora os trabalhos clássicos já consagrados sobre teoria do dano, recentemente muitos avanços têm sido obtidos dentro da área. MAZARS \& 
PIJAUDIER-CABOT [26] apresentam uma revisão dos diferentes modelos baseados na Mecânica do Dano Contínuo formulados no Laboratoire de Mécanique et Technologie (Cachan, França). Anisotropia induzida, comportamento dúctil e efeitos unilaterais, como fechamento de fissuras, são discutidos em conjunto com análises numéricas do comportamento do concreto e do concreto armado. Modelos adequados a cada caso são propostos.

O modelo da plasticidade aplicado ao concreto é tratado no trabalho de CHEN [11], onde procuram-se apresentar aspectos mais qualitativos do comportamento elasto-plástico verificado no material. CHEN também relata os avanços mais significativos de caracterização do comportamento "softening" póspico do concreto. Aponta formulações gerais combinando plasticidade com teoria da fratura e sugere que esforços no desenvolvimento de modelos elasto-plásticos combinados com dano devam ser o caminho mais correto para a modelagem do concreto, atentando para o cuidado de torná-los práticos e simples de se usar nas análises estruturais.

KRAJCINOVIC [20] argumenta que o modo de dissipação de energia tem uma forte influência quantitativa e qualitativa na resposta do material solicitado contendo microfissuras planas. Assim sendo, a lei do dano é derivada do potencial de dissipação em conjunto com o princípio da ortogonalidade. Também afirma que a aplicação da plasticidade convencional ao concreto é limitada na medida em que essa teoria estabelece modelos que descrevem o comportamento do material associado à propagação de discordâncias através da estrutura cristalina, enquanto que, em conjunto com esse mecanismo de dissipação de energia, existe no concreto aquele associado ao crescimento e coalescência de microfissuras.

PAAS et al. [28] apresentam um modelo isótropo de dano. Somente consideram mecanismos de ruptura frágil onde o único processo dissipativo está associado ao crescimento do dano e independe da velocidade de deformação. Uma distinção é feita para dano por fadiga. Algumas formas gerais das equações constitutivas são estabelecidas nas bases da termodinâmica. Apresentam a resposta numérica de uma placa com uma fissura induzida sujeita a carregamento periódico e obedecendo leis específicas postuladas para evolução do dano. 
Aspectos gerais sobre teoria do dano estão em CHABOCHE [9]. Características básicas, capacidades, definições e medidas de dano e sua incorporação em uma estrutura termodinâmica geral são evidenciadas. Algumas equações práticas de crescimento do dano são revistas para fluência, fadiga, interação fluência-fadiga, dano em materiais frágeis e materiais dúcteis. Ferramentas para se estimar a iniciação e propagação de fissuras e os novos desenvolvimentos de aproximações locais para fratura são discutidos.

Mecanismos físicos associados ao processo de crescimento do dano de materiais como o concreto e outros (cerâmicas, metais) foram temas de alguns trabalhos desenvolvidos. BURR [5] ressaltou a importância do entendimento desses mecanismos que devem-se correlacionar com a resposta de testes mecânicos. DIAO [15] questiona o significado físico das variáveis de dano dizendo haver algum grau de arbitrariedade nas suas definições, que são substancialmente diferentes uma das outras, sendo a maior parte associada à degradação de alguma propriedade mecânica do material. Afirma não haver uma boa correspondência entre mecanismo de evolução dos microdefeitos e degradação das propriedades dos materiais de alguns modelos.

CHEN [10] analisa numericamente uma chapa de concreto com uma fenda centrada e solicitada à tração. Utiliza um modelo de dano isótropo e considera uma distribuição estatística de fissuras na massa de concreto. Um modelo exclusivo para análise de vigas de concreto armado é estudado em ALVES e LUBLINER [1].

Sobre respostas de materiais de ruptura frágil e semi-frágil como o concreto, modelados pela Mecânica do Dano, e outros aspectos correlacionados à teoria podem ser encontrados em KRAJCINOVIC [21].

Dentro da EESC-USP, DRIEMEIER [16] apresenta uma extensão do modelo proposto por MAZARS [25] para consideração de solicitações cíclicas em vigas de concreto armado. Além disso, destaca o comportamento micro-estrutural do concreto frente às solicitações repetidas. ÁLVARES [2] apresenta a formulação detalhada do modelo de dano de MAZARS [25], com comentários sobre identificação paramétrica e aplicações a vigas de concreto armado com emprego do método dos elementos finitos. Esse trabalho apresenta confrontos entre respostas 
numéricas e dados experimentais de ensaios laboratoriais de vigas de concreto armado.

BUSSAMRA [6], da EP-USP, apresenta conceitos e princípios da Mecânica do Dano Contínuo e alguns dos principais modelos derivados dessa teoria visando aplicações em peças simples de concreto armado.

\section{3 - Hipóteses e definições básicas dos modelos de dano isótropos}

O processo de ruptura de um elemento de volume representativo de concreto pode ser descrito por uma variável do campo escalar D, que tem estreita correspondência com os níveis de fissuração, desde pequenas fissuras microscópicas até grandes defeitos discretos provenientes da coalescência das fissuras distribuídas no contínuo do sólido representativo.

O tamanho e a distribuição das fissuras delimitam as hipóteses de duas teorias diferentes possíveis de serem aplicadas ao concreto. Tratam-se, como já citado anteriormente, das teorias da Mecânica da Fratura e da Mecânica do Dano.

A primeira lida com defeitos discretos de tamanho significativo dentro da região de análise do fenômeno e considera o material ao redor da fratura íntegro, ou seja, com as propriedades elásticas iniciais não alteradas. A segunda trata as microfissuras continuamente distribuídas de forma aleatória na região de análise do fenômeno, com as propriedades mecânicas do material se alterando em função do grau de deterioração presente. Na figura 3.1 tem-se esquematicamente a diferença entre as teorias.
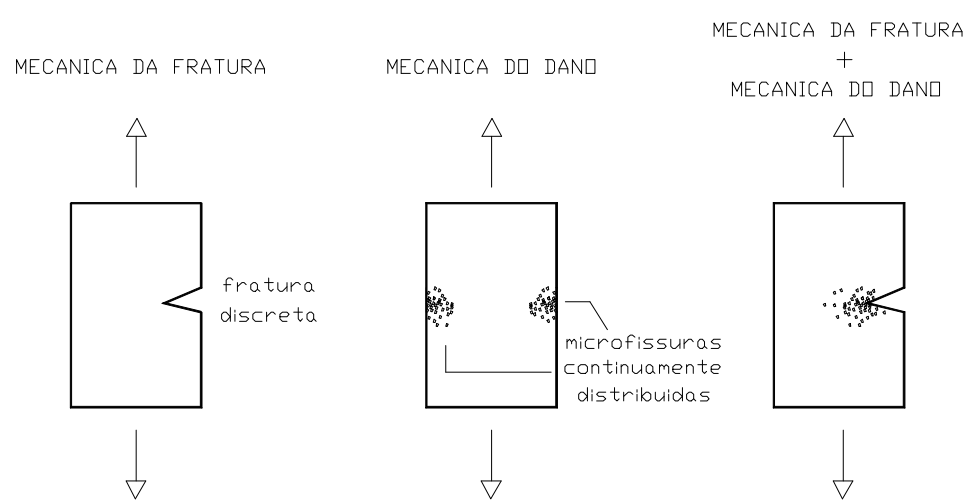

Figura 3.1 - Mecânica do Dano e Mecânica da Fratura. 
A fratura discreta pode ser entendida como proveniente da localização de microdefeitos. Ressalta-se que existem modelos que acoplam as duas teorias, diante de evidências da existência de microfissuras concentradas próximas à ponta da fratura.

Os modelos isótropos fundamentados na Mecânica do Dano Contínuo são de formulação mais simples que os anisótropos. CERVERA et. alli [7] cita que apesar do concreto apresentar anisotropia induzida observável macroscopicamente, ainda há dúvidas quanto à consistência termodinâmica desses últimos modelos quando da ocorrência de abertura e fechamento de fissuras na história do carregamento.

Conforme ilustrado na figura 3.2, em um elemento de volume suficientemente grande para que o material possa ser considerado homogêneo e suficientemente pequeno para que se possam desprezar infinitésimos de ordem superior define-se uma superfície $\mathrm{S}$ com versor normal n que contém uma área $\mathrm{S}_{0}$ de microdefeitos que são proporcionais ao dano.

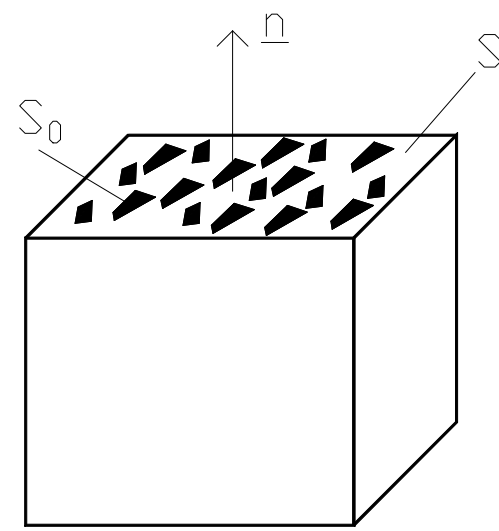

Figura 3.2 - Elemento de volume de um sólido danificado.

Define-se dano como a razão entre a área danificada e a área total.

$$
\mathrm{D}=\frac{\mathrm{S}_{0}}{\mathrm{~S}}
$$

Caso a variável D independa da orientação da normal $\mathrm{n}$ fica verificada a hipótese da isotropia. A variável D é do campo escalar e é definida em cada ponto 
do corpo do material quantificando localmente o grau de deterioração. Seu valor é assumido igual a zero na ausência de defeitos e igual a um no estado de ruptura. A variável está definida no conjunto fechado $[0,1] \subset \mathrm{R}$.

Admitindo-se tensão constante $\sigma$ na área $S$ da figura 3.2, onde atua uma força $\mathrm{F}$ segundo a direção da normal n, define-se tensão efetiva como a relação:

$$
\tilde{\sigma}=\frac{F}{\widetilde{S}}
$$

onde $\widetilde{\mathrm{S}}=\mathrm{S}-\mathrm{S}_{0}$ é a denominada área resistente efetiva.

Substituindo-se 3.1 em 3.2, tem-se:

$$
\tilde{\sigma}=\frac{\sigma}{(1-\mathrm{D})}
$$

Ao tratar um sólido de material com dano como um meio contínuo, pode-se, por facilidade de formulação, fazer uso da hipótese da deformação equivalente estabelecida por LEMAITRE \& CHABOCHE (1985). Segundo essa hipótese a deformação de um material com dano equivale à do material íntegro com tensão efetiva no lugar da tensão atuante (figura 3.3).
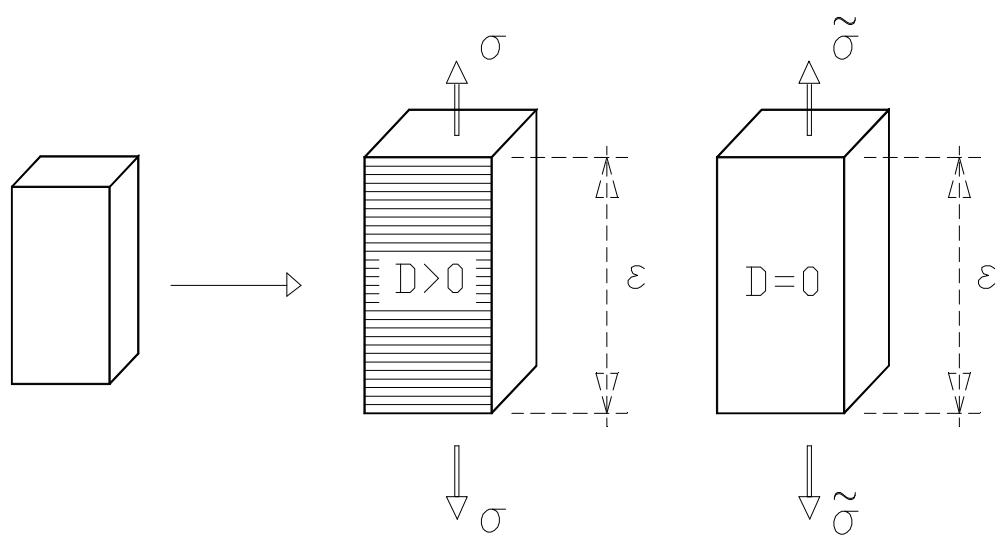

Figura 3.3 - Hipótese da deformação equivalente.

Pela clássica definição de Lei de Hooke, tem-se: 


$$
\varepsilon=\frac{\tilde{\sigma}}{E}=\frac{\sigma}{(1-D) E}
$$

onde E é o módulo de elasticidade longitudinal do concreto íntegro ou sem dano.

Nas aplicações dos modelos de dano para análise de estruturas de concreto, é usual obter o estado de tensão atuante quando conhecido o estado de deformação num dado ponto. Para tal, é interessante associar a variável D à diminuição, por exemplo, do módulo de elasticidade E. Define-se $\widetilde{\mathrm{E}}$ como módulo de elasticidade do material com dano que, para o caso uniaxial de tensão, vale:

$$
\widetilde{\mathrm{E}}=(1-\mathrm{D}) \mathrm{E}
$$

Substituindo-se 3.5 em 3.4 obtém-se:

$$
\varepsilon=\frac{\sigma}{\widetilde{\mathrm{E}}}
$$

A termodinâmica dos processos irreversíveis permite que os modelos de dano sejam formulados de maneira consistente levando-se em conta o caráter energético de dissipação quando ocorre evolução da danificação.

Nos processos irreversíveis, um estado termodinâmico genérico é bem definido pelas variáveis de estado (tensor de deformações e temperatura definidos em cada ponto do sólido) e por variáveis termodinâmicas internas tais como a de dano D, que desse modo pode ser definido. Por se tratar de assunto vasto, não será aqui comentado. DRIEMEIER [16] apresenta conceitos pertinentes ao assunto.

\section{4 - Modelo de dano de Mazars}

No modelo proposto por MAZARS [25] utiliza-se a variável escalar $\mathrm{D}$, com $(0 \leq \mathrm{D} \leq 1)$, para representação do estado local de deterioração do concreto. É um modelo simplificado porque despreza deformações permanentes de qualquer 
origem observáveis nos ensaios de laboratório. Porém aplica-se muito bem ao material já que esse apresenta ruptura por crescimento de fissuras, fenômeno microscópico que procura explicar as leis constitutivas teóricas do modelo.

O modelo é formulado para carregamento crescente e proporcional (carregamento radial), porém nos casos onde se queira considerar descarregamentos deve-se levar em conta o comportamento unilateral do concreto (recuperação da rigidez quando um elemento de concreto é tracionado e comprimido em seguida, figura 3.4). BUSSAMRA [6] apresenta mais detalhes.

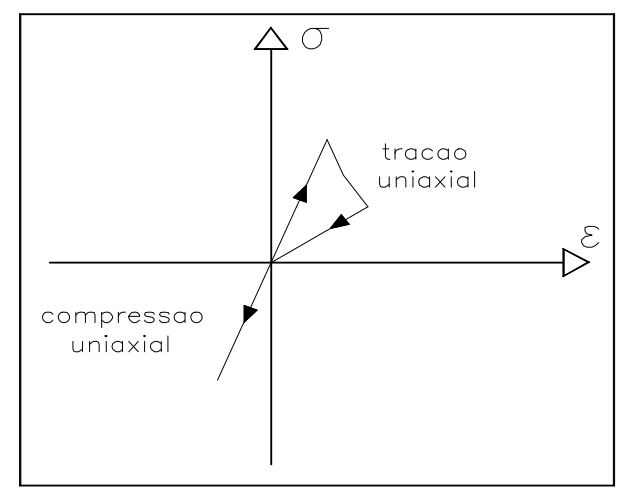

Figura 3.4 - Comportamento unilateral do concreto.

O modelo de dano de Mazars supõe que a degradação do material está associada à presença de deformações de alongamento em pelo menos uma das direções principais. Isso significa admitir modo I de ruptura local ou combinação dos modos I e II (ver item 1.2).

Com o ensejo de caracterizar o estado de alongamento em um dado ponto da estrutura, define-se a variável escalar deformação equivalente $\tilde{\varepsilon}$ como:

$$
\widetilde{\varepsilon}=\sqrt{\left\langle\varepsilon_{1}\right\rangle_{+}^{2}+\left\langle\varepsilon_{2}\right\rangle_{+}^{2}+\left\langle\varepsilon_{3}\right\rangle_{+}^{2}}
$$

sendo $\left\langle\varepsilon_{\mathrm{i}}\right\rangle_{+}$a i-ésima componente positiva do vetor de deformações principais. Ampliando-se a definição, tem-se: 


$$
\left\langle\varepsilon_{\mathrm{i}}\right\rangle_{+}=\frac{1}{2}\left[\varepsilon_{\mathrm{i}}+\left|\varepsilon_{\mathrm{i}}\right|\right]
$$

Da expressão 3.8 verifica-se que $\left\langle\varepsilon_{\mathrm{i}}\right\rangle_{+}$assume o valor de $\varepsilon_{\mathrm{i}}$ quando esse é positivo e zero quando é negativo.

No caso de tração uniaxial na direção 1 , tem-se $\tilde{\varepsilon}=\varepsilon_{1}$. Para compressão uniaxial na mesma direção, $\tilde{\varepsilon}=\sqrt{\varepsilon_{2}^{2}+\varepsilon_{3}^{2}}=-v \varepsilon_{1} \sqrt{2}$. Para compressão biaxial nas direções 1 e $2, \tilde{\varepsilon}=\sqrt{\varepsilon_{3}^{2}}=-\frac{v}{1-v}\left(\varepsilon_{1}+\varepsilon_{2}\right)$. Estados de compressão hidrostática resultam deformação equivalente nula.

Admite-se, convencionalmente, que o início da danificação do material se dá quando o valor da deformação equivalente atinge $\hat{S}(0)$ igual à deformação correspondente ao pico de tensão de um ensaio uniaxial de tração (figura 3.5). Essa deformação é denominada $\varepsilon_{\mathrm{d} 0}$. Logo, $\hat{\mathrm{S}}(0)=\varepsilon_{\mathrm{d} 0}$.

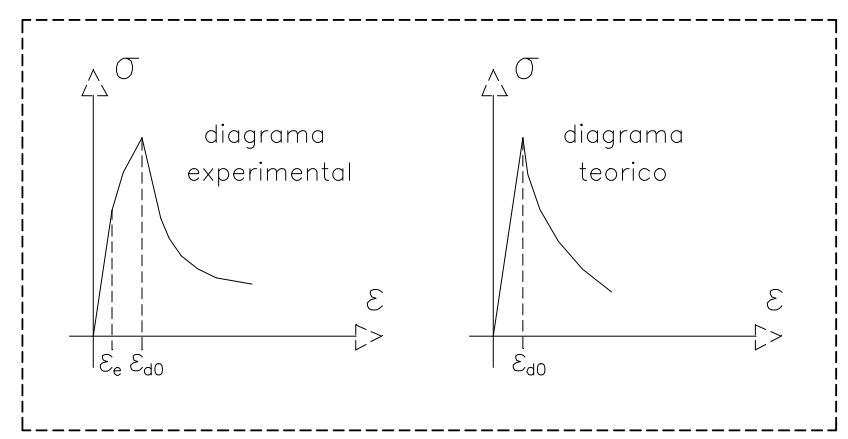

Figura 3.5 - Diagramas do concreto à tração.

Define-se a seguinte função $\underline{\mathrm{f}}$ que fornece o critério de dano:

$$
f(\tilde{\varepsilon}, D)=\tilde{\varepsilon}-\hat{S}(D) \leq 0 \operatorname{com} \hat{S}(0)=\varepsilon_{d 0}
$$

onde D representa a variável escalar de dano. No item 3.6 serão feitas considerações sobre a representação geométrica do critério de dano. 
A variável escalar de dano D apresenta lei de evolução com consistência termodinâmica dada pelas relações escritas em taxas:

$$
\begin{aligned}
& \dot{\mathrm{D}}=0 \quad \text { se } \mathrm{f}<0 \text { ou } \mathrm{f}=0 \text { e } \dot{\mathrm{f}}<0 \\
& \dot{\mathrm{D}}=\mathrm{F}(\tilde{\varepsilon})\langle\dot{\tilde{\varepsilon}}\rangle_{+} \quad \text { se } \mathrm{f}=0 \text { e } \dot{\mathrm{f}}=0
\end{aligned}
$$

onde $\mathrm{F}(\widetilde{\varepsilon})$ é uma função contínua e positiva da deformação equivalente definida com base em resultados experimentais e capaz de reproduzir as curvas de ensaios uniaxiais de corpos de prova de concreto. Para $\dot{\tilde{\varepsilon}} \geq 0$ sempre corresponde $\dot{\mathrm{D}} \geq 0$.

Sabe-se que as respostas do concreto solicitado à tração e à compressão são diferentes. Conforme item 1.2, as fissuras de tração se desenvolvem perpendicularmente à direção da carga enquanto as de compressão paralelamente. Definem-se, assim, duas variáveis escalares independentes $D_{T}$ e $D_{C}$, que teoricamente representam as regiões não-lineares das curvas tensão-deformação de tração e compressão uniaxiais, respectivamente.

$$
\begin{aligned}
& \dot{\mathrm{D}}_{\mathrm{T}}=\mathrm{F}_{\mathrm{T}}(\tilde{\varepsilon})\langle\dot{\tilde{\varepsilon}}\rangle_{+} \\
& \dot{\mathrm{D}}_{\mathrm{C}}=\mathrm{F}_{\mathrm{C}}(\widetilde{\tilde{\varepsilon}})\langle\dot{\tilde{\varepsilon}}\rangle_{+}
\end{aligned}
$$

Integrando-se as expressões 3.12 e 3.13 obtém-se a representação das funções $\mathrm{D}_{\mathrm{T}}(\tilde{\varepsilon})$ e $\mathrm{D}_{\mathrm{C}}(\tilde{\varepsilon})$, conforme figura 3.6. 


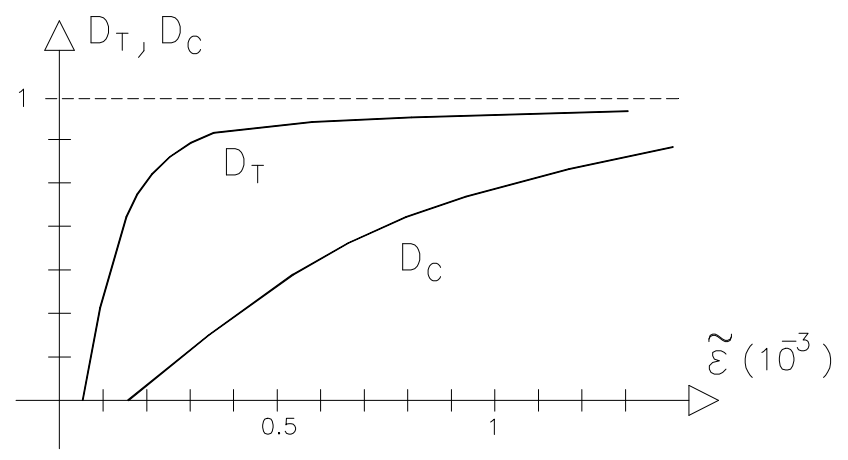

Figura 3.6 - Representação esquemática das variáveis de dano em função de $\widetilde{\varepsilon}$.

O modelo propõem para o cálculo das variáveis $\mathrm{D}_{\mathrm{T}}(\widetilde{\varepsilon})$ e $\mathrm{D}_{\mathrm{C}}(\widetilde{\varepsilon})$ as expressões 3.14 e 3.15 válidas para carregamento proporcional e radial.

$$
\begin{aligned}
& \mathrm{D}_{\mathrm{T}}(\widetilde{\varepsilon})=1-\frac{\varepsilon_{\mathrm{d} 0}\left(1-\mathrm{A}_{\mathrm{T}}\right)}{\tilde{\varepsilon}}-\frac{\mathrm{A}_{\mathrm{T}}}{\exp \left[\mathrm{B}_{\mathrm{T}}\left(\widetilde{\varepsilon}-\varepsilon_{\mathrm{d} 0}\right)\right]} \\
& \mathrm{D}_{\mathrm{C}}(\widetilde{\varepsilon})=1-\frac{\varepsilon_{\mathrm{d} 0}\left(1-\mathrm{A}_{\mathrm{C}}\right)}{\tilde{\varepsilon}}-\frac{\mathrm{A}_{\mathrm{C}}}{\exp \left[\mathrm{B}_{\mathrm{C}}\left(\widetilde{\varepsilon}-\varepsilon_{\mathrm{d} 0}\right)\right]}
\end{aligned}
$$

onde $\mathrm{A}_{\mathrm{T}}, \mathrm{B}_{\mathrm{T}}, \mathrm{A}_{\mathrm{C}}, \mathrm{B}_{\mathrm{C}}$ e $\varepsilon_{\mathrm{d} 0}$ são parâmetros característicos do material a serem identificados mediante procedimento experimental.

A identificação dos parâmetros pode ser feita através do ajuste teórico das expressões das variáveis de dano do modelo com a curva tensão-deformação obtida experimentalmente através da utilização, por exemplo, do método dos mínimos quadrados.

$\mathrm{Na}$ figura 3.7 estão mostradas as curvas experimentais e teóricas para os casos uniaxiais. Pode ser observada a ausência de deformações permanentes do modelo teórico e a diminuição de rigidez nas retas de descarregamento. 


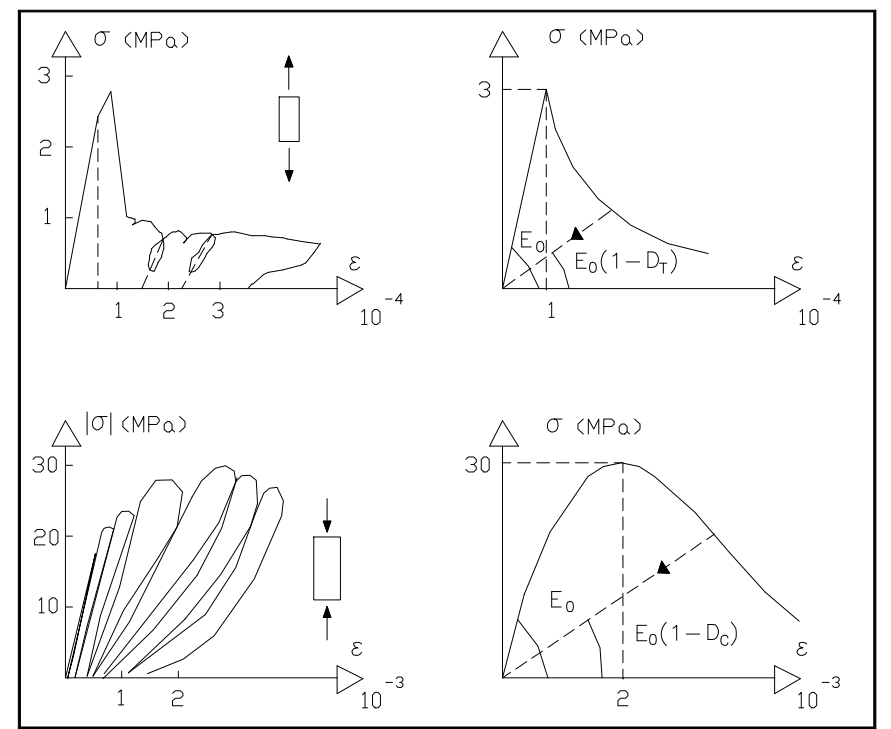

Figura 3.7 - Diagramas experimental e teórico para o concreto à tração e à compressão.

A variável escalar D, no modelo proposto por MAZARS (1984), passa a ser uma combinação linear das variáveis $\mathrm{D}_{\mathrm{T}}$ e $\mathrm{D}_{\mathrm{C}}$ para os casos de solicitações pluriaxiais, conforme expressão 3.16 .

$$
\mathrm{D}=\alpha_{\mathrm{T}} \mathrm{D}_{\mathrm{T}}+\alpha_{\mathrm{C}} \mathrm{D}_{\mathrm{C}}
$$

Os coeficientes $\alpha_{\mathrm{T}}$ e $\alpha_{\mathrm{C}}$ estão definidos no intervalo $[0,1] \subset \mathrm{R}$ e devem satisfazer as condições:

$$
\begin{aligned}
& \text { - tração uniaxial } \Rightarrow \alpha_{T}=1, \alpha_{C}=0 \Rightarrow D=D_{T} \\
& \text { - compressão uniaxial } \Rightarrow \alpha_{T}=0, \alpha_{C}=1 \Rightarrow D=D_{C} \\
& \text { - estados de tensão multiaxiais } \Rightarrow \alpha_{T}+\alpha_{C}=1
\end{aligned}
$$

Define-se tensor de tensões principais efetivas como a aplicação do tensor elástico de quarta ordem do material íntegro $\underline{\underline{D}}_{0}$ no tensor de deformações principais do instante de análise.

$$
\underline{\tilde{\sigma}}=\underline{\mathrm{D}}_{0} \underline{\varepsilon}
$$


Como consequência do comportamento distinto à tração e à compressão do concreto, separa-se o tensor de tensões efetivas $\underline{\tilde{\sigma}}$ em uma parte positiva $\langle\underline{\sigma}\rangle_{+}$e outra negativa $\langle\underline{\sigma}\rangle_{-}$, tal que:

$$
\underline{\tilde{\sigma}}=\langle\underline{\sigma}\rangle_{+}+\langle\underline{\sigma}\rangle_{-}
$$

onde definem-se:

$$
\begin{aligned}
& \left\langle\sigma_{\mathrm{i}}\right\rangle_{+}=\frac{1}{2}\left(\sigma_{\mathrm{i}}+\left|\sigma_{\mathrm{i}}\right|\right) \\
& \left\langle\sigma_{\mathrm{i}}\right\rangle_{-}=\frac{1}{2}\left(\sigma_{\mathrm{i}}-\left|\sigma_{\mathrm{i}}\right|\right)
\end{aligned}
$$

Observa-se das expressões 3.19 e 3.20 que as componentes positivas de tensões principais compõem o tensor $\langle\underline{\sigma}\rangle_{+}$e as negativas $\langle\underline{\sigma}\rangle_{-}$, sendo nulas as demais componentes em ambos os tensores. Em correspondência a essa divisão, definem-se as partes positiva e negativa do tensor de deformações principais $\underline{\varepsilon}$.

$$
\begin{aligned}
& \underline{\varepsilon}_{\mathrm{T}}=\frac{1+v}{\mathrm{E}}\langle\underline{\sigma}\rangle_{+}-\frac{v}{\mathrm{E}}\left\langle\sum_{\mathrm{i}} \sigma_{\mathrm{i}}\right\rangle_{+} \mathrm{I}_{+} \\
& \underline{\varepsilon}_{\mathrm{C}}=\frac{1+v}{\mathrm{E}}\langle\underline{\sigma}\rangle_{-}-\frac{v}{\mathrm{E}}\left\langle\sum_{\mathrm{i}} \sigma_{\mathrm{i}}\right\rangle_{-}^{\mathrm{I}}
\end{aligned}
$$

onde I é o tensor identidade de quarta ordem, E o módulo de Young e $v$ o coeficiente de Poisson. A relação 3.23 deve ser satisfeita.

$$
\underline{\varepsilon}=\underline{\varepsilon}_{\mathrm{T}}+\underline{\varepsilon}_{\mathrm{C}}
$$


Definem-se, para o cálculo dos coeficientes $\alpha_{\mathrm{T}}$ e $\alpha_{\mathrm{C}}$, as expressões:

$$
\begin{gathered}
\alpha_{\mathrm{T}}=\frac{\sum_{\mathrm{i}}\left\langle\varepsilon_{\mathrm{T}_{\mathrm{i}}}\right\rangle_{+}}{\varepsilon_{\mathrm{V}}^{+}} \\
\alpha_{\mathrm{C}}=\frac{\sum_{\mathrm{i}}\left\langle\varepsilon_{\mathrm{C}_{\mathrm{i}}}\right\rangle_{+}}{\varepsilon_{\mathrm{V}}^{+}}
\end{gathered}
$$

onde $\left\langle\varepsilon_{\mathrm{T}_{\mathrm{i}}}\right\rangle_{+}$é a i-ésima componente positiva do tensor de deformações $\underline{\varepsilon}_{\mathrm{T}}$ e $\left\langle\varepsilon_{\mathrm{C}_{\mathrm{i}}}\right\rangle_{+}$a i-ésima componente positiva do tensor de deformações $\underline{\varepsilon}_{\mathrm{C}}$. Utilizando-se da condição imposta $\alpha_{\mathrm{T}}+\alpha_{\mathrm{C}}=1$ e das expressões 3.24 e 3.25, conclui-se que:

$$
\varepsilon_{\mathrm{V}}^{+}=\left\langle\varepsilon_{\mathrm{T}_{\mathrm{i}}}\right\rangle_{+}+\left\langle\varepsilon_{\mathrm{C}_{\mathrm{i}}}\right\rangle_{+}
$$

O tensor de tensões reais, conhecido o valor da variável D é dado por:

$$
\underline{\sigma}=(1-\mathrm{D}) \underline{\underline{D}}_{0} \underline{\varepsilon}
$$

Conforme será visto no capítulo 5, os resultados numéricos têm forte influência dos valores dos parâmetros $\mathrm{A}_{\mathrm{T}}$ e $\mathrm{B}_{\mathrm{T}}$ do dano à tração e $\mathrm{A}_{\mathrm{C}}$ e $\mathrm{B}_{\mathrm{C}}$ do dano à compressão e, principalmente, do valor da deformação limite elástica $\varepsilon_{\mathrm{d} 0}$. Daí decorre a importância que assume uma boa identificação paramétrica que deve ser obtida dos resultados experimentais. ÁLVARES [2] apresenta uma análise mais detalhada desses parâmetros e suas influências no comportamento das curvas tensãodeformação.

MAZARS (1984), entretanto, propõe limites de variação para os parâmetros do modelo com base nas análises experimentais que são: 


$$
\begin{array}{ll}
0.7 \leq \mathrm{A}_{\mathrm{T}} \leq 1 & 10^{4} \leq \mathrm{B}_{\mathrm{T}} \leq 10^{5} \\
1 \leq \mathrm{A}_{\mathrm{C}} \leq 1.5 & 10^{3} \leq \mathrm{B}_{\mathrm{C}} \leq 2.10^{3} \\
10^{-5} \leq \varepsilon_{\mathrm{d} 0} \leq 10^{-4} &
\end{array}
$$

\section{5 - Modelo de dano proposto por Cervera et. alli}

O modelo de dano isótropo que aqui será apresentado encontra-se descrito em CERVERA et. alli. [7]. No referido trabalho apresenta-se uma formulação que leva em conta a dependência do comportamento do concreto da velocidade de deformação imposta nas estruturas. Os sismos são ações típicas que conduzem as estruturas a apresentarem taxas de variação das deformações bem altas. O texto trata da aplicação de um modelo de dano isótropo para análise de sismos em barragens de gravidade de concreto.

O modelo de dano que considera dependência da velocidade de deformação é formulado sobre um modelo não-dependente com a consideração de uma regularização viscosa das leis de evolução das superfícies de dano. Nesse item, será apresentada a formulação do modelo não-dependente da velocidade de deformação para posteriores análises estáticas das grelhas de pavimentos de edifícios de concreto armado.

A expressão para o tensor de tensões principais efetivas definida em 3.17 continua sendo válida na formulação do modelo de Cervera. Porém, como se verá, o tensor será utilizado para outra finalidade. O modelo faz uso de duas variáveis escalares de dano e, tal como postulado no modelo de Mazars, considera uma separação do tensor de tensões efetivas numa parte positiva com as tensões de tração e em outra negativa com as de compressão.

A divisão do tensor de tensões é idêntica àquela formulada no modelo

de Mazars. O tensor da parte positiva do tensor de tensões $\langle\underline{\sigma}\rangle_{+}$reúne as tensões principais de tração do tensor efetivo $\underline{\tilde{\sigma}}$ enquanto o tensor da parte negativa $\langle\underline{\sigma}\rangle_{-}$ reúne as tensões negativas de $\underline{\tilde{\sigma}}$. Os tensores são definidos por: 


$$
\begin{aligned}
& \langle\underline{\sigma}\rangle_{+}=\sum_{\mathrm{i}=1}^{3}\left\langle\sigma_{\mathrm{i}}\right\rangle \mathrm{p}_{\mathrm{i}} \otimes \mathrm{p}_{\mathrm{i}} \\
& \left.\langle\underline{\sigma}\rangle_{-}=\sum_{\mathrm{i}=1}^{3}\right\rangle \sigma_{\mathrm{i}}\left\langle\mathrm{p}_{\mathrm{i}} \otimes \mathrm{p}_{\mathrm{i}}\right.
\end{aligned}
$$

onde $\sigma_{\mathrm{i}}$ é a i-ésima tensão principal do tensor de tensões efetivas $\tilde{\sigma}, \mathrm{p}_{\mathrm{i}}$ é o vetor unitário associado à i-ésima direção principal, enquanto o símbolo $\otimes$ indica produto tensorial.

$$
\text { O resultado da operação } \sum_{\mathrm{i}=1}^{3} \mathrm{p}_{\mathrm{i}} \otimes \mathrm{p}_{\mathrm{i}} \text { pode esquematicamente ser }
$$
representado por uma matriz identidade de ordem 3. O símbolo $\langle-\rangle$ retorna o valor interno caso ele seja positivo e zero se negativo. O símbolo $\rangle-\langle$ retorna o valor interno caso ele seja negativo e zero se positivo.

$$
\begin{array}{ll}
\left\langle\sigma_{i}\right\rangle=\sigma_{i} \text { se } \sigma_{i} \geq 0 & \left\langle\sigma_{i}\right\rangle=0 \text { se } \sigma_{i}<0 \\
\rangle \sigma_{i}\left\langle=0 \text { se } \sigma_{i}>0\right. & >\sigma_{i}\left\langle=\sigma_{i} \text { se } \sigma_{i} \leq 0\right. \\
\left\langle\sigma_{i}\right\rangle+>\sigma_{i}\left\langle=\sigma_{i}\right. &
\end{array}
$$

Como consequência da separação do tensor de tensões efetivas, a lei constitutiva do modelo pode ser definida explicitamente resultando para a determinação do tensor de Cauchy em um dado instante de análise a expressão:

$$
\underline{\sigma}=\left(1-\mathrm{d}^{+}\right)\langle\underline{\sigma}\rangle_{+}+\left(1-\mathrm{d}^{-}\right)\langle\underline{\sigma}\rangle_{-}
$$

com

$$
0 \leq \mathrm{d}^{+} \leq 1 \text { e } 0 \leq \mathrm{d}^{-} \leq 1
$$


onde $\mathrm{d}^{+}$e $\mathrm{d}^{-}$são as variáveis escalares de dano à tração e à compressão, respectivamente. Isso implica também que as duas variáveis de dano controlam a degradação de todas as propriedades elásticas do material, como módulo de Young e coeficiente de Poisson. Sabe-se que considerações da termodinâmica sobre dissipação de energia garantem as desigualdades em taxas:

$$
\dot{\mathrm{d}}^{+} \geq 0 \text { e } \dot{\mathrm{d}}^{-} \geq 0
$$

Para a completa descrição do modelo devem ser formuladas apropriadas leis de evolução das variáveis internas de dano $\mathrm{d}^{+} \mathrm{e}^{-}$. Nota-se que as variáveis de dano do modelo de Cervera aparecem de forma explícita na expressão 3.32 do tensor de tensões reais, enquanto que no modelo de Mazars (item 3.4) uma única variável de dano $\mathrm{D}$ contém implicitamente as contribuições do dano no concreto à tração e à compressão.

Com o objetivo de individualizar claramente situações de carregamento, descarregamento ou recarregamento, uma quantidade escalar positiva denominada tensão equivalente, será definida. Isso permite uma comparação entre diferentes estados tridimensionais de tensão por meio de variáveis escalares associadas e esses estados e obtidas, de forma menos dispendiosa, em ensaios simples uniaxiais. Em função da separação do tensor de tensões efetivas, definem-se norma equivalente de tração efetiva $\bar{\tau}^{+}$e norma equivalente de compressão efetiva $\bar{\tau}^{-}$por:

$$
\begin{aligned}
& \bar{\tau}^{+}=\sqrt{\langle\underline{\sigma}\rangle_{+}: \underline{\mathrm{D}}_{0}^{-1}:\langle\underline{\sigma}\rangle_{+}} \\
& \bar{\tau}^{-}=\sqrt{\sqrt{3}\left(\mathrm{~K} \sigma_{\mathrm{oct}}^{-}+\tau_{\mathrm{oct}}^{-}\right)}
\end{aligned}
$$

onde $\sigma_{\text {oct }}^{-}$e $\tau_{\text {oct }}^{-}$são, respectivamente, as tensões normal e cisalhante octaédricas do tensor de tensões $\langle\underline{\sigma}\rangle_{-}$. K é uma propriedade que depende da razão $\beta$ entre as 
resistências bi e uniaxial do concreto comprimido e vale $K=\sqrt{2}(\beta-1) /(2 \beta-1)$. Típicos valores para concretos usuais são $\beta=1.16$ e $\mathrm{K}=0.171$.

Definem-se dois critérios de dano distintos, o primeiro para tração e o segundo para compressão:

$$
\begin{aligned}
& \mathrm{g}^{+}\left(\bar{\tau}^{+}, \mathrm{r}^{+}\right)=\bar{\tau}^{+}-\mathrm{r}^{+} \leq 0 \\
& \mathrm{~g}^{-}\left(\bar{\tau}^{-}, \mathrm{r}^{-}\right)=\bar{\tau}^{-}-\mathrm{r}^{-} \leq 0
\end{aligned}
$$

As variáveis $\mathrm{r}^{+}$e $\mathrm{r}^{-}$correspondem aos limites do dano, isto é, seus valores controlam o tamanho das superfícies expandidas de dano. As condições 3.39 e 3.40 devem ser obedecidas quando o ponto se encontra na superfície de dano à tração ou $\mathrm{g}^{+}=0$ (o mesmo raciocínio é válido para a superfície de dano à compressão ou $\mathrm{g}^{-}=0$ ):

$$
\begin{aligned}
& \text { - Se } \dot{\mathrm{g}}^{+}=0 \Rightarrow \dot{\mathrm{r}}^{+} \geq 0 \\
& \text { - Se } \dot{\mathrm{g}}^{+}<0 \Rightarrow \dot{\mathrm{r}}^{+}=0
\end{aligned}
$$

Devem ainda serem respeitadas as condições (extensão também válida para o critério de dano à compressão):

$$
\begin{aligned}
& \text { - Se } \mathrm{g}=0 \Rightarrow \dot{\mathrm{r}} \geq 0 \\
& \text { - Se } \mathrm{g}<0 \Rightarrow \dot{\mathrm{r}}=0
\end{aligned}
$$

Para o estágio inicial, ou seja, quando nenhum carregamento foi aplicado, são atribuídos os valores de $\mathrm{r}_{0}{ }^{+}$e $\mathrm{r}_{0}{ }^{-}$aos limites de dano à tração e à 
compressão, respectivamente. Esses valores estão relacionados com as curvas obtidas de ensaios uniaxiais.

As taxas de variação dos valores representativos das superfícies limite

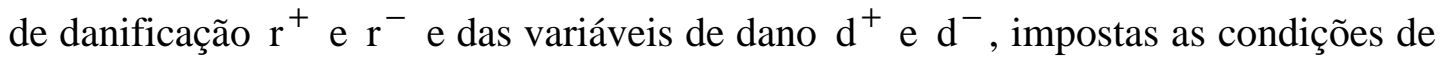
Kuhn-Tucker (3.41 e 3.42), são dadas por:

$$
\begin{aligned}
& \dot{\mathrm{r}}^{+}=\dot{\bar{\tau}}^{+} \geq 0, \quad \dot{\mathrm{d}}^{+}=\dot{\mathrm{r}}^{+} \frac{\partial \mathrm{G}^{+}\left(\mathrm{r}^{+}\right)}{\partial \mathrm{r}^{+}}=\dot{\mathrm{G}}^{+}\left(\mathrm{r}^{+}\right) \geq 0 \\
& \dot{\mathrm{r}}^{-}=\dot{\bar{\tau}}^{-} \geq 0, \quad \dot{\mathrm{d}}^{-}=\dot{\mathrm{r}}^{-} \frac{\partial \mathrm{G}^{-}\left(\mathrm{r}^{-}\right)}{\partial \mathrm{r}^{-}}=\dot{\mathrm{G}}^{-}\left(\mathrm{r}^{-}\right) \geq 0
\end{aligned}
$$

sendo $\mathrm{G}^{+} \mathrm{e}^{-}$adequadas funções monotônica-crescentes obtidas de observações experimentais. Através de uma integração trivial das expressões 3.43 e 3.44, chega-se às leis de evolução das variáveis de dano, quando se impõem as condições de dano inicial nulo na tração e na compressão.

$$
\begin{aligned}
& \mathrm{r}^{+}=\max \left(\mathrm{r}_{0}^{+}, \max \left(\bar{\tau}^{+}\right)\right), \mathrm{d}^{+}=\mathrm{G}^{+}\left(\mathrm{r}^{+}\right) \\
& \mathrm{r}^{-}=\max \left(\mathrm{r}_{0}{ }^{-}, \max \left(\bar{\tau}^{-}\right)\right), \mathrm{d}^{-}=\mathrm{G}^{-}\left(\mathrm{r}^{-}\right)
\end{aligned}
$$

Observa-se das expressões 3.45 e 3.46 a dependência dos valores das variáveis $\mathrm{r}^{+}$e $\mathrm{r}^{-}$da "história do carregamento" já que a cada instante da análise devem ser conhecidos os máximos valores atingidos até então pelas variáveis $\bar{\tau}^{+} \mathrm{e}$ $\bar{\tau}^{-}$

A formulação do modelo como apresentada evidencia seu caráter explícito de resolução numérica. Uma vez conhecido, num dado instante da análise, o tensor de deformações $\underline{\varepsilon}$, as variáveis escalares de dano podem ser explicitamente 
calculadas com o conhecimento das normas equivalentes $\bar{\tau}^{+}$e $\bar{\tau}^{-}$, que são determinadas do tensor de tensões efetivas $\underline{\tilde{\sigma}}$, que se relaciona linearmente com $\underline{\varepsilon}$.

Uma escolha adequada das funções $\mathrm{G}^{+}$e $\mathrm{G}^{-}$torna-se particularmente importante na medida em que essas devem representar teoricamente o formato das curvas experimentais tensão-deformação uniaxiais do concreto.

$$
\begin{aligned}
& G^{+}=d^{+}=1-\frac{r_{0}^{+}}{r^{+}} e^{A^{+}\left(1-r^{+} / r_{0}^{+}\right)} \\
& G^{-}=d^{-}=1-\frac{r_{0}^{-}}{r^{-}}\left(1-A^{-}\right)-A^{-} e^{B^{-}\left(1-r^{-} / r_{0}^{-}\right)}
\end{aligned}
$$

$\mathrm{O}$ modelo tem cinco parâmetros $\mathrm{A}^{+}, \mathrm{A}^{-}, \mathrm{B}^{-}, \mathrm{r}_{0}^{+}$e $\mathrm{r}_{0}^{-}$que deverão reproduzir adequadamente o comportamento softening das curvas tensãodeformação do concreto à tração e à compressão. Vê-se que a proposição de diferentes funções para $\mathrm{G}^{+}$e $\mathrm{G}^{-}$não altera a sequência algorítmica do procedimento explícito de resolução, permitindo grande versatilidade do modelo e possibilidades de aperfeiçoamento constante e adequação das expressões ao comportamento real do concreto.

\section{6 - Representação geométrica dos critérios de dano}

Os critérios de dano são funções das variáveis internas de um determinado modelo, representando estados de tensão admissíveis em cada instante da análise. As funções dos critérios de dano têm imagem definida no conjunto dos números reais. Nos modelos de dano de Mazars (expressão 3.9) e de Cervera (expressões 3.37 e 3.38 ) as funções têm imagem no intervalo $(-\infty, 0] \in R$.

Define-se uma superfície de dano como o lugar geométrico definido no espaço das tensões ou das deformações principais que contém os pontos onde é nula a função representativa do critério de dano. Com a imposição da condição 
inicial de dano nulo, no caso dos modelos de Mazars e de Cervera, a superfície assume uma forma inicial antes de qualquer carregamento ser aplicado e, quando atingida e superada, a superfície expande no espaço em que foi definida.

Substituindo-se a expressão 3.7, da deformação equivalente do modelo de Mazars, na 3.9 do critério de dano, para onde a função f vale zero, chegase que:

$$
\tilde{\varepsilon}=\hat{S}(D)=\sqrt{\left\langle\varepsilon_{1}\right\rangle_{+}^{2}+\left\langle\varepsilon_{2}\right\rangle_{+}^{2}+\left\langle\varepsilon_{3}\right\rangle_{+}^{2}}
$$

É notório que a expressão 3.49 representa um escalar $\tilde{\varepsilon}$ e que a esse valor estão associados infinitos estados de deformação principais possíveis através de diferentes combinações das componentes $\varepsilon_{\mathrm{i}}$. Logo, é possível representar geometricamente esses possíveis estados no espaço tri-ortogonal das deformações principais, daí resultando a superfície de dano. Para o octante onde se encontram os eixos positivos das três deformações principais a forma da superfície de dano é a de um oitavo de esfera com raio $\hat{S}(D)$ (figura 3.8).

Nas ocasiões em que o valor da deformação equivalente atinge e supera o máximo valor já atingido por ela ao longo da história do carregamento a superfície de dano se expande. No descarregamento e posterior recarregamento o modelo prevê regime elástico sem deformações residuais resultado de uma aproximação do comportamento real que evidencia deformações permanentes no concreto tanto na tração quanto na compressão.

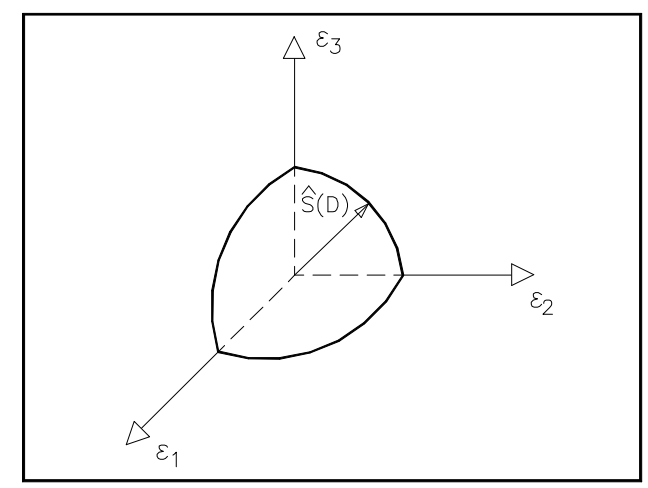

Figura 3.8 - Superfície de dano no espaço das deformações principais. 
A combinação dos dois critérios de dano $\mathrm{g}^{+}$e $\mathrm{g}^{-}$(3.37 e 3.38) do modelo de Cervera permite a representação geométrica da superfície de dano no espaço das tensões principais efetivas. Para que um ponto do espaço se encontre sobre a superfície deve-se ter $\mathrm{g}^{+}=0$ ou $\mathrm{g}^{-}=0$ ou ambas as igualdades ao mesmo tempo. A figura 3.9 mostra a superfície inicial de dano através da combinação dos dois critérios para estados biaxiais de tensão representada no espaço bidimensional das tensões principais efetivas.

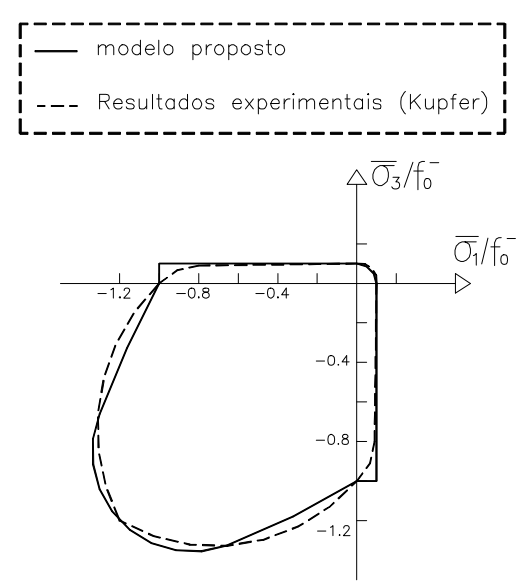

Figura 3.9 - Superfície inicial para estados biaxiais de tensões principais efetivas. Figura adaptada de Cervera [7].

A figura 3.9 apresenta os eixos com coordenadas normalizadas pela tensão $\mathrm{f}_{0}^{-}$que corresponde à tensão de compressão do ensaio uniaxial, associada ao valor de $\mathrm{r}_{0}{ }^{-}$(limite do início da danificação relativo à parte negativa do tensor de tensões efetivas $\langle\underline{\sigma}\rangle_{-}$, na ausência de carregamentos anteriores).

No quadrante superior a direita da figura 3.9 onde os sinais de $\bar{\sigma}_{1}$ e $\bar{\sigma}_{3}$ são iguais e positivos vale o critério de dano à tração $\mathrm{g}^{+}$na determinação da forma da superfície naquele quadrante. No quadrante oposto, onde $\bar{\sigma}_{1}$ e $\bar{\sigma}_{3}$ são iguais e negativos vale o critério de dano $\mathrm{g}^{-}$. Nos outros dois quadrantes tem-se uma combinação dos dois critérios. 
Individualmente cada um dos dois critérios de dano $\mathrm{g}^{+} \mathrm{e}^{-}$podem ser representados geometricamente no espaço das tensões principais efetivas. Da definição do cálculo da variável $\bar{\tau}^{+}$(3.35) observa-se que o critério de dano $\mathrm{g}^{+}$ (3.37) corresponde a uma superfície elipsoidal de dano, centrada na origem do espaço das tensões principais da parte positiva do tensor de tensões efetivas $\langle\underline{\sigma}\rangle_{+}$. A superfície é encontrada impondo-se $\bar{\tau}^{+}=\mathrm{r}^{+}$com $\mathrm{r}^{+}=\mathrm{r}_{0}{ }^{+}$no instante inicial de análise, sendo também expandível de acordo com as condições 3.39 e 3.40.

Observando-se a expressão 3.36 de $\bar{\tau}^{-}$conclui-se que o critério de dano $\mathrm{g}^{-}$(3.38) define um cone de compressão do tipo de Drucker-Prager. Para materiais que obedecem ao critério de Mohr-Coulomb, mediante uma regularização desse, o critério de Drucker-Prager pode vir a substituí-lo. O plano desviatório do critério de Mohr-Coulomb é um hexágono cujas arestas nem sempre são convenientes podendo acarretar complicações em uma análise numérica. O critério de Drucker-Prager (figura 3.10) aproxima o plano desviatório hexagonal para um círculo através de uma simples modificação no critério de Von Mises (ver CHEN[]).

A expressão de $\bar{\tau}^{-}$em $\mathrm{g}^{-}$, conforme citado, permite a construção de um cone do tipo Drucker-Prager adaptado para o concreto. Portanto, não se trata do cone de Drucker-Prager mas de uma adaptação que leva em conta inclusive a danificação do concreto sob estados hidrostáticos de compressão, não levado em conta no critério original.

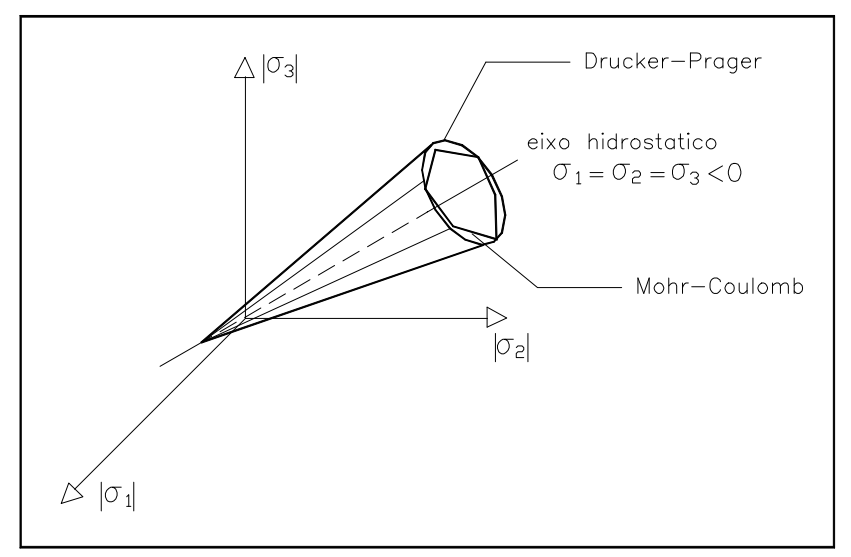

Figura 3.10 - Critério de Drucker-Prager para um material isótropo. 


\section{7 - Influência dos parâmetros de dano à tração na resposta numérica}

A expressão (3.47) do modelo de Cervera para cálculo da variável escalar de dano à tração $\mathrm{d}^{+}$reproduz o ramo softening de um ensaio uniaxial de tração no concreto. Verifica-se que a curva teórica $\underline{\sigma}=\left(1-\mathrm{d}^{+}\right)\langle\underline{\sigma}\rangle_{+}$(para estados de tração uniaxial apenas uma das tensões principais de $\underline{\sigma}$ é diferente de zero e a equação pode ser reduzida para $\sigma_{1}=\left(1-\mathrm{d}^{+}\right)\left\langle\sigma_{1}\right\rangle_{+}$, onde $\sigma_{1}$ é a tensão principal de tração) tende assintoticamente para o eixo das deformações.

Uma área finita fica definida entre a curva tensão-deformação teórica e o eixo " $x "$ das deformações. Essa área é numericamente igual à energia a ser dissipada por unidade de volume num ensaio de tração simples de acordo com a aproximação matemática do modelo (figura 3.11). Essa área deve ser apropriadamente relacionada com a energia de fratura do concreto.

A necessidade de se proceder dessa maneira é para que não haja problemas de instabilidade e perda de objetividade da resposta numérica. A primeira tem como efeito o desenvolvimento irregular da resposta numérica em termos de carga-deslocamento ou momento-curvatura ('non-smooth') enquanto a segunda tem efeito contrário a da melhoria da resposta numérica com refinamento da malha. Esses problemas são característicos de materiais que apresentam comportamento “softening” pós pico de tensão.

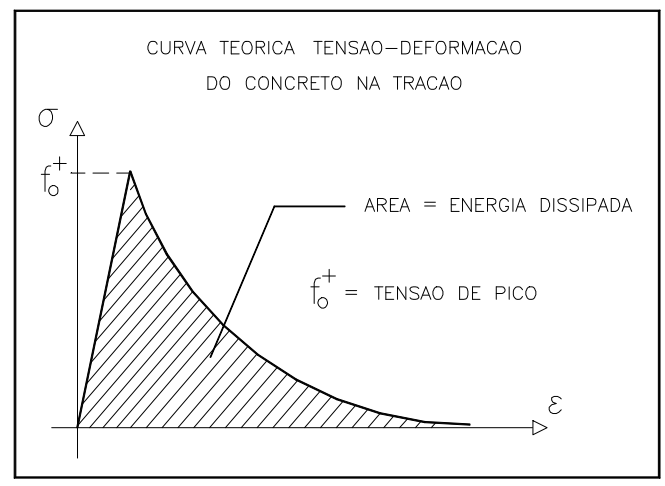

Figura 3.11 - Energia dissipada na tração no modelo de Cervera. 
A melhor solução para a recuperação da estabilidade e da objetividade da resposta numérica é a adoção de um fator geométrico $1_{\mathrm{ch}}$, denominado "comprimento característico", que depende da discretização espacial da malha de elementos finitos e que garante que a energia dissipada em todo esse comprimento se relacionará com a energia de fratura do concreto à tração.

Para exemplificar, supõe-se que a lei constitutiva para o trecho softening do concreto à tração simples seja aproximada linearmente, com a variável de dano $\mathrm{d}^{+}$calculada pela expressão:

$$
\mathrm{d}^{+}=\mathrm{G}\left(\mathrm{r}^{+}\right)=\frac{1}{(1-\mathrm{Z})}\left[1-\frac{\mathrm{r}_{0}^{+}}{\mathrm{r}^{+}}\right]
$$

com $r_{0}{ }^{+} \leq r^{+} \leq r_{u}, \quad r_{u}=r_{0}{ }^{+} / Z$. O parâmetro $Z$ é da aproximação linear estabelecida no modelo.

Sabe-se do modelo de Cervera que a expressão para determinação da norma equivalente $\bar{\tau}^{+}$para o caso de tração uniaxial em uma das direções principais recai em (particularizada para $\bar{\tau}^{+}=\mathrm{r}_{0}{ }^{+}$):

$$
\bar{\tau}^{+}=\mathrm{r}_{0}^{+}=\mathrm{f}_{0}^{+} / \sqrt{\mathrm{E}}
$$

onde $\mathrm{f}_{0}{ }^{+}$corresponde à tensão de pico da curva teórica (figura 3.11) que deve ser a própria tensão máxima do ensaio experimental de tração simples.

Para que o ramo pós-pico de tensão seja softening impõe-se na expressão 3.50 a condição: $Z \geq 0$. E para que seja verificada a desigualdade $\dot{\mathrm{d}}^{+} \geq 0$ no tempo $\mathrm{t}=0$ tem-se a condição: $\mathrm{Z} \leq 1$.

A energia dissipada por unidade de volume $\mathrm{g}_{\mathrm{qst}}$ no modelo com trecho softening linear é dada pela expressão: 


$$
\mathrm{g}_{\mathrm{qst}}=\int_{\mathrm{r}_{0}^{+}}^{\mathrm{r}_{\mathrm{u}}} \psi_{0}^{+} \frac{\mathrm{dG}^{+}}{\mathrm{dr}^{+}} \mathrm{dr}
$$

sendo $\psi_{0}^{+}=\frac{1}{2}\langle\underline{\sigma}\rangle_{+}: \underline{\underline{D}}_{0}^{-1}:\langle\underline{\sigma}\rangle_{+}=\frac{1}{2}\left(\bar{\tau}^{+}\right)^{2}=\frac{1}{2}\left(\mathrm{r}^{+}\right)^{2}$

Substituindo-se os termos do integrando e resolvendo 3.52, tem-se:

$$
\mathrm{g}_{\mathrm{qst}}=\int_{\mathrm{r}_{0}^{+}}^{\mathrm{r}_{\mathrm{u}}} \frac{1}{2}\left(\frac{\mathrm{r}_{0}{ }^{+}}{1-\mathrm{Z}}\right) \mathrm{dr}=\frac{\mathrm{r}_{0}{ }^{+2}}{2 \mathrm{Z}}
$$

A figura 3.12 mostra como seria o trecho softening da curva tensãodeformação do concreto na tração para diferentes valores do parâmetro Z.

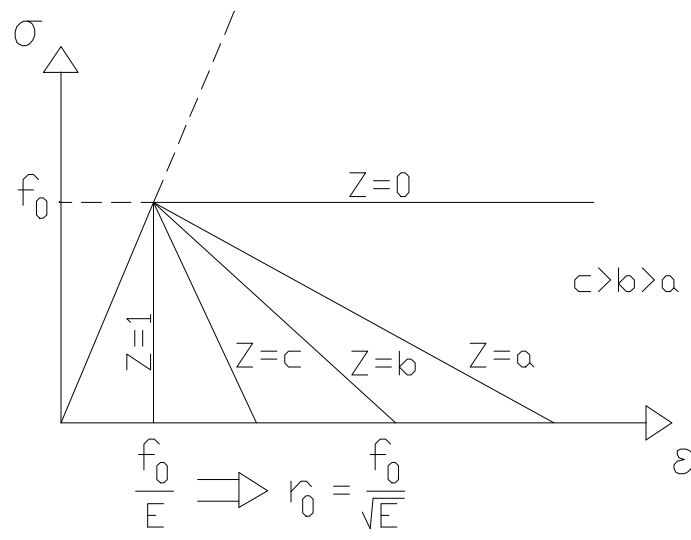

Figura 3.12 - Trecho softening linear do concreto na tração uniaxial.

A energia dissipada $\mathrm{g}_{\mathrm{qst}}$ pode ser dada pela relação $\mathrm{g}_{\mathrm{qst}}=\overline{\mathrm{g}} / 1_{\mathrm{ch}}$, onde $\bar{g}$ é a energia dissipada por unidade de área. Esse valor depende das propriedades do material porém independe do valor de $1_{\mathrm{ch}}$. Pode-se particularizar a expressão de $\mathrm{g}_{\mathrm{qst}}$ para o concreto resultando $\mathrm{g}_{\mathrm{qst}}=\mathrm{G}_{\mathrm{f}} / \mathrm{l}_{\mathrm{ch}}$, sendo $\mathrm{G}_{\mathrm{f}}$ a energia de fratura do material. Portanto, 3.53 pode ser reescrita como: 


$$
\mathrm{Z}=\frac{\mathrm{r}_{0}{ }^{+2} \cdot 1_{\mathrm{ch}}}{2 \mathrm{G}_{\mathrm{f}}}=\overline{\mathrm{Z}} \cdot 1_{\mathrm{ch}}
$$

Como deve-se ter $\mathrm{Z} \leq 1$, chega-se a seguinte limitação para o valor do comprimento característico $1_{\mathrm{ch}}$ :

$$
\mathrm{l}_{\mathrm{ch}} \leq \frac{1}{\overline{\mathrm{Z}}}=\frac{2 \mathrm{G}_{\mathrm{f}}}{\mathrm{r}_{0}{ }^{+2}}
$$

Percebe-se da expressão 3.54 que o parâmetro do modelo $\mathrm{Z}$ é determinado em função do comprimento característico. Implicitamente está dito que a energia dissipada em um comprimento $1_{\text {ch }}$ para a evolução das fissuras de tração pelo concreto, que é uma propriedade do material, está relacionada com a área do diagrama $\sigma-\varepsilon$ teórico para cada valor de $\mathrm{Z}$.

Retornando-se agora para a lei exponencial do trecho softening do concreto à tração do modelo de Cervera, deve-se impor a condição $\mathrm{A}^{+} \geq 0$ na expressão 3.47 para que o trecho pós-pico de tensão seja softening. Seguindo o mesmo raciocínio feito para o trecho linear, a energia dissipada por unidade de volume no caso exponencial é dada por:

$$
\mathrm{g}_{\mathrm{qst}}=\int_{\mathrm{r}_{0}^{+}}^{\mathrm{r}_{\mathrm{u}}} \psi_{0}^{+} \frac{\mathrm{dG}^{+}}{\mathrm{dr}^{+}} \mathrm{dr}=\frac{1}{2}\left(1+\frac{2}{\mathrm{~A}^{+}}\right) \mathrm{r}_{0}{ }^{+2}
$$

Com a variação do parâmetro $\mathrm{A}^{+}$a curva tensão-deformação assumiria as formas da figura 3.13 . 


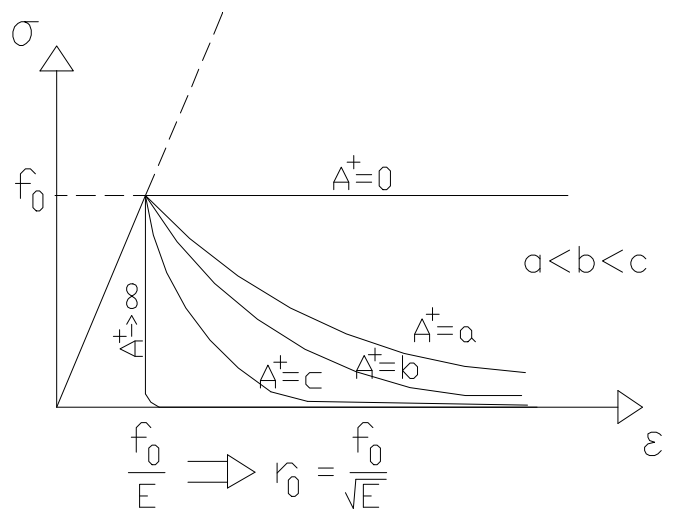

Figura 3.13 - Trecho softening exponencial do concreto na tração uniaxial.

A limitação da expressão 3.55 para $1_{\text {ch }}$ é válida. Sabendo-se que $\mathrm{g}_{\mathrm{qst}}=\mathrm{G}_{\mathrm{f}} / 1_{\mathrm{ch}}$ chega-se $\mathrm{a}$ :

$$
\frac{1}{\mathrm{~A}^{+}}=\frac{1}{2 \overline{\mathrm{Z}}}\left(\frac{1}{1_{\mathrm{ch}}}-\overline{\mathrm{Z}}\right) \geq 0
$$

Da mesma forma que concluiu-se no caso da lei softening linear, o parâmetro $\mathrm{A}^{+}$é determinado em função do comprimento característico $1_{\mathrm{ch}}$ dos elementos finitos da malha adotada.

Conforme citado em ÁLVARES [2] o parâmetro $\mathrm{B}_{\mathrm{T}}$ da expressão 3.14 da variável de dano à tração $\mathrm{D}_{\mathrm{T}}(\widetilde{\varepsilon})$ do modelo de Mazars deve ser relacionada com a energia de fratura $G_{f}$ por unidade de área do concreto para que não ocorram os problemas de instabilidade e perda de objetividade da resposta numérica.

A expressão para o cálculo de $\mathrm{B}_{\mathrm{T}}$ em função do comprimento característico $1_{\text {ch }}$ é dada por:

$$
\mathrm{B}_{\mathrm{T}}=\frac{\varepsilon_{\mathrm{d} 0}+\sqrt{\varepsilon_{\mathrm{d} 0}^{2}+4\left(\frac{\mathrm{G}_{\mathrm{f}}}{\mathrm{El} l_{\mathrm{ch}}}-\frac{\varepsilon_{\mathrm{d} 0}^{2}}{2}\right)}}{2\left(\frac{\mathrm{G}_{\mathrm{f}}}{\mathrm{E} l_{\mathrm{ch}}}-\frac{\varepsilon_{\mathrm{d} 0}^{2}}{2}\right)}
$$


Sendo $\quad \mathrm{B}_{\mathrm{T}}>0$ condição imposta segue a limitação para o comprimento característico dos elementos finitos:

$$
1_{\mathrm{ch}}<\frac{2 \mathrm{G}_{\mathrm{f}}}{\mathrm{E} \varepsilon_{\mathrm{d} 0}{ }^{2}}
$$




\section{CAPÍTULO 4}

\section{APLICAÇÃO NUMÉRICA DOS MODELOS DE DANO À ANÁLISE DE PAVIMENTOS DE CONCRETO ARMADO}

\section{1 - Elementos finitos lineares de barra para modelagem de grelhas.}

Sabe-se que as grelhas são sistemas estruturais reticulados constituídos de elementos de barra dispostos num único plano horizontal, cujas intersecções são denominadas nós, e nas quais o carregamento atua perpendicularmente ao plano dos elementos. As vinculações existentes devem ser tais que não introduzam solicitações no plano do reticulado.

Três graus de liberdade de deslocamento estão definidos em uma seção transversal de uma grelha. $\mathrm{O}$ primeiro corresponde à rotação da seção em torno do eixo "x" do sistema cartesiano ortogonal do plano da estrutura. O segundo é a rotação em torno do eixo "y" do mesmo sistema e o terceiro é o deslocamento vertical perpendicular ao plano da grelha. Portanto, os três esforços solicitantes: momento fletor, momento torçor e força cortante, estão também definidos.

Tratando-se de um sistema estrutural reticulado, as grelhas podem ser subdivididas em elementos finitos lineares de barra visando as aplicações numéricas com o método dos elementos finitos. Dois tipos de sistemas de coordenadas locais são definidos. O primeiro associado ao sistema global de coordenadas cartesianas da estrutura com eixos em cada extremidade de barra paralelos aos eixos do sistema global e o segundo associado ao eixo de cada barra, sendo esse paralelo a um dos 
eixos do sistema local em cada extremidade de barra. A figura 4.1 apresenta as coordenadas de cada um dos sistemas locais definidos.

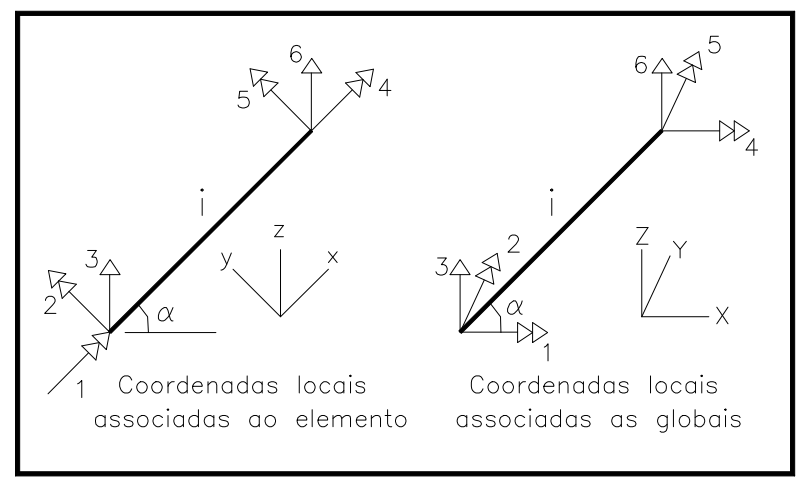

Figura 4.1 - Sistemas de coordenadas locais para o elemento finito de grelha.

Utilizando-se da teoria da elasticidade linear, campo onde é válida a lei de Hooke, chega-se à matriz de rigidez de um elemento finito de barra escrita em qualquer um dos sistemas de coordenadas locais, aplicando-se o princípio da mínima energia potencial total $\delta \pi_{p}=\delta(U+\Omega)=0$, onde $U$ vem a ser a energia interna de deformação do elemento estrutural e $\Omega$ a energia potencial das cargas atuantes.

O valor da energia potencial total $\pi_{\mathrm{p}}$ de um elemento finito é dado por uma expressão em função de parâmetros nodais que têm significado próprio (deslocamentos verticais e giros para os elementos finitos de grelha). Tal expressão deriva da escolha de funções aproximadoras para o deslocamento vertical e para a rotação em torno do eixo da barra. Adota-se, para o elemento de grelha, polinômio de terceiro grau para a primeira função e polinômio de primeiro grau para a segunda.

A matriz de rigidez do elemento finito de grelha $[R]_{\mathrm{e}}$ segundo o sistema de coordenadas locais associado ao elemento (sistema à esquerda na figura 4.1) conforme consta em GERE \& WEAVER [17] é a expressa em 4.1. Fazendo-se uso das matrizes de incidência cinemática chega-se à matriz de rigidez escrita no sistema local associado ao global (sistema à direita na figura 4.1) de cada elemento. A partir do conhecimento das matrizes de rigidez de cada elemento finito da grelha procede-se a montagem da matriz de rigidez global da estrutura. 


$$
[R]_{\mathrm{e}}=\left[\begin{array}{cccccc}
\frac{\mathrm{GJ}_{\mathrm{t}}}{\mathrm{L}} & 0 & 0 & -\frac{\mathrm{GJ}_{\mathrm{t}}}{\mathrm{L}} & 0 & 0 \\
0 & \frac{4 \mathrm{EI}}{\mathrm{L}} & -\frac{6 \mathrm{EI}}{\mathrm{L}^{2}} & 0 & \frac{2 \mathrm{EI}}{\mathrm{L}} & \frac{6 \mathrm{EI}}{\mathrm{L}^{2}} \\
0 & -\frac{6 \mathrm{EI}}{\mathrm{L}^{2}} & \frac{12 \mathrm{EI}}{\mathrm{L}^{3}} & 0 & -\frac{6 \mathrm{EI}}{\mathrm{L}^{2}} & -\frac{12 \mathrm{EI}}{\mathrm{L}^{3}} \\
-\frac{\mathrm{GJ}_{\mathrm{t}}}{\mathrm{L}} & 0 & 0 & \frac{\mathrm{GJ}_{\mathrm{t}}}{\mathrm{L}} & 0 & 0 \\
0 & \frac{2 \mathrm{EI}}{\mathrm{L}} & -\frac{6 \mathrm{EI}}{\mathrm{L}^{2}} & 0 & \frac{4 \mathrm{EI}}{\mathrm{L}} & \frac{6 \mathrm{EI}}{\mathrm{L}^{2}} \\
0 & \frac{6 \mathrm{EI}}{\mathrm{L}^{2}} & -\frac{12 \mathrm{EI}}{\mathrm{L}^{3}} & 0 & \frac{6 \mathrm{EI}}{\mathrm{L}^{2}} & \frac{12 \mathrm{EI}}{\mathrm{L}^{3}}
\end{array}\right]
$$

\section{2 - Modelos de dano escritos em variáveis generalizadas}

Os modelos de dano de Mazars (item 3.4) e de Cervera (item 3.5) foram apresentados segundo uma formulação onde se relacionam não-linearmente campo de deformações com campo de tensões. Particularizadas para o caso unidimensional, as expressões dos modelos procuram representar matematicamente a trajetória da curva tensão-deformação uniaxial do concreto na tração e na compressão.

Esse tipo de formulação é conveniente por permitir uma melhor visualização dos conceitos associados à danificação de meios contínuos, como é tratado o concreto nos modelos de dano. No que diz respeito às aplicações numéricas pode-se dizer que as expressões dos modelos escritos em termos de relações entre tensões e deformações são empregadas na implementação computacional de problemas que fazem uso de elementos finitos tais como os de chapa, com deformação constante ou linear.

Adotando-se aproximações independentes para os deslocamentos segundo os eixos " $\mathrm{x}$ " e " $\mathrm{y}$ " ortogonais de um sistema cartesiano contido no plano do elemento finito de chapa, a determinação do campo de deformações é feita a partir da aplicação de operadores diferenciais de primeira ordem ao campo de deslocamentos. Conhecendo-se as leis constitutivas de um modelo de dano genérico, do campo de deformações determinam-se as variáveis internas do modelo e o campo de tensões. 
As coordenadas 2 e 5 do sistema local associado às barras do elemento finito de grelha (figura 4.1, à esquerda) que representam as rotações em torno do eixo "y" estão relacionadas ao esforço momento fletor. Para que a aplicação dos modelos de dano na análise de grelhas utilizando-se elementos finitos lineares possa ser descrita de forma mais consistente, é conveniente a transformação dos modelos escritos em termos de relações entre tensões e deformações para outros equivalentes escritos em termos de relações entre momentos fletores e curvaturas.

A hipótese básica para que se proceda a transformação é a admissão da manutenção das seções transversais planas após ocorrerem as deformações (hipótese de Bernouille). Também serão consideradas nulas as tensões tangenciais oriundas do momento torçor e da força cortante, cabendo às tensões normais provenientes do momento fletor a evolução do dano. Essa última hipótese tem consistência de acordo com o sistema estrutural em análise. Para o caso em estudo das grelhas de pavimentos usuais de edifícios de concreto armado em que as barras têm baixa rigidez à torção a hipótese se aproxima do comportamento real.

No regime elástico-linear no âmbito da teoria de primeira ordem em que são pequenos os deslocamentos angulares da estrutura e pequenas as deformações específicas do material, é conhecida a relação linear entre momento fletor e curvatura em uma dada seção.

$$
\frac{1}{\mathrm{r}}=-\frac{\mathrm{M}}{\mathrm{EI}}
$$

onde utiliza-se a convenção de sinais clássica da resistência dos materiais.

Para materiais com regime não-linear de comportamento tais como o concreto a relação linear 4.2 não mais é válida. Na realidade o produto EI do denominador da expressão varia com a curvatura da seção transversal segundo uma lei qualquer.

Para o caso particular dos elementos de um sistema estrutural em grelha as seções são solicitadas à flexão simples (força normal nula). Em regimes não-lineares onde o comportamento do material à tração e à compressão são simétricos, a linha neutra passa pelo centróide da seção (para seções simétricas em 
relação ao eixo de flexão). Caso contrário, a posição da linha neutra deve ser determinada impondo-se a condição de força normal resultante nula na seção. Uma das etapas da aplicação dos modelos de dano do capítulo 3 na análise numérica com elementos finitos lineares de barra é a determinação da linha neutra de cada extremidade de cada barra (item 4.3).

Conhecendo-se de uma seção transversal de concreto armado a curvatura e a posição da linha neutra, determina-se o diagrama de deformações específicas ao longo da altura da seção que é linear e se relaciona com a curvatura através de:

$$
\frac{1}{\mathrm{r}}=\frac{\mathrm{d}^{2} \mathrm{v}(\mathrm{x})}{\mathrm{dx}^{2}}=\frac{\varepsilon_{2}-\varepsilon_{1}}{\mathrm{~h}_{\mathrm{s}}}
$$

onde $\mathrm{v}(\mathrm{x})$ é a função para os deslocamentos verticais do eixo do elemento finito linear, $\varepsilon_{2}$ e $\varepsilon_{1}$ são as deformações específicas, respectivamente, das fibras superior e inferior de uma seção transversal de extremidade de barra e $\mathrm{h}_{\mathrm{s}}$ é a altura da seção.

A figura 4.2 mostra esquematicamente as relações entre curvaturas e deformações específicas numa seção transversal de concreto armado.

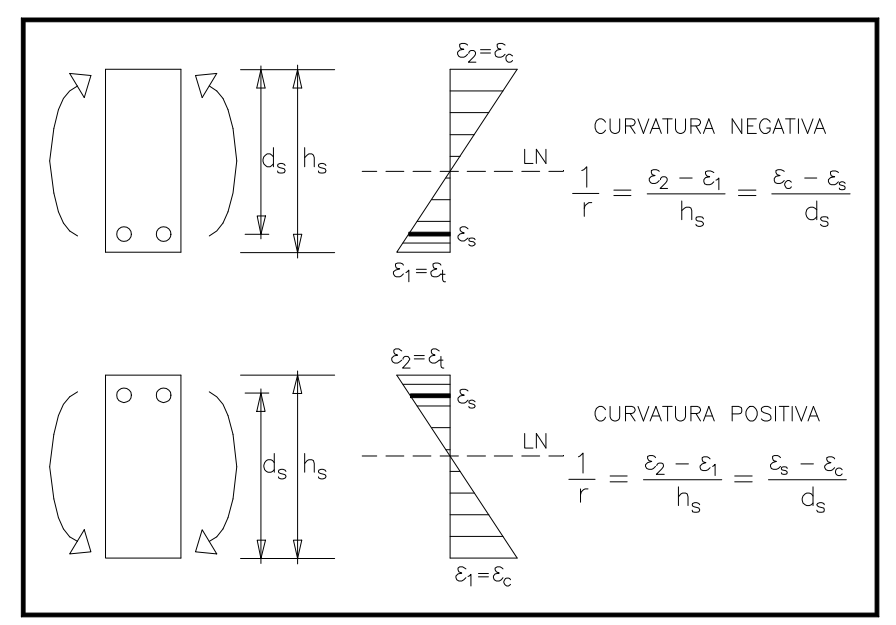

Figura 4.2 - Relações entre curvaturas e deformações.

Constata-se que a determinação do diagrama linear de deformações específicas só depende do conhecimento da curvatura e da linha neutra. Do diagrama 
de deformações determina-se o de tensões utilizando-se das relações constitutivas. Em particular, para peças de concreto armado, têm-se o diagrama de tensões no concreto dos modelos de dano descritos no capítulo 3 e a tensão na armadura do modelo elasto-plástico com encruamento isótropo (item 2.3). Admite-se que a deformação da armadura coincide com a deformação da fibra de concreto que a contém (hipótese de aderência perfeita).

A figura 4.3 mostra o diagrama de tensões no concreto de um modelo de dano genérico e a tensão constante que atua na armadura em correspondência a um diagrama linear de deformações de uma seção transversal de concreto armado.

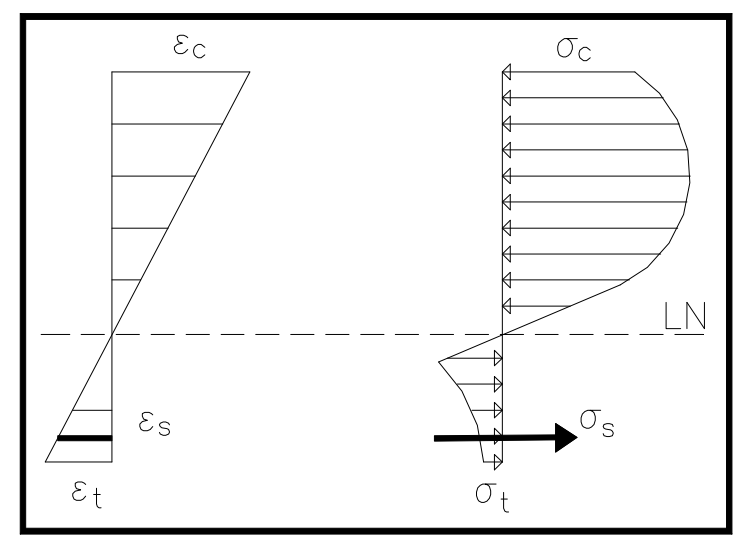

Figura 4.3 - Diagrama de tensões no concreto e na armadura.

O momento fletor resistente de uma seção transversal é determinado através de uma integração simples ao longo da altura da seção do produto da tensão pelo distância do ponto em que ela atua em relação a um referencial. Nas aplicações dos modelos de dano com elemento finito de barra a integração numérica por quadratura de Gauss será utilizada. Admite-se a nomenclatura da figura 4.4 para as características geométricas das seções transversais retangulares. 


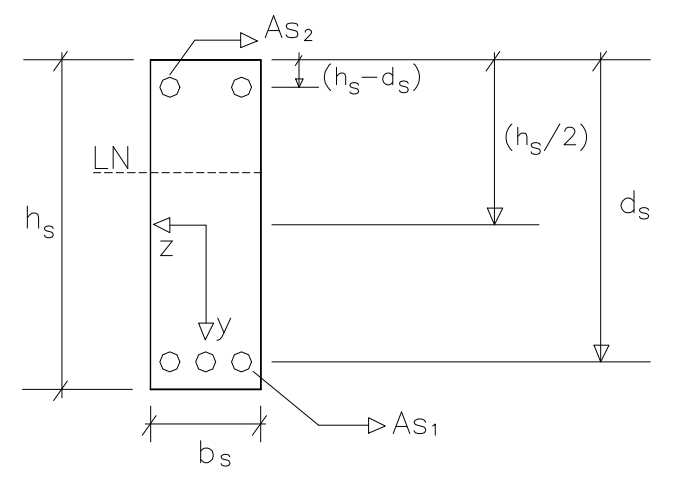

Figura 4.4 - Características geométricas de seções retangulares.

O cálculo do momento fletor resistente interno de uma seção retangular de concreto armado por quadratura de Gauss é feito a partir da expressão 4.4 de equilíbrio de momentos em relação ao eixo $\mathrm{y}=0$ observada a nomenclatura da figura 4.4 .

$$
M_{\text {int }}=\int_{-h_{\mathrm{s}} / 2}^{\mathrm{h}_{\mathrm{s}} / 2} \mathrm{~b}_{\mathrm{s}} \sigma(\mathrm{y}) \mathrm{ydy}+\left(\mathrm{As}_{1} \sigma \mathrm{s}_{1}-\mathrm{As}_{2} \sigma \mathrm{s}_{2}\right)\left(\mathrm{d}_{\mathrm{s}}-\frac{\mathrm{h}_{\mathrm{s}}}{2}\right)
$$

onde $\sigma(\mathrm{y})$ é a tensão no concreto na fibra de ordenada y da lei constitutiva de dano e $\sigma s_{1}$ e $\sigma s_{2}$ são, respectivamente, as tensões nas armaduras de área $A_{1}$ e $\mathrm{As}_{2}$.

O primeiro termo do segundo membro da expressão 4.4 que se refere a parcela do momento fletor proveniente das tensões no concreto pode ser aproximado por uma somatória de termos, conforme expressão 4.5, que equivale a integral no domínio normalizado.

$$
\int_{-\mathrm{h}_{\mathrm{s}} / 2}^{\mathrm{h}_{\mathrm{s}} / 2} \mathrm{~b}_{\mathrm{s}} \sigma(\mathrm{y}) \mathrm{ydy}=\int_{-1}^{1} \mathrm{~b}_{\mathrm{s}} \sigma(\xi) \frac{\mathrm{h}_{\mathrm{s}}}{2} \frac{\mathrm{h}_{\mathrm{s}}}{2} \xi \mathrm{d} \xi=\frac{\mathrm{b}_{\mathrm{s}} \mathrm{h}_{\mathrm{s}}^{2}}{4} \sum_{\mathrm{i}=1}^{\mathrm{n}} \sigma\left(\xi_{\mathrm{i}}\right) \xi_{\mathrm{i}} \mathrm{w}_{\mathrm{i}}
$$

onde $\xi$ é a variável de integração do domínio normalizado com dy $=\frac{\mathrm{h}_{\mathrm{s}}}{2} \mathrm{~d} \xi$. O número de termos da somatória n é o número de pontos de Gauss, $\sigma\left(\xi_{\mathrm{i}}\right)$ é a tensão 
no ponto de integração i e $\mathrm{w}_{\mathrm{i}}$ é o fator peso associado ao ponto i. Em BREBBIA \& DOMINGUEZ [4] encontram-se os valores de $\mathrm{i}$ e $\mathrm{w}_{\mathrm{i}}$ para diferentes números de pontos de Gauss. A somatória do último termo da expressão 4.5 é acrescida de um erro tão menor quanto maior o número de pontos de Gauss para que se chegue ao valor exato da integral.

Fazendo-se uso da expressão 4.5 pode-se traçar um diagrama que relaciona curvaturas com momentos fletores (figura 4.5). O diagrama é função das variáveis que definem a geometria de uma seção transversal. Qualquer alteração em uma delas bem como dos parâmetros que definem os modelos constitutivos do concreto e da armadura modifica o diagrama.

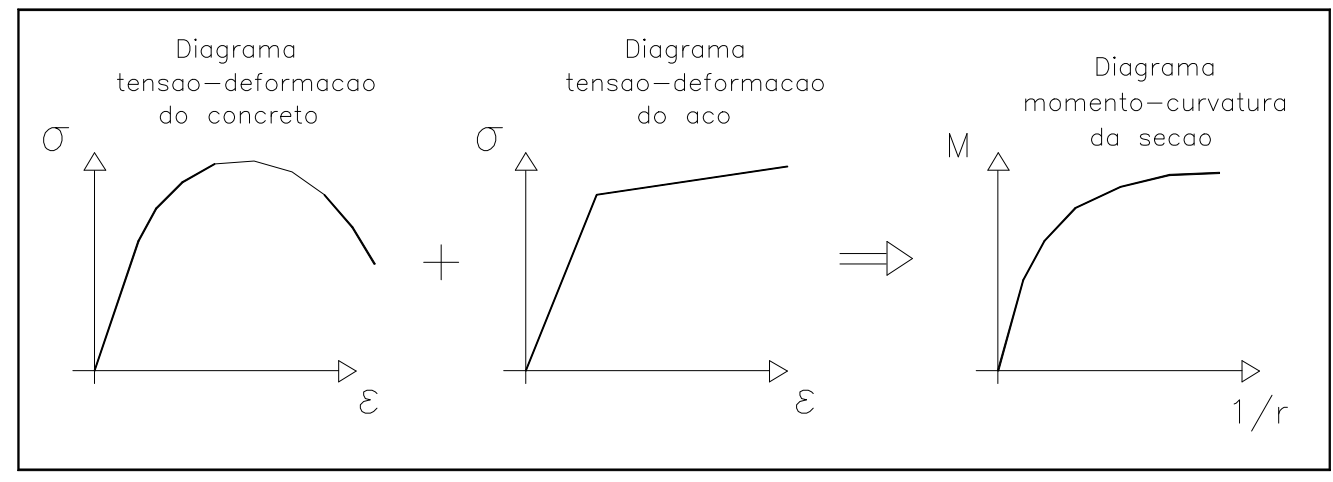

Figura 4.5 - Diagrama momento-curvatura de uma seção de concreto armado.

\section{3 - Procedimento para cálculo da linha neutra de uma seção.}

Uma das etapas do algoritmo de resolução numérica do problema de aplicação dos modelos de dano à análise de grelhas de pavimentos de edifícios com utilização de elementos finitos de barra consiste na determinação da linha neutra para solicitação de flexão simples de uma seção de extremidade de barra conhecida sua curvatura. Essa etapa de análise repete-se a cada passo de iteração do procedimento incremental-iterativo para cada extremidade de cada elemento finito da estrutura.

A solução para esse problema consiste em admitir-se inicialmente a linha neutra passando pelo centróide da seção transversal. Conhecido o valor da curvatura determinado a partir dos deslocamentos nodais do elemento finito ao final de um passo iterativo de um incremento de carga genérico, conhece-se o diagrama 
linear de deformações específicas longitudinais ao longo da altura da seção. A deformação em cada fibra é o produto da curvatura pela distância vertical da fibra a linha neutra admitida (figura 4.6).

A partir do diagrama linear de deformações e da lei constitutiva de dano tem-se o diagrama de tensões no concreto (análogo ao da figura 4.3). Utilizando-se do modelo elasto-plástico para a armadura, tem-se a tensão correspondente à deformação da fibra que contém o centróide da área ocupada pelas barras de aço.

Esse procedimento permite que a cada posição admitida para a linha neutra da seção, conhecidos daí o diagrama de tensões no concreto e as tensões nas armaduras $\mathrm{As}_{1}$ e $\mathrm{As}_{2}$, seja possível determinar a força resistente na seção utilizando quadratura de Gauss para integração numérica.

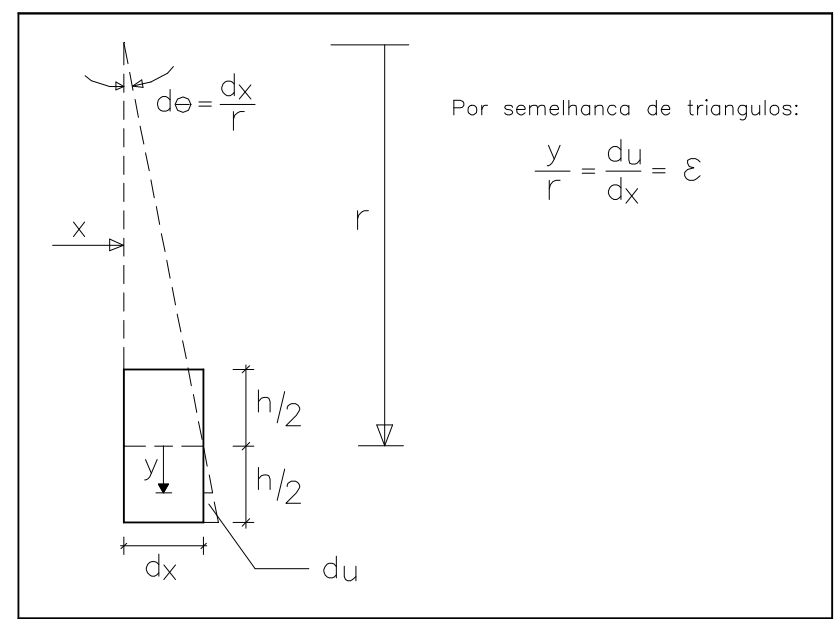

Figura 4.6 - Deformações específicas em função da posição da linha neutra.

A força normal resultante interna em uma seção transversal é obtida segundo a expressão:

$$
\mathrm{N}_{\text {int }}=\int_{-\mathrm{h}_{\mathrm{s}} / 2}^{\mathrm{h} / 2} \mathrm{~b}_{\mathrm{s}} \sigma(\mathrm{y}) \mathrm{dy}+\mathrm{As}_{1} \sigma \mathrm{s}_{1}+\mathrm{As}_{2} \sigma \mathrm{s}_{2}
$$


A integral da expressão 4.6 pode, a exemplo do que foi feito para o cálculo do momento fletor resistente interno, ser aproximado pela somatória:

$$
\int_{-\mathrm{h}_{\mathrm{s}} / 2}^{\mathrm{h}_{\mathrm{s}} / 2} \mathrm{~b}_{\mathrm{s}} \sigma(\mathrm{y}) \mathrm{dy}=\int_{-1}^{1} \mathrm{~b}_{\mathrm{s}} \sigma(\xi) \frac{\mathrm{h}_{\mathrm{s}}}{2} \mathrm{~d} \xi=\frac{\mathrm{b}_{\mathrm{s}} \mathrm{h}_{\mathrm{s}}}{2} \sum_{\mathrm{i}=1}^{\mathrm{n}} \sigma\left(\xi_{\mathrm{i}}\right) \mathrm{w}_{\mathrm{i}}
$$

onde os termos da somatória têm o mesmo significado visto da expressão 4.5.

Caso o valor da força normal resistente interna seja diferente de zero para uma linha neutra admitida, o procedimento numérico iterativo de aproximações sucessivas é utilizado na busca do zero da função que relaciona linha neutra com força normal resistente (figura 4.7).

Esse procedimento admite que a raiz da equação (valor da linha neutra para $\mathrm{N}_{\text {int }}=\mathrm{f}(\mathrm{LN})=0$ ) em qualquer passo do processo iterativo está contida num intervalo fechado do eixo das abcissas (eixo das linhas neutras). Esse intervalo diminui de amplitude sempre que o valor da função calculado para a linha neutra do centro geométrico do intervalo resulta diferente de zero.

Para duas iterações subsequentes o intervalo no eixo das abcissas na iteração i+1 tem a metade da amplitude do intervalo na iteração i. Em qualquer iteração do procedimento os valores da função calculados para os extremos do intervalo corrente devem ser de sinais opostos para que se tenha o zero da função contido no intervalo.

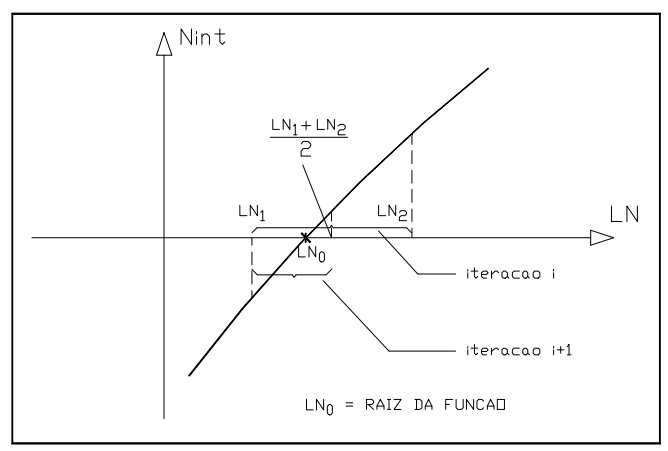

Figura 4.7 - Procedimento numérico de aproximações sucessivas para busca de raízes de funções. 
Conforme observa-se da figura 4.7, a amplitude do intervalo que contém a raiz da função na iteração i vale $\left(\mathrm{LN}_{2}-\mathrm{LN}_{1}\right)$. O centro do intervalo é a abcissa de valor $\left(\mathrm{LN}_{2}+\mathrm{LN}_{1}\right) / 2$. A função calculada para esse último valor é positiva e o intervalo da iteração $\mathrm{i}+1$ passa a ter amplitude $\left(\mathrm{LN}_{2}-\mathrm{LN}_{1}\right) / 2$. O intervalo diminui a cada iteração até que se atinja uma convergência com tolerância pré-estabelecida.

Deve ser lembrado que sendo a curvatura nas peças delgadas uma relação infinitesimal entre deformação angular $\mathrm{d} \theta$ e comprimento $\mathrm{dx}$, para qualquer linha neutra admitida essa relação não se modifica. Esquematicamente, conforme tem-se na figura 4.8, pode-se dizer que alterando-se a linha neutra a curvatura "varre" a seção transversal no sentido de sua altura sem alterar a deformação angular $\mathrm{d} \theta$.

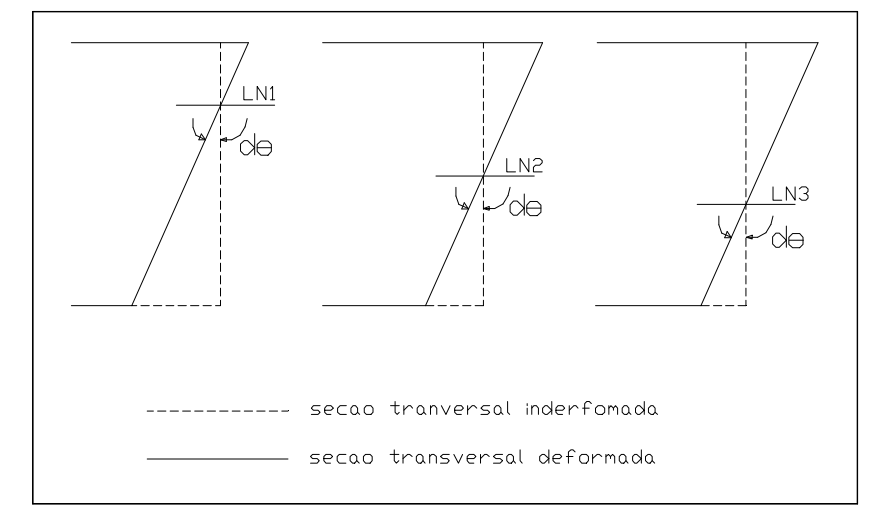

Figura 4.8 - Deformação angular constante para diferentes valores da LN.

\section{4 - Procedimento incremental-iterativo de resolução numérica.}

A utilização do método dos elementos finitos para análise de estruturas com regime não-linear de comportamento resulta num sistema linear de equações simultâneas a cada passo de iteração da forma:

$$
\underline{\underline{\mathrm{Kq}}}=\underline{\mathrm{R}}
$$


onde $\underline{\mathrm{q}}$ é o vetor dos deslocamentos segundo as coordenadas globais, $\underline{\underline{K}}$ é a matriz de rigidez da estrutura montada a partir das matrizes de rigidez elementares dos elementos finitos e $\underline{\mathrm{R}}$ é o vetor de cargas nodais. Se os elementos da matriz $\underline{\underline{K}}$ dependem dos valores dos deslocamentos do vetor q então o problema tem a característica de não-linearidade.

O procedimento de resolução incremental-iterativo do tipo de Newton-Raphson para problemas não-lineares é muito empregado em análise estrutural. A menos que tenha ocorrido uma convergência, o sistema linear da expressão 4.8 não será satisfeito durante os passos de iteração do procedimento de busca da solução e um vetor de forças residuais $\underline{\psi}$ será definido a cada passo iterativo como:

$$
\underline{\psi}=\underline{\underline{\mathrm{K}}} \underline{\underline{\mathrm{R}}} \neq \underline{\mathrm{R}} 0
$$

Os valores das componentes do vetor $\underline{\Psi}$ podem ser interpretados como desvios da situação de equilíbrio segundo os esforços das coordenadas que eles representam.

Para uma visualização gráfica do procedimento incremental-iterativo admite-se o caso unidimensional em que a matriz $\underline{\underline{K}}$ assim como os vetores $\underline{\mathrm{q}}$ e $\underline{\mathrm{R}}$ possuem apenas uma componente associada a um único grau de liberdade de deslocamento e relacionadas por:

$$
K(q) q=R
$$

Para que a análise gráfica se aproxime mais da aplicação com elementos finitos de grelha, admita-se que a variável q seja a curvatura de uma seção e que a variável R seja o momento fletor externo aplicado. A figura 4.9 mostra os valores do resíduo de momento $\psi$ que deve ser reaplicado a cada iteração. 


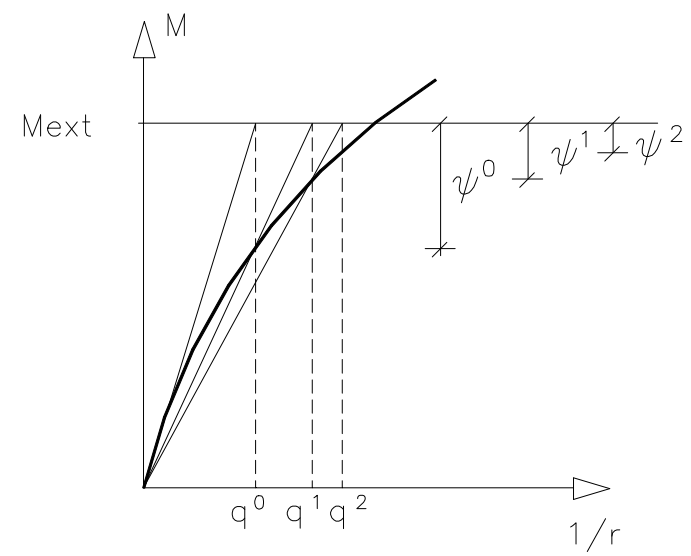

Figura 4.9 - Procedimento de Newton-Raphson para caso unidimensional.

A função representada no eixo das ordenadas da figura $4.9 \mathrm{em}$ correspondência com a expressão 4.10 particularizada para a relação momentocurvatura é da forma:

$$
\mathrm{M}=\mathrm{K}(1 / \mathrm{r}) \cdot 1 / \mathrm{r}
$$

Para o regime elástico-linear ter-se-ia $\mathrm{K}(1 / \mathrm{r})=\mathrm{E} . \mathrm{I}$, onde $\mathrm{E}$ corresponde ao módulo de elasticidade longitudinal e I ao momento de inércia à flexão de uma seção transversal genérica. Para regimes de comportamento não-linear o diagrama "momento-curvatura" é da forma como apresentado na figura 4.9. Observa-se da mesma figura que a cada passo de iteração o valor de K é atualizado pela inclinação da reta secante que passa em cada ponto do diagrama "momentocurvatura" atualizado pela iteração anterior.

Pode-se também atualizar o valor de K pela inclinação da reta tangente a cada ponto do digrama "momento-curvatura" atualizado pela iteração anterior. Caso se mantenha o valor de $\mathrm{K}$ da primeira iteração constante (K=E.I) nas demais iterações tem-se o denominado procedimento de Newton-Raphson puro.

O carregamento total de uma estrutura que formará o vetor de cargas nodais $\underline{\mathrm{R}}$ deverá ser aplicado em incrementos dentro dos quais se terá várias iterações até que se verifique uma convergência. O carregamento efetuado em incrementos tem a característica de ser proporcional, ou seja, o vetor de forças nodais 
$\underline{R}_{\text {ext } j+1}$ em um incremento de carga $j+1$ é dado pelo produto $\alpha_{j+1} \underline{R}_{\text {ext }}$ com $\alpha_{j+1}$ um número escalar contido no intervalo real $[0,1]$ e $\underline{\mathrm{R}}_{\mathrm{ext}} \mathrm{o}$ vetor de forças nodais equivalente ao carregamento total da estrutura. Deve ser verificada a igualdade $\sum_{j=1}^{m} \alpha_{j}=1$ para m incrementos de carga.

\section{5 - Solução do problema de valor de contorno com modelos de dano para o concreto.}

À medida que se processa a danificação do material nota-se, do diagrama "momento-curvatura", que a rigidez secante da curva diminui. A cada passo iterativo do procedimento de busca da solução, para carregamento crescente, a rigidez inicial dada pelo produto (E.I) é penalizada pelo fator (1-d). Na figura 4.10 pode ser observada a perda de rigidez com carregamento crescente de uma seção transversal de concreto armado com relação constitutiva "momento-curvatura".

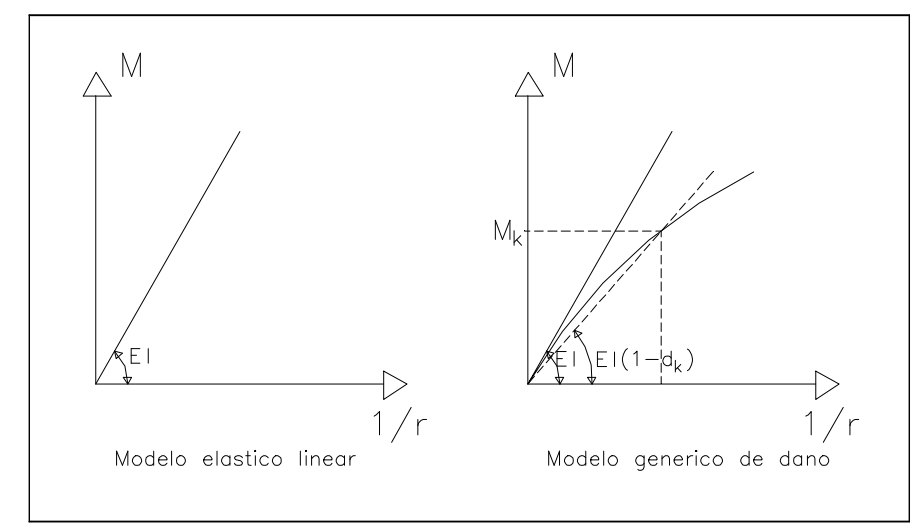

Figura 4.10 - Rigidez secante da curva "momento-curvatura".

A variável $\mathrm{d}_{\mathrm{K}}$ definida na figura 4.10 não tem nenhuma relação com as variáveis de dano dos modelos de Mazars e de Cervera. Porém elas são utilizadas no procedimento explícito para resolução de grelhas com modelo constitutivo de dano. As matrizes de rigidez dos elementos finitos de grelha a cada passo de iteração é a matriz elástica do material íntegro expressa em 4.1 multiplicada pelo fator 
(1- $\mathrm{d}_{\mathrm{K}}$ ) onde $\mathrm{d}_{\mathrm{K}}$, nesse caso, é a média aritmética dos valores da rigidez calculados para cada extremidade do elemento finito de barra:

$$
\mathrm{d}_{\mathrm{K}}=1-\frac{\left[\frac{\mathrm{M}_{1}}{(1 / \mathrm{r})_{1} \mathrm{EI}}+\frac{\mathrm{M}_{2}}{\left(1 / \mathrm{r}_{2} \mathrm{EI}\right.}\right]}{2}
$$

onde o índice 1 representa a seção da extremidade inicial do elemento de barra e o índice 2 a seção da extremidade final. $M_{i}$ vem a ser o momento fletor atuante na seção i e $(1 / \mathrm{r})_{\mathrm{i}}$ a curvatura de i.

Supõem-se conhecidos ao final do passo i de iteração do incremento de carga $\mathrm{j}$, o vetor de forças internas $\underline{\mathrm{R}}_{\mathrm{int}} \mathrm{j}$ segundo as coordenadas globais da estrutura obtido dos modelos de dano para o concreto e elasto-plástico para as barras de aço e em equilíbrio com o vetor de forças externas $\underline{R}_{\text {ext }_{\mathrm{j}}}$ que representa o carregamento total aplicado até o incremento j. Também admitem-se conhecidos o estado de deformações (curvaturas) compatível com os deslocamentos nodais $\underline{\mathrm{q}}_{\mathrm{j}} \mathrm{e}$ com o modelo constitutivo escrito em termos de relação "momento-curvatura" e as variáveis internas do modelo obtidas, conforme figura 4.10, para cada elemento finito da estrutura e representada genericamente por $\mathrm{d}_{\mathrm{j}}$. Para o próximo incremento de carga as relações $4.13,4.14$ e 4.15 devem ser verificadas.

$$
\begin{aligned}
& \underline{\underline{K}}\left(\mathrm{~d}_{\mathrm{j}+1}\right) \underline{\mathrm{q}}_{\mathrm{j}+1}=\underline{\mathrm{R}}_{\mathrm{ext}}+\Delta \underline{\mathrm{R}}_{\mathrm{ext}}=\underline{\mathrm{R}}_{\mathrm{ext} \mathrm{j}+1} \\
& \underline{\psi}_{\mathrm{j}+1}=\underline{\mathrm{R}}_{\mathrm{int}}^{\mathrm{j}+1} \underline{\mathrm{R}}_{\mathrm{ext} \mathrm{j}+1} \\
& \left\|\underline{\Psi}_{j+1}\right\| \leq \delta
\end{aligned}
$$

onde $\delta$ é um valor de tolerância pré-estabelecida. 
A expressão 4.15 traduz uma situação de convergência do processo iterativo dentro de um incremento de carga. Nas aplicações do capítulo 5 essa convergência será estabelecida comparando-se medidas de cada coordenada do vetor de deslocamentos nodais em duas iterações sucessivas. O primeiro membro da desigualdade 4.15 (norma do vetor $\underline{\Psi}$ ) é dado segundo a expressão:

$$
\left\|\underline{\psi}_{j+1}\right\|=\frac{\mid \sqrt{\left[\sum_{m=1}^{N}\left(q_{m}^{i}\right)^{2}\right]}-\sqrt{\left[\sum_{m=1}^{N}\left(q_{m}^{i-1}\right)^{2}\right]}}{\sqrt{\left[\sum_{m=1}^{N}\left(q_{m}^{1}\right)^{2}\right]}} \times 100
$$

onde $\mathrm{N}$ é o número de coordenadas do vetor q e os índices superiores i e i-1 denotam iterações sucessivas.

Se em uma iteração não for verificada a desigualdade 4.15 , o vetor resíduo $\underline{\psi}$ deve então ser reaplicado como carregamento sucessivas vezes até que a norma do vetor resíduo (expressão 4.16) seja menor ou igual a $\delta$.

$\mathrm{O}$ procedimento é dito explícito porque as variáveis de dano $\mathrm{d}_{\mathrm{j}}^{\mathrm{i}}$ (iteração i do incremento j) para cada elemento finito de barra obtidas das relações entre momentos e curvaturas são atualizadas anteriormente ao novo passo de iteração. Optou-se pelo procedimento explícito nas aplicação do capítulo 5.

Os passos principais da análise numérica de grelhas de pavimentos de edifícios com elemento finito linear de barra para um incremento de carga $\mathrm{j}$ são descritos no quadro que segue. 


\section{Passos da análise numérica para um incremento de carga $\mathbf{j}$}

- Na primeira iteração (índice sobrescrito 0) admitem-se conhecidas as variáveis:

$$
\text { INPUT: } \underline{(1 / \mathrm{r})} \mathrm{j}=\underline{(1 / \mathrm{r})} \mathrm{j-1}, \underline{\mathrm{q}}_{\mathrm{j}}=\underline{\mathrm{q}}_{\mathrm{j}-1}, \mathrm{~d}_{\mathrm{j}}^{0}=\mathrm{d}_{\mathrm{j}-1}
$$

- Ao final do incremento de carga $\mathrm{j}$ deseja-se obter:

$$
\text { OUTPUT: }(1 / \mathrm{r})_{\mathrm{j}}, \underline{\mathrm{q}}_{\mathrm{j}}, \mathrm{d}_{\mathrm{j}}
$$

(1) Aplica-se como carregamento $o$ vetor de forças nodais $\underline{\mathrm{R}}_{\text {ext } \mathrm{j}}=\underline{\mathrm{R}}_{\mathrm{ext} \mathrm{j}-1}+\Delta \underline{\mathrm{R}}_{\mathrm{ext}}$. A variável i (iteração) recebe 0 .

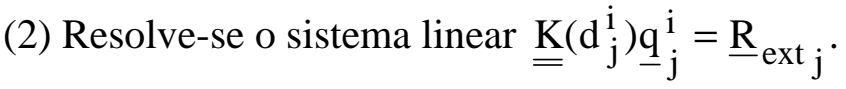

(3) $\underline{\mathrm{q}}_{\mathrm{j}}=\underline{\mathrm{q}}_{\mathrm{j}}+\underline{\mathrm{q}}_{\mathrm{j}}^{\mathrm{i}}$.

(4) A partir de $\underline{\mathrm{q}}_{\mathrm{j}}$ atualiza-se $\underline{(1 / \mathrm{r})} \mathrm{j}=\underline{(1 / \mathrm{r})} \mathrm{j}+\underline{(1 / \mathrm{r})^{\mathrm{i}}} \mathrm{j}$.

(5) Cálculo iterativo das linhas neutras das extremidades de barra de cada elemento finito: expressão 4.6 + procedimento de aproximações sucessivas.

(6) Conhecidas as posições das linhas neutras de cada extremidade de barra de cada elemento finito $\Rightarrow\left|\mathrm{N}_{\text {int }}\right| \leq$ tolerância calcula-se:

- $\mathrm{O}$ vetor de forças internas $\underline{R}_{\text {int }_{j}}$.

- O vetor resíduo $\underline{\psi}_{\mathrm{j}}^{\mathrm{i}}=\underline{\mathrm{R}}_{\text {int }_{\mathrm{j}}}^{\mathrm{i}}-\underline{\mathrm{R}}_{\text {ext }_{\mathrm{j}}}$

- Os valores das variáveis de dano de cada elemento finito representados genericamente por $\mathrm{d}_{\mathrm{j}}^{\mathrm{i}+1}$.

(7) Se $\left\|\underline{\Psi}_{\mathrm{j}}^{\mathrm{i}}\right\| \leq \delta$ então tem-se as variáveis de OUTPUT.

Senão: - i=i+1

- Resolve-se $\underline{\underline{K}}\left(\mathrm{~d}_{\mathrm{j}}^{\mathrm{i}} \underline{\underline{\mathrm{q}}}_{\mathrm{j}}^{\mathrm{i}}=\underline{\psi}_{\mathrm{j}}^{\mathrm{i}-1}\right.$

- Retorna-se ao passo (3) e repete-se mais uma iteração. 
Alguns esclarecimentos devem ser fornecidos quanto aos passos da análise numérica colocados na página 67.

- As variáveis vetor de deslocamentos nodais q (sistema de coordenadas globais) e vetores de curvaturas $1 / \mathrm{r}$ (sistema de coordenadas locais associado às extremidades de barra) são sempre atualizadas a cada iteração conforme passos (3) e (4).

- O vetor de forças internas $\underline{R}_{\text {int }_{j}}^{\mathrm{i}}$ (sistema de coordenadas globais) é obtido do modelo constitutivo de dano para o concreto e do modelo elasto-plástico para a armadura segundo as coordenadas 2 e 5 relativas ao momento fletor do sistema local (sistema a esquerda na figura 4.1) e com a devida aplicação das matrizes de incidência cinemática.

- O procedimento é do tipo explícito, em que a variável representativa da perda de rigidez $\mathrm{d}_{\mathrm{j}}^{\mathrm{i}}$ é calculada antes do passo de iteração $\mathrm{i}+1$ para cada elemento finito de barra. A matriz de rigidez secante de cada barra (figura 4.10) contribui para a montagem da matriz de rigidez global.

- Durante a implementação torna-se mais simples calcular o vetor resíduo $\underline{\psi}$ conhecendo-se o momento fletor obtido e subtraindo-o do momento fletor verdadeiro. As ações segundo as coordenadas 3 e 6 do sistema local associado às extremidades de barra contribuem para o vetor resíduo. Todas as ações são transformadas do sistema local para o global aplicando-se adequadamente as matrizes de incidência. 


\section{CAPÍTULO 5}

\section{EXEMPLOS DE APLICAÇÃO}

Apresentam-se nesse capítulo alguns exemplos numéricos de aplicações dos modelos de dano descritos no capítulo 3 à análise de estruturas reticuladas de concreto armado. Com isso, pretende-se mostrar o comportamento não-linear do concreto armado com utilização de modelos de dano e com a técnica dos elementos finitos, conforme discutido no capítulo 4.

No primeiro exemplo procura-se confrontar as respostas numéricas com respostas experimentais de vigas ensaiadas na EESC-USP por ÁLVARES [2]. São analisadas três vigas que cobrem as situações de peças subarmada, normalmente armada e superarmada.

No segundo exemplo é analisado um pavimento de um pilotis de um edifício em concreto armado com cargas de utilização e traçados diagramas "carga $\mathrm{x}$ deslocamento" de alguns pontos importantes e diagramas de esforços solicitantes para duas vigas.

No terceiro exemplo procura-se modificar os parâmetros dos modelos de dano para que esses se ajustem ao modelo proposto pelo CEB (boletim 158). Para tal finalidade, analisa-se uma viga com diagrama de momentos fletores constante.

Em todos os três exemplos utiliza-se um código de cálculo desenvolvido em linguagem FORTRAN que segue um algoritmo detalhado a partir dos passos de análise numérica do quadro A (capítulo 4). Esse código permite analisar qualquer estrutura reticulada com comportamento de grelha utilizando-se os modelos de dano colocados no capítulo 3 para o concreto e o modelo elasto-plástico (item 2.3) para as barras de aço da armadura. 


\section{Exemplo 01 - Vigas em concreto armado com cargas concentradas}

Os três exemplos desse item encontram-se em ÁLVARES [2]. As vigas foram ensaiadas por ÁLVARES em laboratório e analisadas numericamente utilizando-se o mesmo modelo de dano de Mazars descrito no capítulo 3. No mesmo trabalho foi analisada a resposta numérica das vigas utilizando dois tipos de elementos finitos. Uma das análises foi com elementos tridimensionais (elementos finitos isoparamétricos degenerados) e outra com elementos finitos planos.

\section{$\underline{\text { Características das vigas: }}$}

As vigas em concreto armado têm $2.40 \mathrm{~m}$ de comprimento, biapoiadas, com seções transversais de $12 \times 30 \mathrm{~cm}$ e carregamentos concentrados nos terços de vão (figura 5.1). As vigas se diferenciam pela quantidade e distribuição das armaduras de flexão (armadura longitudinal inferior). As seções estão mostradas na figura 5.2. Os três casos cobrem as situações de viga pouco armada, normalmente armada e super armada. A armadura longitudinal superior, nos três casos, é constituída por $2 \phi 5 \mathrm{~mm}$. Os estribos de $\phi 5 \mathrm{~mm} \mathrm{c} / 12 \mathrm{~cm}$ contribuem na resistência aos esforços de cisalhamento nas regiões compreendidas entre as cargas e os apoios.

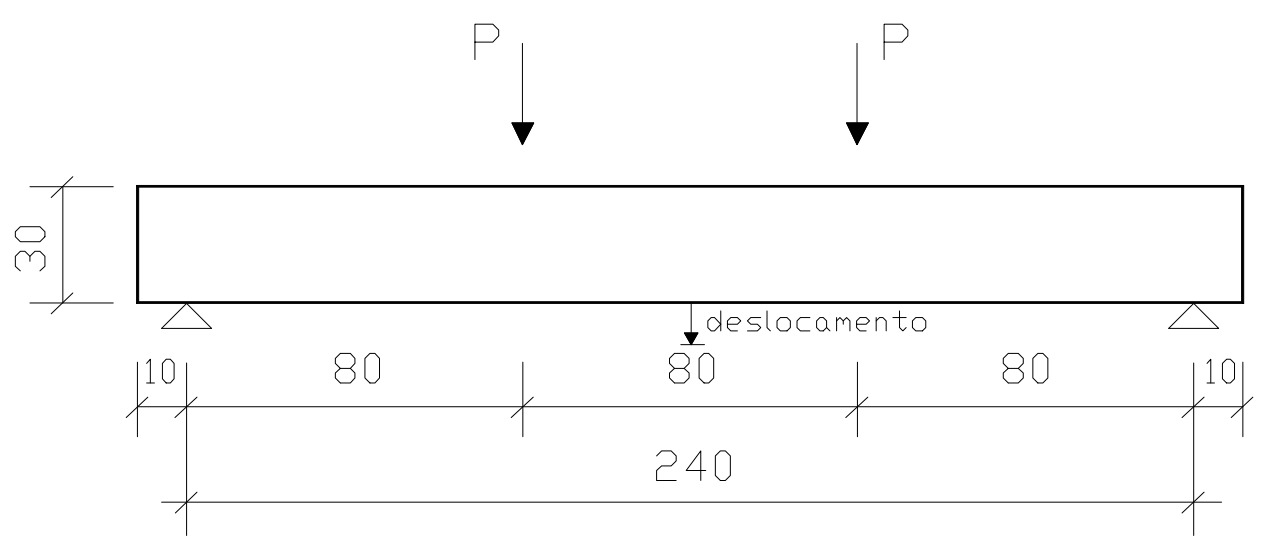

Figura 5.1 - Geometria das vigas em concreto armado.

Figura adaptada de Álvares [2]. 


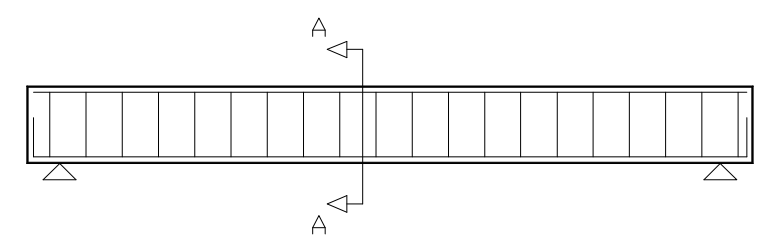

CORTE A-A

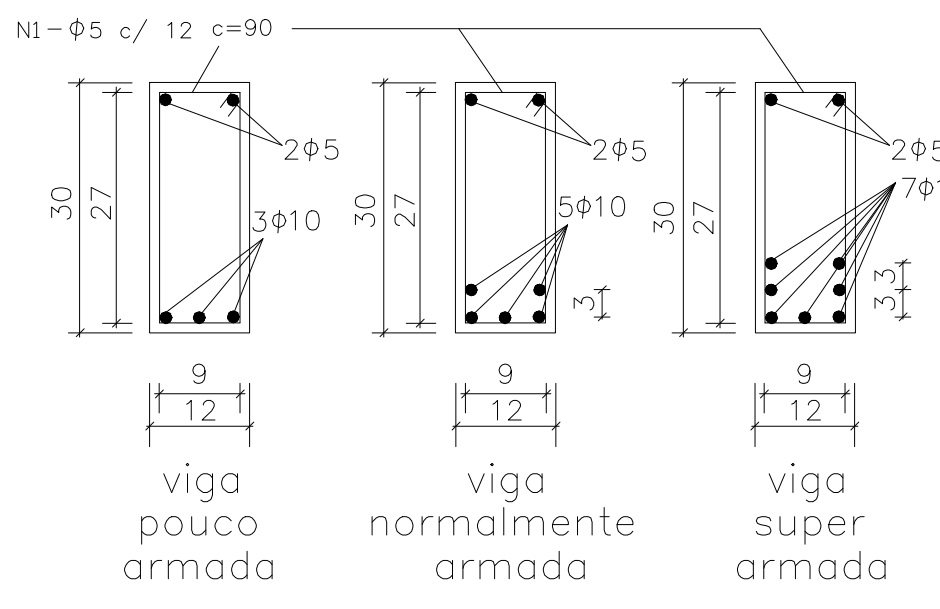

Figura 5.2 - Distribuições das armaduras nas vigas.

Figura adaptada de Álvares [2].

\section{Parâmetros dos modelos:}

Serão realizadas duas análises numéricas das vigas da figura 5.2. Uma utilizando o modelo de dano de Mazars (item 3.4) e outra o modelo de Cervera (item 3.5) para o concreto. Para as barras de aço admite-se comportamento elasto-plástico com encruamento isótropo (item 2.3).

Os parâmetros do modelo de dano de Mazars são os sugeridos em ÁLVARES [2] obtidos através de experimentação com corpos de prova de concreto e identificados numericamente pelo método dos mínimos quadrados. Os parâmetros do modelo de dano de Cervera são os que constam em CERVERA [7]. Esses últimos valores foram obtidos da curva tensão-deformação do concreto para solicitação cíclica uniaxial (figura 5.3). 


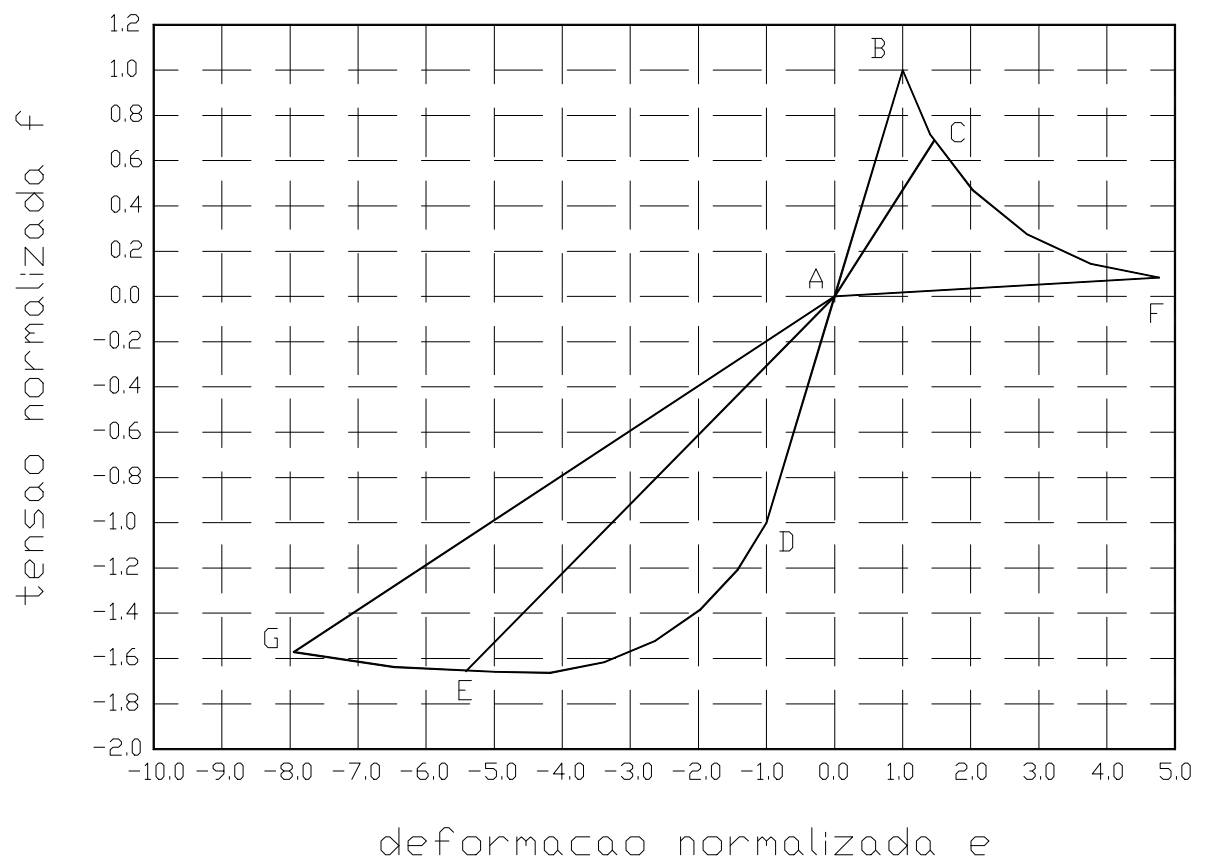

Figura 5.3 - Diagrama tensão-deformação uniaxial para carregamento cíclico. Figura adaptada de Cervera [7].

A figura 5.3 mostra o resultado numérico de um ciclo completo de carregamento uniaxial com utilização de elementos finitos de 4 nós sujeitos a deslocamentos axiais prescritos. A figura está apresentada segundo eixos normalizados obtidos dividindo-se a tensão atuante pela tensão uniaxial de compressão ou de tração do limiar do início da danificação $\left(\mathrm{f}=\sigma / \mathrm{f}_{0}^{+/-}\right)$e dividindo-se também a deformação pela respectiva deformação associada ao limiar do dano $\left(\mathrm{e}=\varepsilon /\left(\mathrm{f}_{0}^{+/-} / \mathrm{E}\right)\right)$. Os parâmetros do modelo de Cervera podem ser obtidos (a menos de $\mathrm{r}_{0}{ }^{+}{\mathrm{e} \mathrm{r}_{0}}^{-}$) a partir do diagrama da figura 5.3.

Aproveitando-se do diagrama da figura 5.3 é possível observar o comportamento completo de um ciclo de tensão com os parâmetros do modelo de Cervera. O concreto é primeiro tensionado até que ocorra dano por tração (trecho ABC). Depois ocorre o descarregamento pela secante, recuperação da rigidez inicial e danificação por compressão (trecho CADE). Um novo descarregamento com rigidez secante, inversão do sinal do carregamento e aumento da danificação por tração até praticamente desaparecer a tensão de tração (trecho EACF). Uma nova 
descarga com recarregamento de compressão (trecho FAEG). Finalmente ocorre o descarregamento secante até a origem (trecho GA). Nota-se que, a exemplo do modelo de dano de Mazars, o de Cervera não faz consideração de deformações plásticas.

Na tabela 1 têm-se os parâmetros dos modelos de dano de Mazars e de Cervera e do modelo elasto-plástico para as armaduras utilizados na análise numérica das vigas.

\section{TABELA 1}

\section{Parâmetros do modelo de dano de Mazars}

$\begin{array}{ll}\mathrm{E}_{\text {concreto }}=2920 \mathrm{kN} / \mathrm{cm}^{2} & v=0.2 \\ \varepsilon_{\mathrm{d} 0}=0.00007 & \mathrm{~A}_{\mathrm{T}}=0.995 \\ \mathrm{~A}_{\mathrm{C}}=0.85 & \mathrm{G}_{\mathrm{f}}=0.0016 \mathrm{kN} / \mathrm{cm} \\ \mathrm{B}_{\mathrm{C}}=1620 & \mathrm{~B}_{\mathrm{T}}=8000\end{array}$

\section{Parâmetros do modelo de dano de Cervera}

$$
\begin{array}{ll}
\mathrm{E}_{\text {concreto }}=2920 \mathrm{kN} / \mathrm{cm}^{2} & v=0.2 \\
\mathrm{r}_{0}^{+}=0.0037012 & \mathrm{r}_{0}^{-}=1.047983 \\
\mathrm{~A}^{-}=0.52 & \mathrm{~B}^{-}=0.20 \\
\mathrm{G}_{\mathrm{f}}=0.0025 \mathrm{kN} / \mathrm{cm} & \mathrm{A}^{+}=0.65
\end{array}
$$

\section{Parâmetros do modelo elasto-plástico com encruamento isótropo}

$$
\begin{aligned}
& \mathrm{E}_{\text {armadura }}=19600 \mathrm{kN} / \mathrm{cm}^{2} \quad \mathrm{H}=1960 \mathrm{kN} / \mathrm{cm}^{2} \\
& \sigma_{\mathrm{y}}=50 \mathrm{kN} / \mathrm{cm}^{2}
\end{aligned}
$$

Discretização das vigas e incrementos de carga:

As vigas analisadas numericamente foram discretizadas em 48 elementos finitos para um total de 49 nós. Cada elemento finito de barra tem comprimento de $5 \mathrm{~cm}$. Foram aplicados 20 incrementos uniformes de carga de $5 \%$ do 
valor total. O carregamento é sempre proporcional e crescente. A tolerância estabelecida $\delta$ (expressão 4.15) é de $0.1 \%$ para os três casos de vigas analisadas.

Os resultados estão apresentados em diagramas que relacionam carregamento com deslocamento vertical do nó central da viga (figura 5.4).

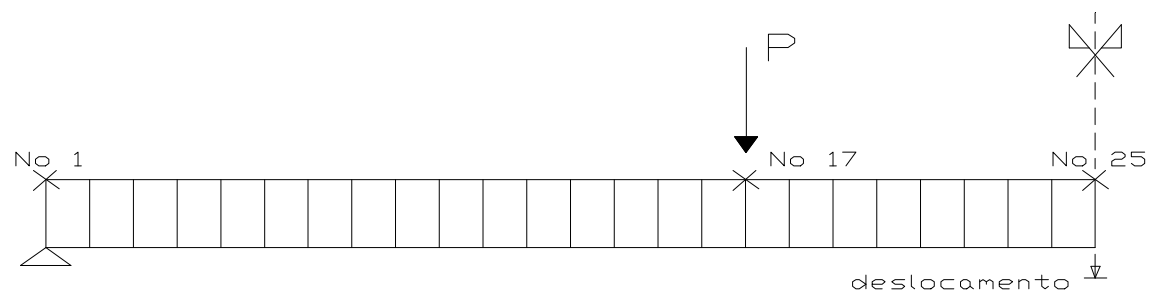

Figura 5.4 - Discretização das vigas em elementos de barra para análise numérica.

$\underline{\text { Resultados numéricos: }}$

- Viga pouco armada:

- Seção transversal: $12 \times 30 \mathrm{~cm}$

- $\mathrm{As}_{1}=2.356 \mathrm{~cm}^{2}(3$ barras de $10 \mathrm{~mm})$

$-\mathrm{d}=27.50 \mathrm{~cm}$

- Viga normalmente armada:

- Seção transversal: $12 \times 30 \mathrm{~cm}$

- $\mathrm{As}_{1}=3.927 \mathrm{~cm}^{2}(5$ barras de $10 \mathrm{~mm})$

$-\mathrm{d}=27.00 \mathrm{~cm}$

- Viga super armada:

- Seção transversal: $12 \times 30 \mathrm{~cm}$

- $\mathrm{As}_{1}=5.498 \mathrm{~cm}^{2}(7$ barras de $10 \mathrm{~mm})$

$-\mathrm{d}=26.00 \mathrm{~cm}$

Os resultados numéricos da implementação dos dois modelos de dano (Mazars e Cervera) e as respostas do comportamento experimental obtidas por ÁLVARES [2] das três vigas ensaiadas em laboratório se encontram nas figuras 5.5, 5.6 e 5.7. Além da curva obtida com os parâmetros do modelo de Mazars colocados na tabela 1 , tem-se uma segunda curva do mesmo modelo para outro parâmetro $\varepsilon_{\mathrm{d} 0}$. 


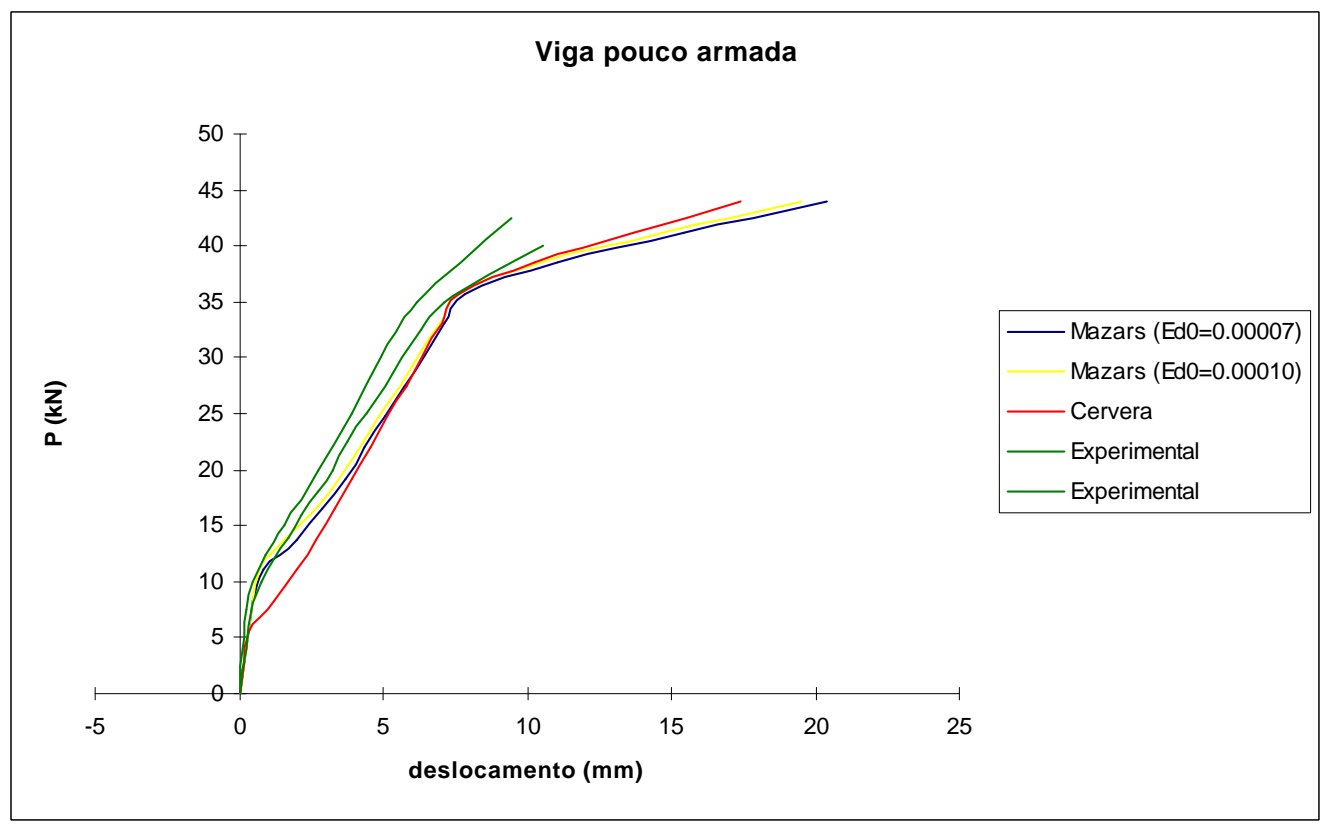

Figura 5.5 - Diagrama carga $x$ deslocamento para viga pouco armada.

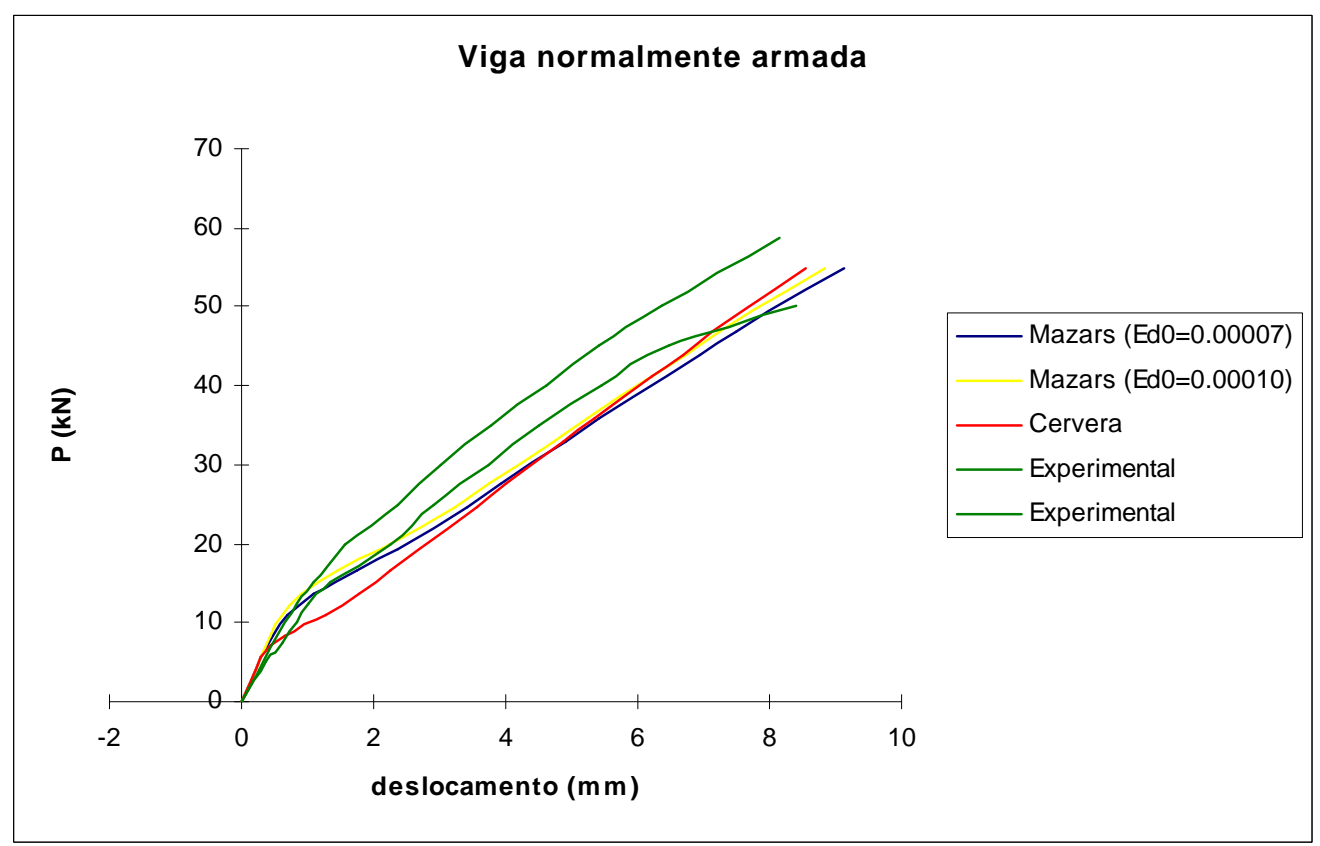

Figura 5.6 - Diagrama carga $x$ deslocamento para viga normalmente armada. 


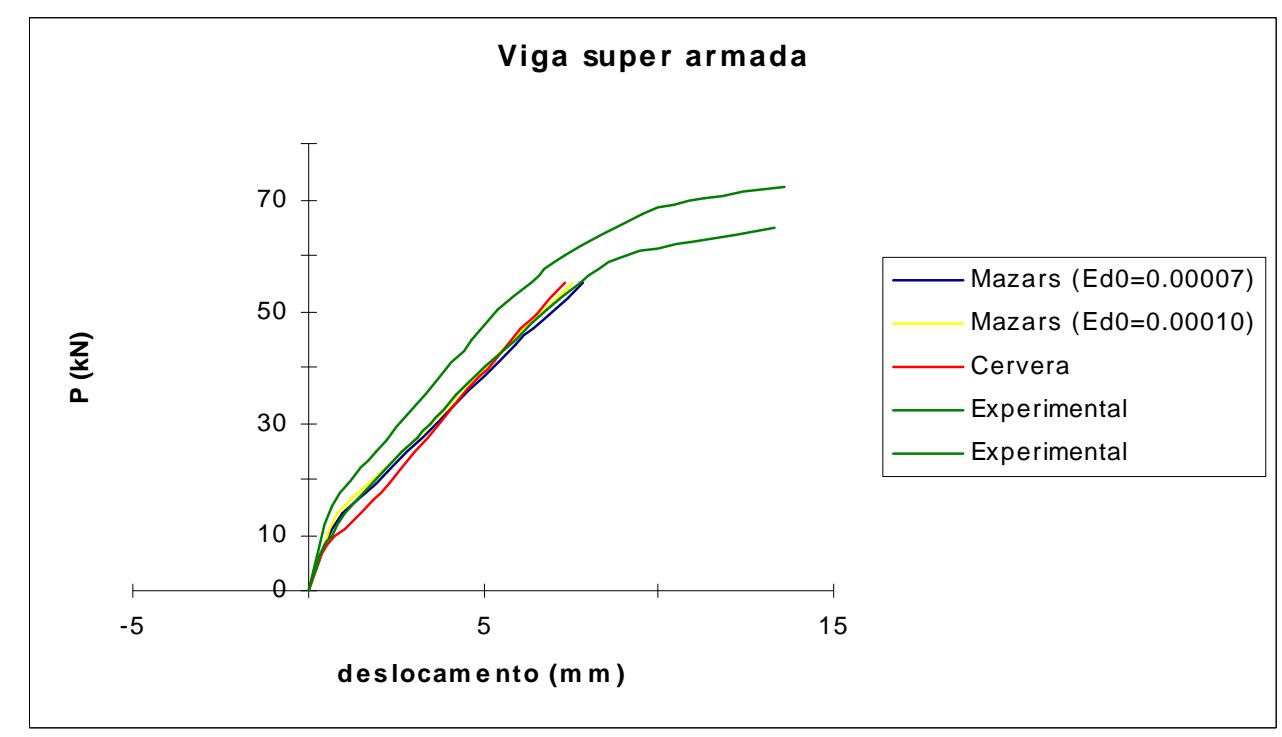

Figura 5.7 - Diagrama carga $x$ deslocamento para viga super armada.

\section{Conclusões do exemplo.}

Conforme pôde ser observado dos diagramas carga x deslocamento os resultados numéricos fornecidos pelos modelos de dano de Mazars e de Cervera estão um pouco a favor da segurança nos três casos em estudo. Isso é verificado pelo desenvolvimento das curvas que se encontram à esquerda da nuvem de resultados experimentais delimitada pelas duas curvas que a definem.

Deve-se ressaltar que uma das questões principais que deve ser levada em conta para o bom funcionamento de um modelo de dano é o problema da identificação paramétrica. Para as duas curvas do modelo de Mazars, verifica-se que a mudança em um dos parâmetros $\left(\varepsilon_{\mathrm{d} 0}=0.00007\right.$ e $\left.\varepsilon_{\mathrm{d} 0}=0.00010\right)$ é suficiente para modificar em grande escala o comportamento do diagrama carga $\mathrm{x}$ deslocamento. Para cada classe de resistência do concreto modificam-se os parâmetros de um modelo ou até mesmo viabiliza ou inviabiliza a aplicação de um determinado modelo específico.

Dos diagramas observa-se que os parâmetros sugeridos por CERVERA [7] levam o modelo a apresentar uma resposta menos rígida para o comportamento das vigas em comparação a do modelo de Mazars com os parâmetros 
sugeridos por ÁLVARES [2]. De novo ressalta-se a importância da identificação paramétrica. A modificação de alguns parâmetros do modelo de Cervera podem levar as curvas dos diagramas mais próximas às da resposta experimental. CERVERA [7] não especifica a resistência do concreto a partir da qual obteve os parâmetros do modelo que fornecem a resposta da figura 5.3.

Uma importante observação, que não diz respeito aos modelos mas sim ao método numérico de resolução, refere-se à integração das tensões ao longo da altura das seções. A integração numérica por quadratura de Gauss é dependente do número de pontos. No código de cálculo desenvolvido foram utilizados 12 pontos de Gauss ao longo da altura das seções. Porém observa-se que a adoção de uma técnica de subdivisão da altura da seção em sub-elementos e a associação de 12 pontos de Gauss a cada um deles com a correta transformação dos limites de integração resulta numa melhor aproximação para as integrais cujos erros acumulados podem influenciar o comportamento final das curvas carga $\mathrm{x}$ deslocamento em um procedimento incremental-iterativo. 


\title{
Exemplo 02 - Pavimento de edifício em concreto armado.
}

\author{
Nesse exemplo é analisado numericamente o comportamento em \\ grelha de um pavimento de um edifício em concreto armado utilizando-se os \\ modelos de dano de Mazars e de Cervera cuja planta foi cedida pela empresa \\ TECSOF - ENGENHARIA DE ESTRUTURAS, sediada em São Carlos - SP. Trata- \\ se de um pavimento de um pilotis que recebe cargas de alvenaria estrutural. A análise \\ é feita com as cargas de serviço onde interessa conhecer os deslocamentos e a \\ distribuição dos esforços solicitantes nos elementos de grelha. \\ A discretização em elementos finitos da grelha do pavimento é feita \\ apenas em metade da planta em função da simetria do edifício. A resistência \\ característica do concreto à compressão $\mathrm{f}_{\mathrm{ck}}$ é de $20 \mathrm{Mpa}$. As barras de aço da \\ armadura possuem resistência característica à tração $\mathrm{f}_{\mathrm{yk}}=500 \mathrm{Mpa}$.
}

\section{Características do pavimento:}

O pavimento completo é constituído de 50 vigas e 36 pilares. As figuras 5.8 e 5.9 mostram a planta de forma do pavimento. Nessa figura estão especificadas as dimensões das vigas que são de seção retangular de $20 \times 50 \mathrm{~cm}^{2}$ ou 20x60 $\mathrm{cm}^{2}$. Os pilares, para efeito de análise numérica, são considerados como pontos com restrição apenas ao deslocamento vertical. Os eixos das vigas definem a geometria da malha de elementos finitos.

\section{Discretização do pavimento, carregamento e armaduras:}

O pavimento está discretizado em 142 elementos finitos com um total de 128 nós. Na figura 5.10 tem-se a malha de elementos finitos com a numeração dos nós e dos elementos de metade do pavimento simétrico. As coordenadas dos nós estão em anexo ao final do texto. O carregamento de serviço em cada viga está definido na figura 5.11. Trata-se de cargas de alvenaria estrutural que descarregam no 
pilotis somadas com as das lajes do pavimento do pilotis (permanentes + variáveis). Essas últimas foram admitidas constantes iguais a $17 \mathrm{kN} / \mathrm{m}$.

O detalhamento da armadura não está apresentado em função do elevado número de desenhos de armação. Das folhas de armação das vigas retiram-se as armaduras junto às faces superiores e inferiores de cada elemento finito. Esses valores, bem como os demais valores que definem a geometria de cada elemento finito de barra, estão em anexo ao final.

\section{Parâmetros dos modelos:}

Serão considerados os parâmetros da tabela 1 para análise numérica com os modelos dano. No próximo exemplo tem-se uma solução alternativa para os parâmetros dos modelos de Mazars e de Cervera e algumas respostas desse pavimento com outros parâmetros são apresentadas. 


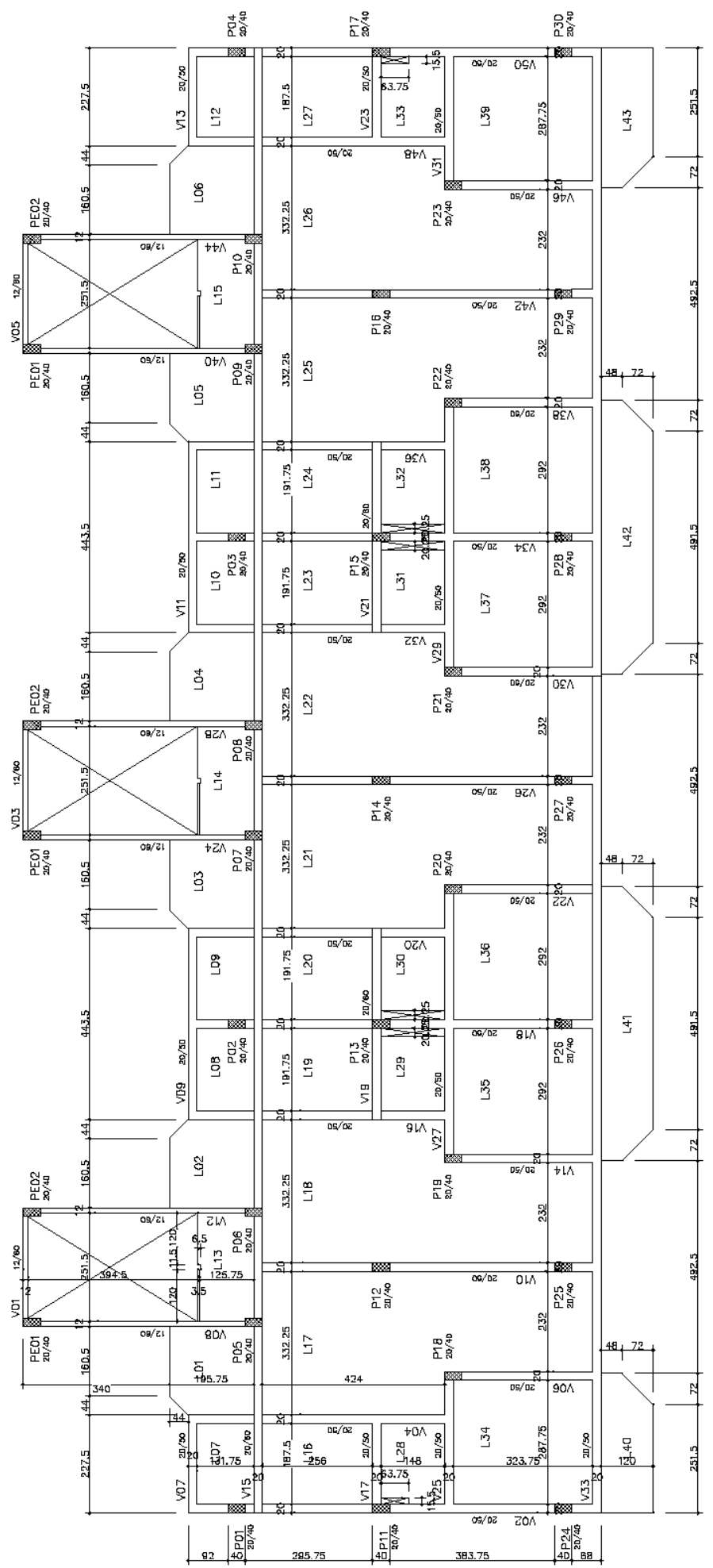

Figura 5.8 - Forma do pavimento do pilotis. 


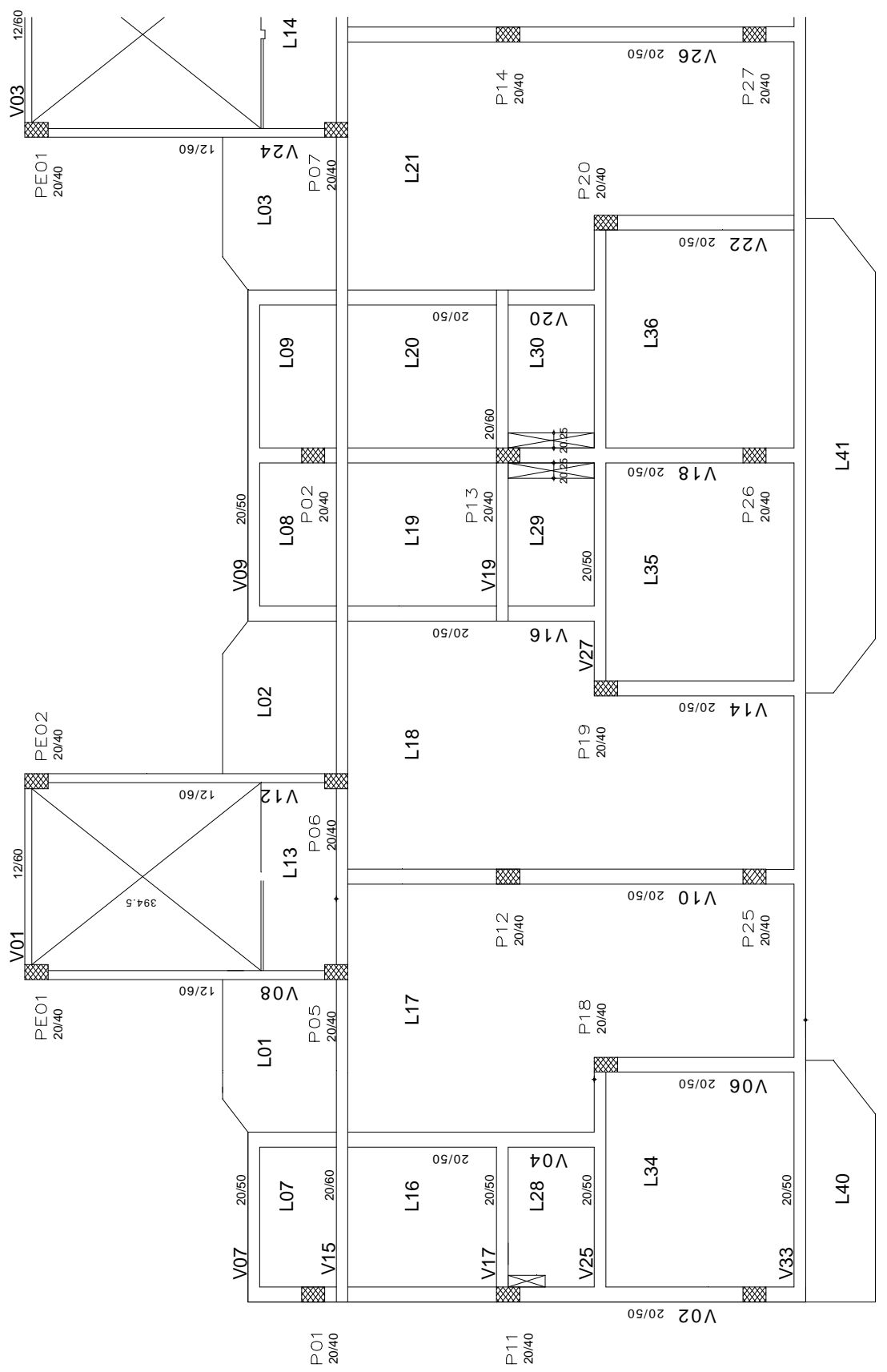

Figura 5.9 - Metade do pavimento simétrico. 


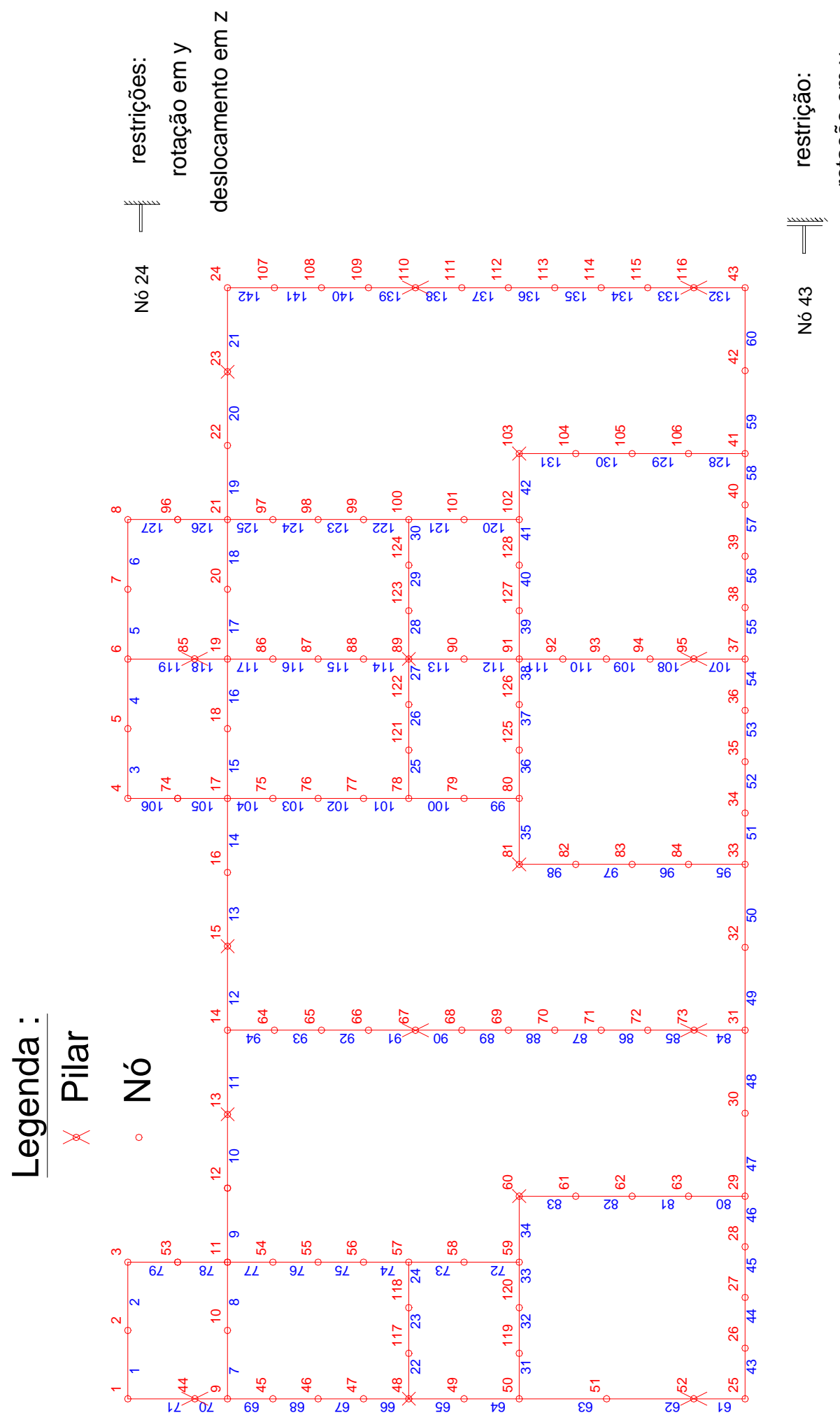

Figura 5.10 - Numeração de nós e elementos da malha de elementos finitos. 


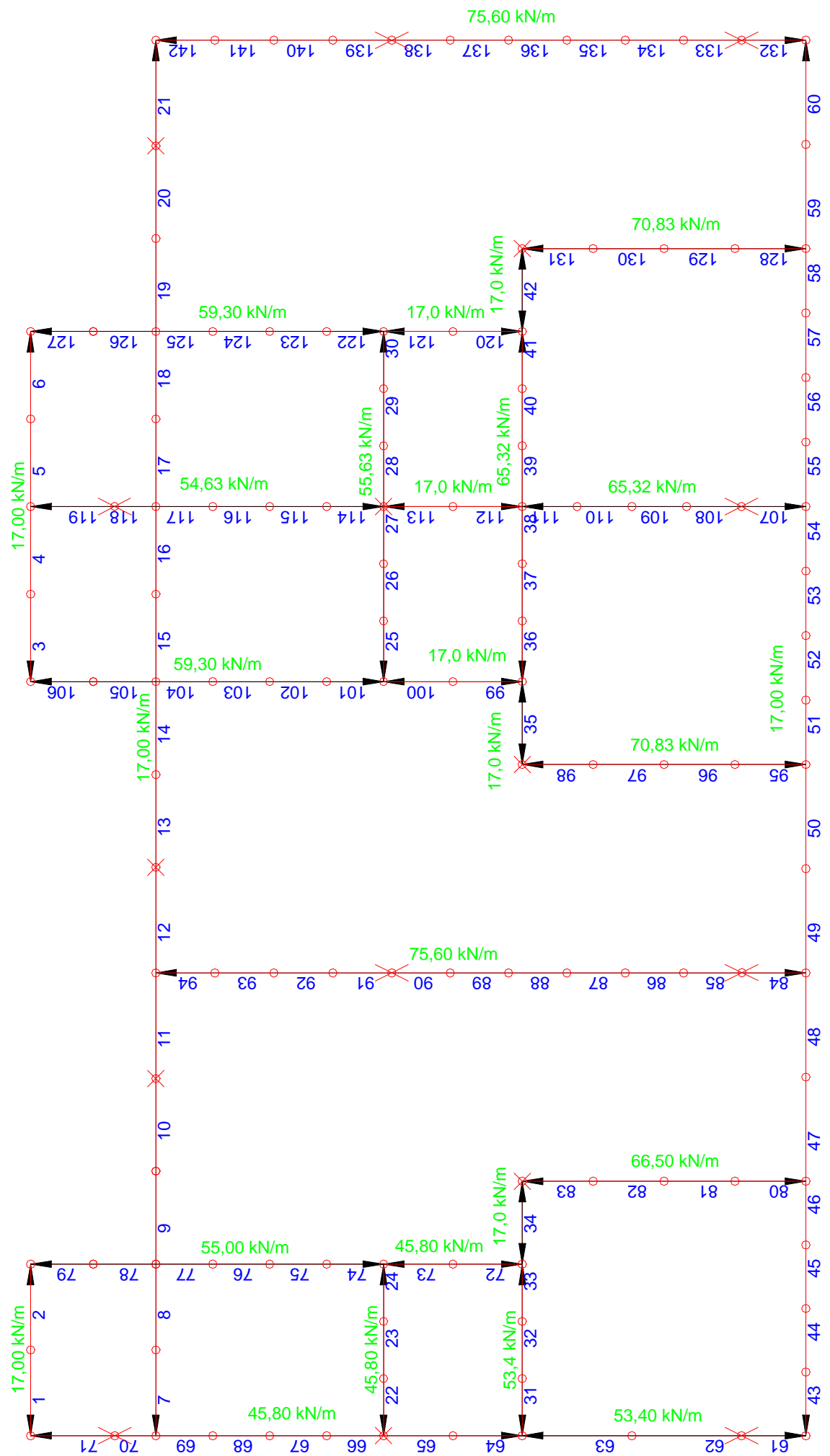

Figura 5.11 - Carregamento de serviço distribuído nas vigas do pavimento. 
$\underline{\text { Resultados numéricos. }}$

No pavimento foram aplicados 10 incrementos de carga iguais com tolerância $\delta$ pré-estabelecida de $0.1 \%$. Os resultados obtidos são descritos em diagramas carga x deslocamento vertical para 4 nós da malha $(29,56,83$ e 105) e em diagramas de momento fletor em 3 vigas (V10 e V18).

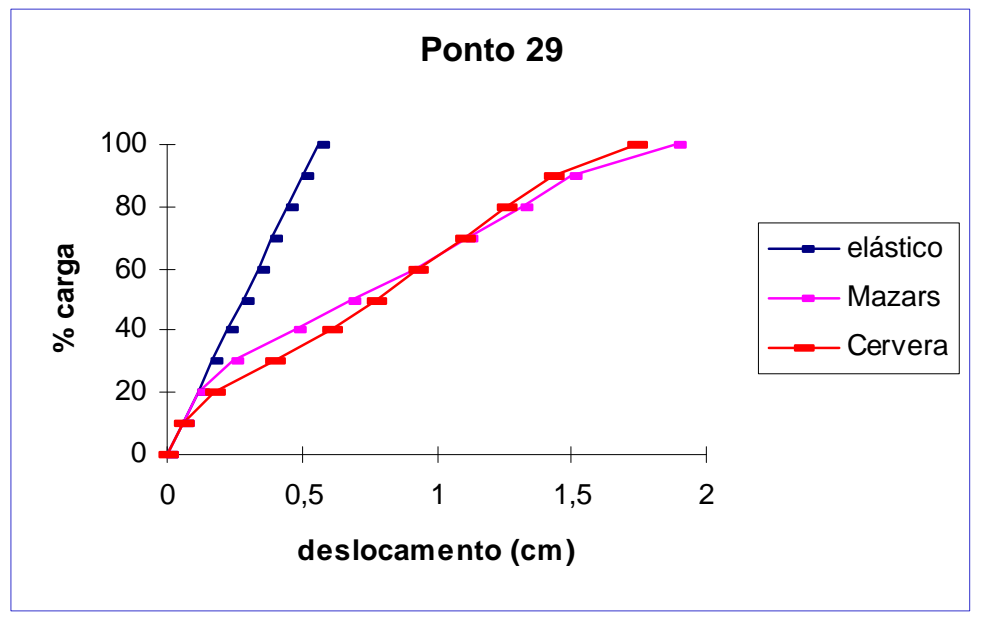

Figura 5.12 - Diagrama carga x deslocamento do nó 29.

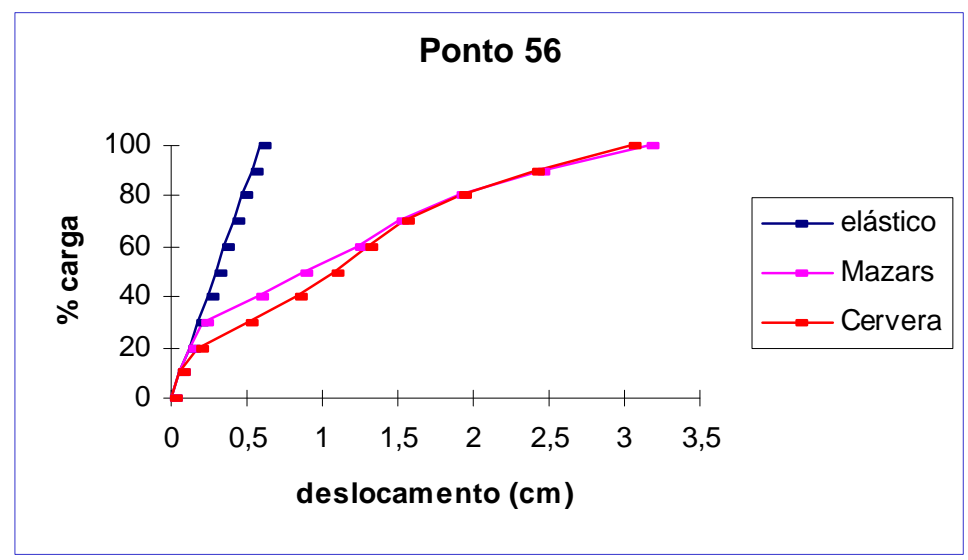

Figura 5.13 - Diagrama carga x deslocamento do nó 56. 


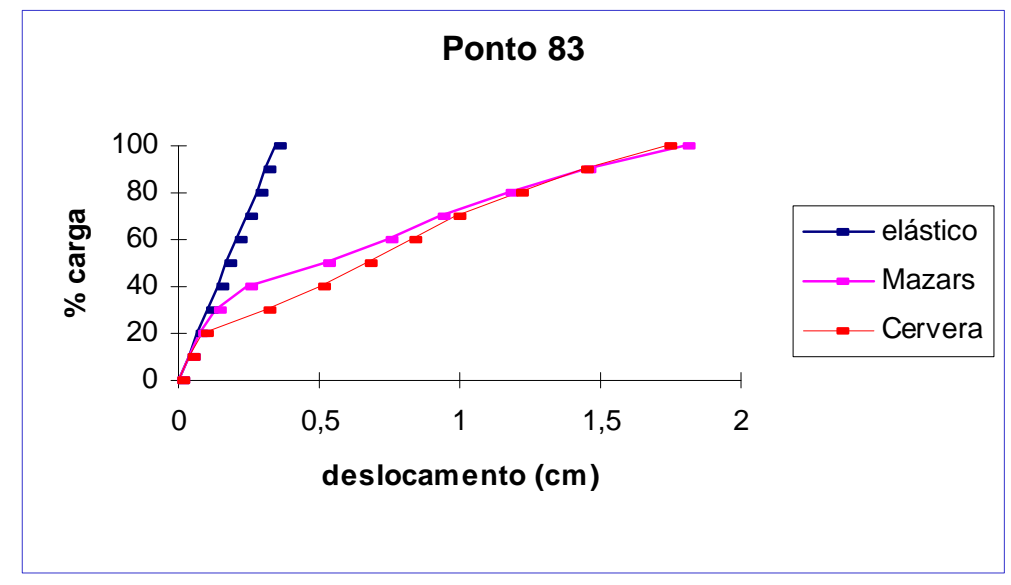

Figura 5.14 - Diagrama carga x deslocamento do nó 83.

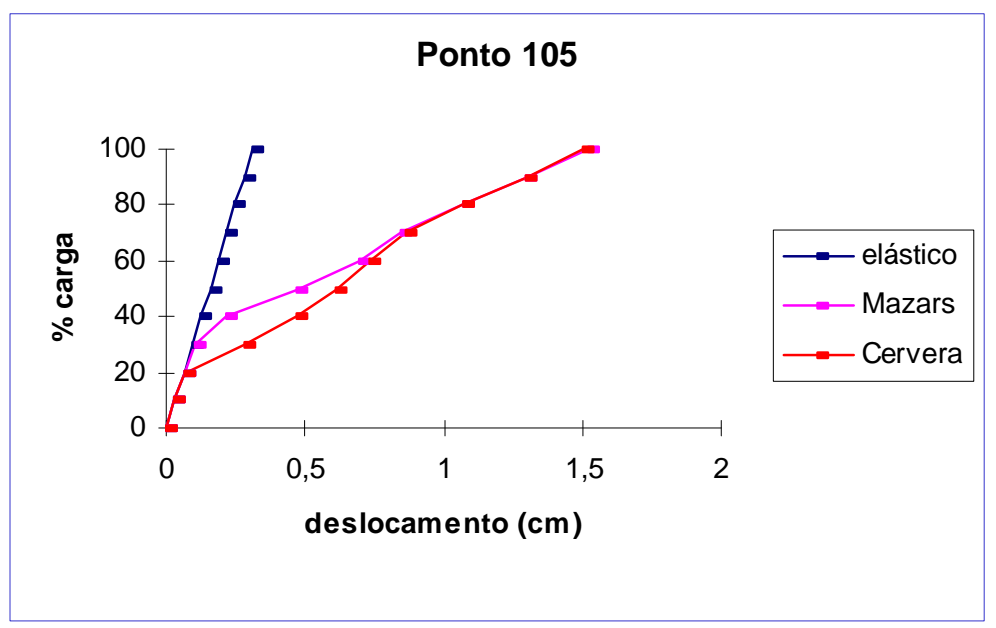

Figura 5.15 - Diagrama carga x deslocamento do nó 105.

Na tabela 2 estão os deslocamentos em centímetros obtidos para os quatro nós com o carregamento total aplicado.

TABELA 2

\begin{tabular}{||c|c|c||}
\hline NÓ & MODELO DE MAZARS & MODELO DE CERVERA \\
\hline 29 & 1.88 & 1.74 \\
\hline 56 & 3.15 & 3.04 \\
\hline 83 & 1.80 & 1.73 \\
\hline 105 & 1.52 & 1.51 \\
\hline
\end{tabular}



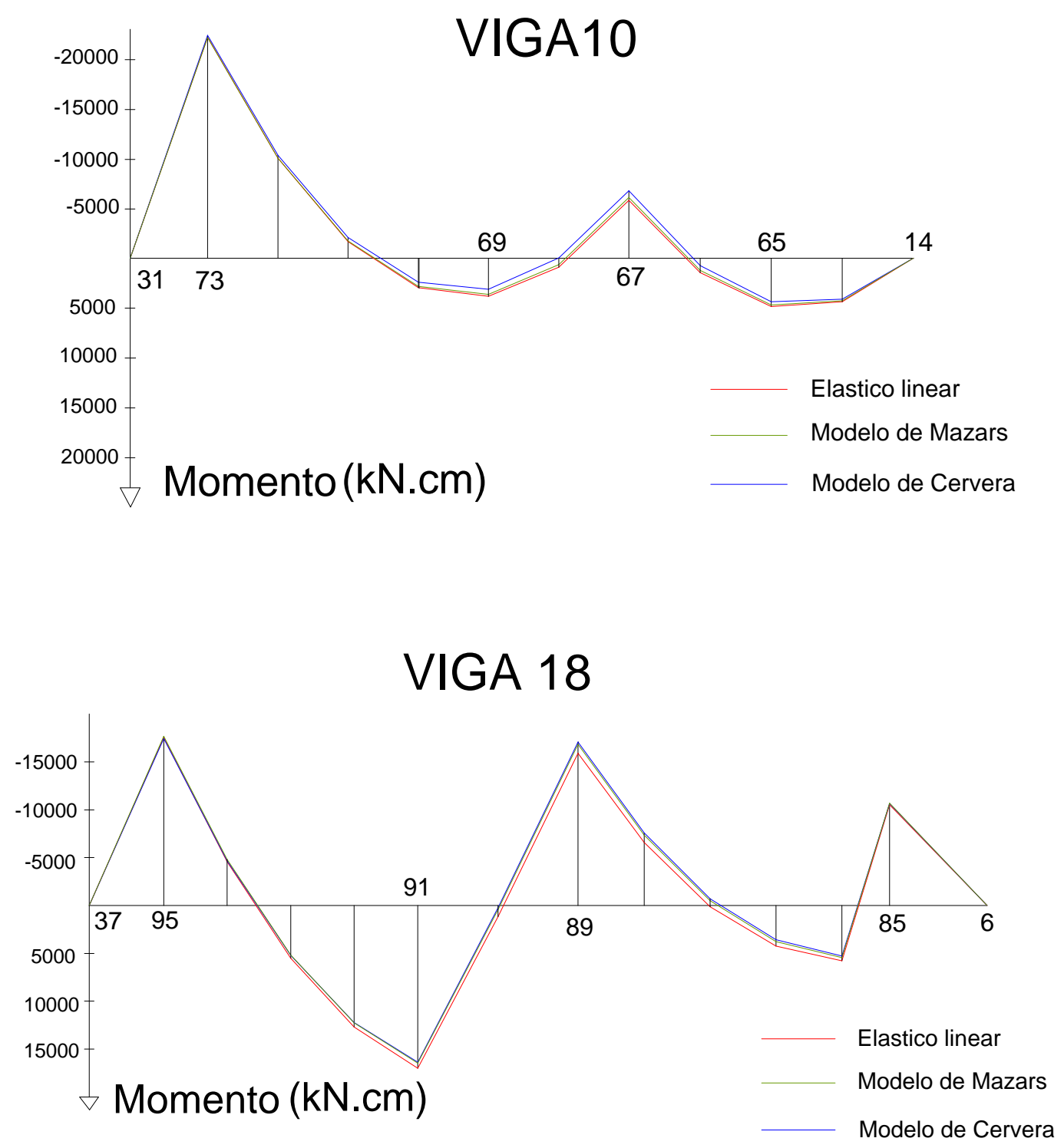

Figura 5.16 - Distribuição dos momentos fletores nas vigas do pavimento.

Verifica-se da observação dos diagramas carga $\mathrm{x}$ deslocamento $\mathrm{o}$ comportamento para os dois modelos de dano implementados. Como se esperava, o deslocamento ao final de todos os incrementos de carga difere muito daquele calculado em regime elástico linear. $\mathrm{O}$ diagrama de momentos fletores pouco difere do diagrama elástico linear em todas as vigas do pavimento. Essa é uma situação comum em pavimentos cujos elementos tem rigidezes da mesma ordem de grandeza. 


\section{Exemplo 03 - Comparação entre modelos de dano e modelo do CEB.}

Nesse exemplo os parâmetros dos modelos de dano de Mazars e de Cervera são ajustados para se aproximarem do modelo proposto pelo CEB (boletim 158). Esse exemplo tem o objetivo de mostrar a influência dos parâmetros dos modelos de dano nas respostas numéricas obtidas.

O diagrama "momento-curvatura" dos modelos de dano bem como do modelo do $\mathrm{CEB} / 158$ variam de seção para seção em função de suas geometrias e quantidades de armadura e das resistências características do concreto.

Como referência para o exemplo, admite-se uma viga solicitada a um momento fletor constante ao longo de seu comprimento com seção transversal mostrada na figura 5.17 .
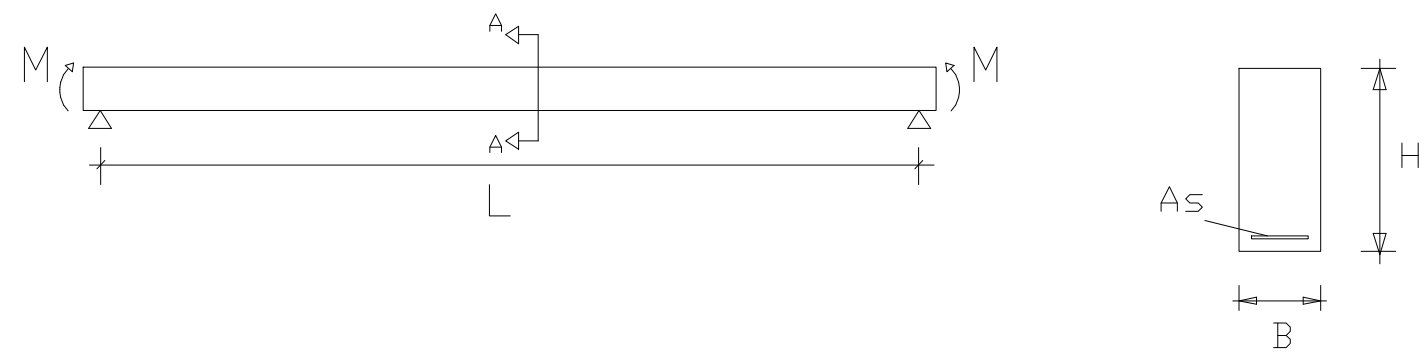

Figura 5.17 - Viga solicitada a momento fletor constante.

Para a viga da figura 5.17 admitem-se os seguintes valores: $\mathrm{H}=50 \mathrm{~cm}$, $\mathrm{B}=20 \mathrm{~cm}, \mathrm{As}=9.00 \mathrm{~cm}^{2}$ e L=300 cm. Admite-se também um momento fletor aplicado nas extremidades da barra $\mathrm{M}=10000 \mathrm{kN} . \mathrm{cm}$. Utilizando-se do modelo do CEB/158 e dos modelos de dano de Mazars e de Cervera com os parâmetros da tabela 1, obtémse os diagramas "momento-curvatura" da figura 5.18, válidos para a viga com as características geométricas definidas. 


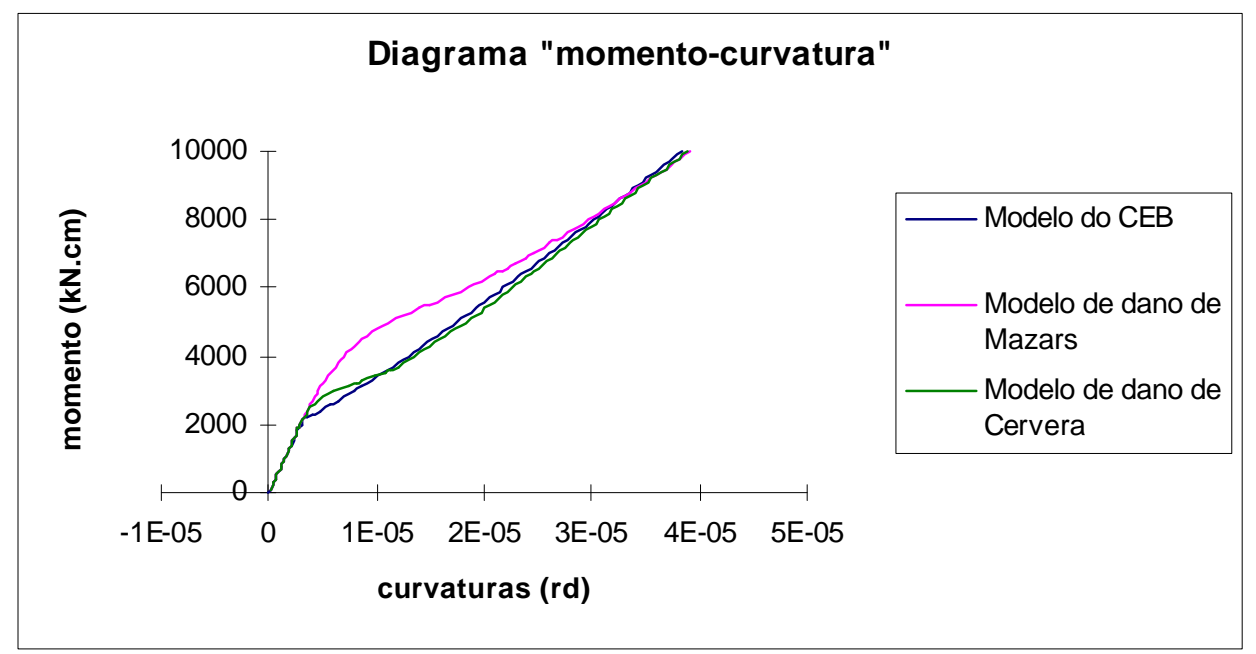

Figura 5.18 - Diagramas “momento-curvatura” para viga com momento constante.

Os parâmetros dos modelos de dano podem ser modificados para que os diagramas "momento-curvatura" com esses novos valores se aproximem do diagrama obtido do modelo do $\mathrm{CEB} / 158$.

Utilizando-se dos parâmetros definidos na tabela 3 para os modelos de dano de Mazars e de Cervera, obtém-se os diagramas "momento-curvatura" da figura 5.19 que melhor se aproximam daquele definido pelo CEB/158. 


\section{TABELA 3}

\section{Parâmetros do modelo de dano de Mazars para ajuste com CEB}

$$
\begin{array}{ll}
\mathrm{E}_{\text {concreto }}=2880 \mathrm{kN} / \mathrm{cm}^{2} & v=0.2 \\
\varepsilon_{\mathrm{d} 0}=0.000045 & \mathrm{~A}_{\mathrm{T}}=0.85 \\
\mathrm{~A}_{\mathrm{C}}=0.995 & \mathrm{G}_{\mathrm{f}}=0.0016 \mathrm{kN} / \mathrm{cm} \\
\mathrm{B}_{\mathrm{C}}=500 & \mathrm{~B}_{\mathrm{T}}=17000
\end{array}
$$

Parâmetros do modelo de dano de Cervera para ajuste com CEB

$$
\begin{array}{ll}
\mathrm{E}_{\text {concreto }}=2880 \mathrm{kN} / \mathrm{cm}^{2} & v=0.2 \\
\mathrm{r}_{0}^{+}=0.0035 & \mathrm{r}_{0}^{-}=0.80 \\
\mathrm{~A}^{-}=1.0 & \mathrm{~B}^{-}=0.10 \\
\mathrm{G}_{\mathrm{f}}=0.0025 \mathrm{kN} / \mathrm{cm} & \mathrm{A}^{+}=0.80
\end{array}
$$

\section{Parâmetros do modelo elasto-plástico com encruamento isótropo}

$$
\begin{aligned}
& \mathrm{E}_{\text {armadura }}=21000 \mathrm{kN} / \mathrm{cm}^{2} \quad \mathrm{H}=2100 \mathrm{kN} / \mathrm{cm}^{2} \\
& \sigma_{\mathrm{y}}=50 \mathrm{kN} / \mathrm{cm}^{2}
\end{aligned}
$$

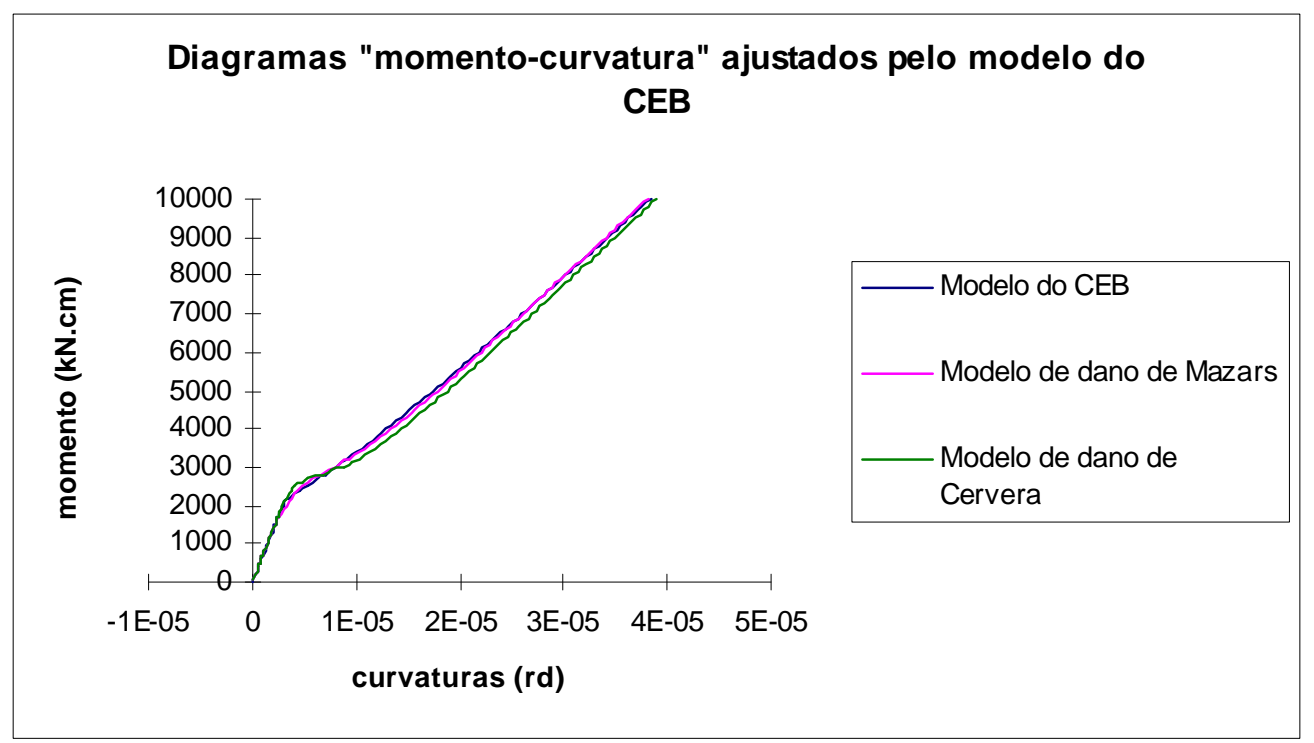

Figura 5.19 - Diagramas "momento-curvatura" ajustados pelo modelo do CEB para viga com momento constante. 
Utilizando-se dos parâmetros da tabela 3 para a análise do pavimento do exemplo 02, obtém-se novos diagramas "carga x deslocamento" dos pontos analisados naquele exemplo.

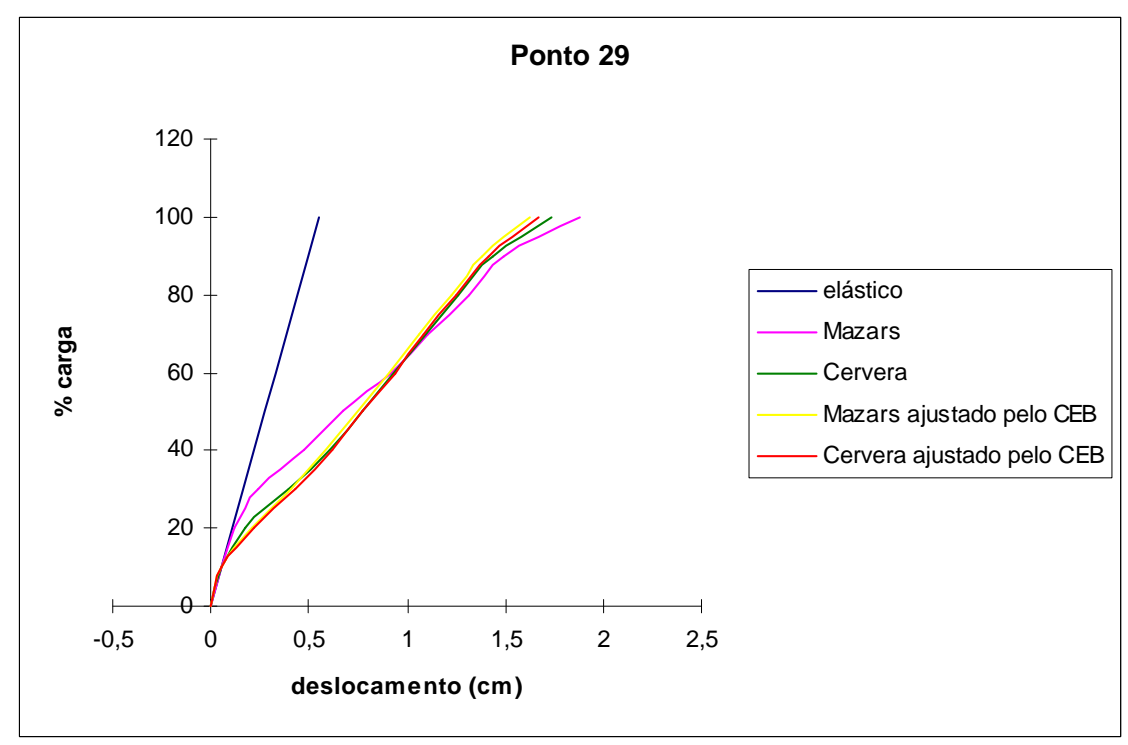

Figura 5.20 - Diagrama carga x deslocamento do nó 29 para parâmetros de dano ajustados pelo modelo do CEB.

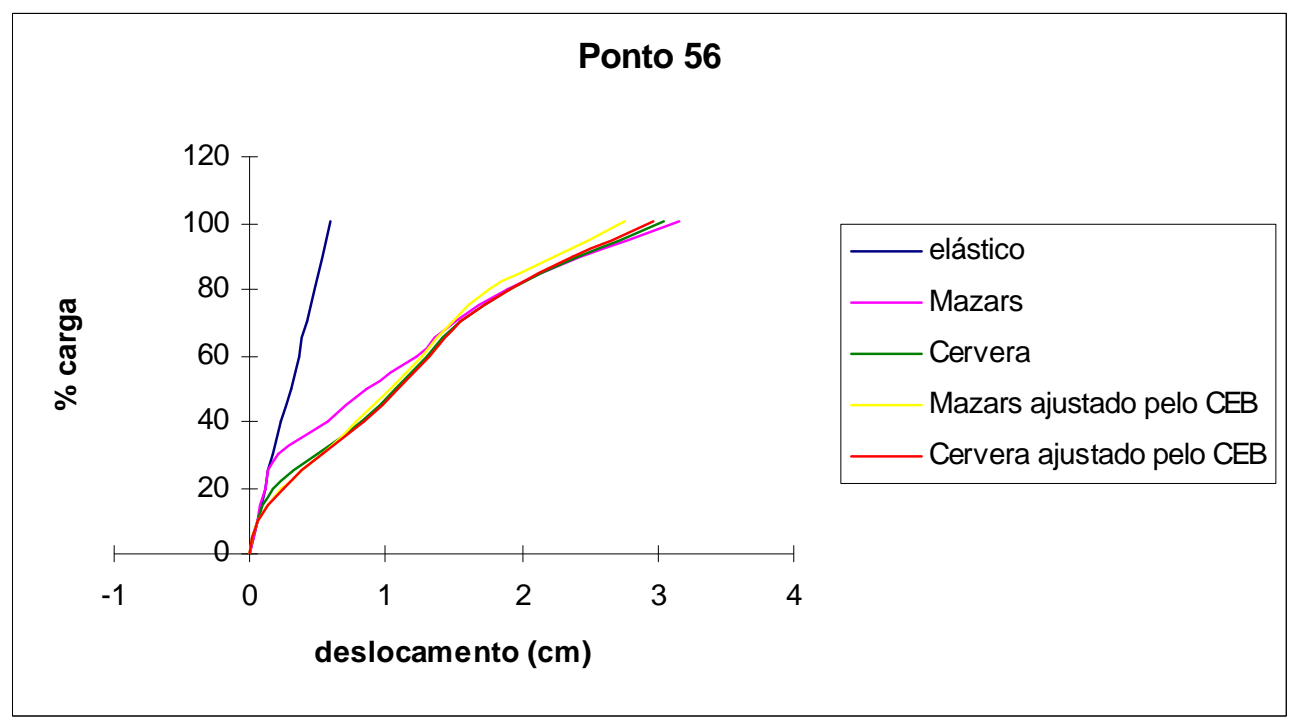

Figura 5.21 - Diagrama carga x deslocamento do nó 56 para parâmetros de dano ajustados pelo modelo do CEB. 


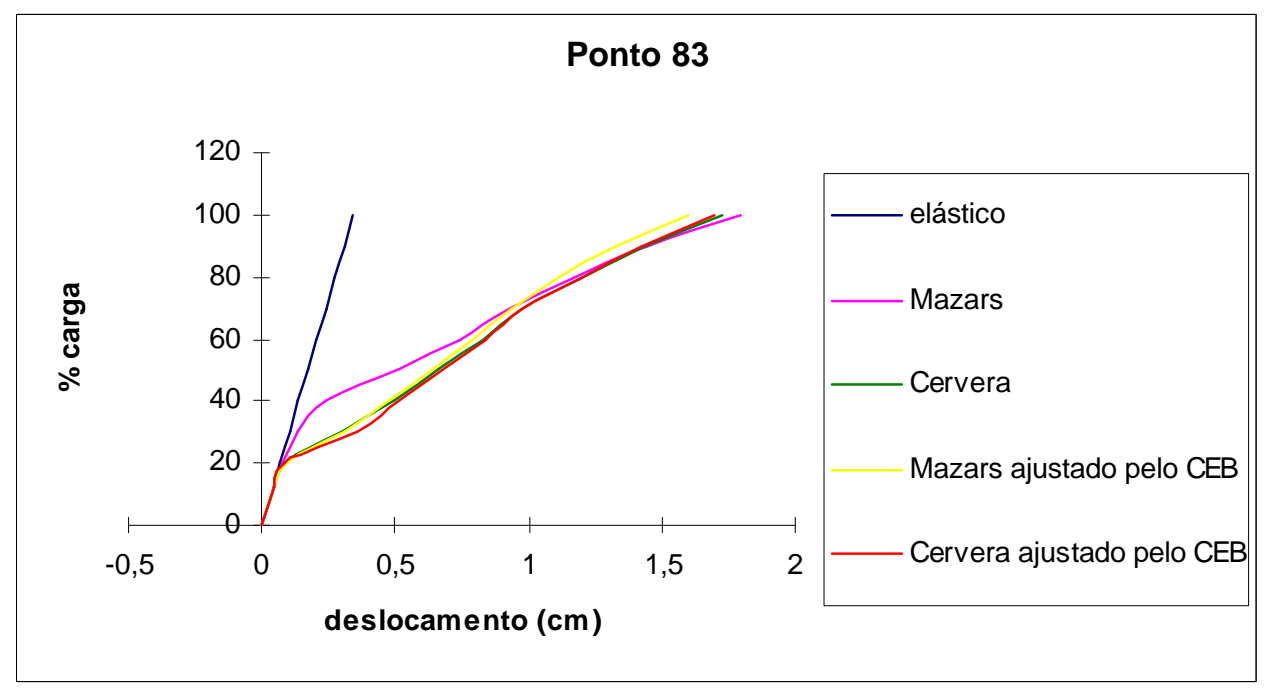

Figura 5.22 - Diagrama carga x deslocamento do nó 83 para parâmetros de dano ajustados pelo modelo do CEB.

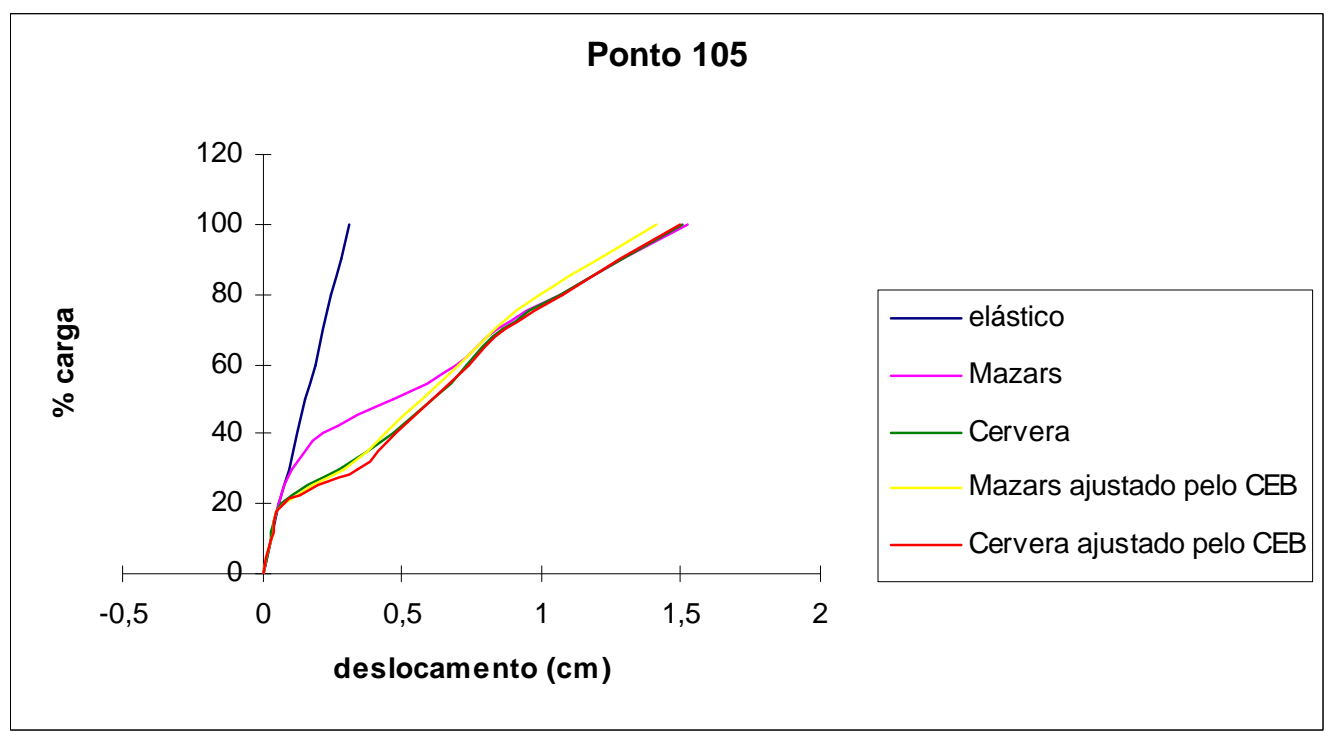

Figura 5.23 - Diagrama carga x deslocamento do nó 105 para parâmetros de dano ajustados pelo modelo do CEB.

Observa-se desse exemplo que a variação dos parâmetros dos modelos de dano podem recuperar, de modo aproximado, um modelo proposto para normas de cálculo (CEB). O contrário também se justifica e deve ser a diretriz principal para a elaboração de modelos simplificados para normas de cálculo de concreto armado, ou 
seja, modelos que se fundamentam em simplificações das experimentações em mecânica do dano.

$\mathrm{Na}$ tabela 4, os deslocamentos estão tomados em centímetros e foram obtidos para os quatro nós ao final do carregamento incremental com modelos de dano ajustados de acordo com o modelo do CEB.

TABELA 4

\begin{tabular}{|c|c|c||}
\hline NÓ & $\begin{array}{c}\text { MODELO DE MAZARS } \\
\text { AJUSTADO PELO CEB }\end{array}$ & $\begin{array}{c}\text { MODELO DE CERVERA } \\
\text { AJUSTADO PELO CEB }\end{array}$ \\
\hline 29 & 1.63 & 1.67 \\
\hline 56 & 2.75 & 2.96 \\
\hline 83 & 1.60 & 1.70 \\
\hline 105 & 1.41 & 1.50 \\
\hline
\end{tabular}




\section{CAPÍTULO 6}

\section{CONCLUSÕES}

O trabalho desenvolvido teve o propósito de adaptar modelos nãolineares fundamentados na mecânica do dano contínuo à análise estrutural de grelhas de pavimentos de edifícios de concreto armado. No início da pesquisa procurou-se estudar as teorias gerais sobre mecânica do dano contínuo procurando, assim, adquirir conceitos e relacioná-los com a aplicação ao concreto. O estudo dos processos físicos de deformação e ruptura do concreto a nível microscópico mostrou que as teorias de dano são uma boa ferramenta de previsão do comportamento do material.

O estudo das técnicas numéricas foi de grande importância para que as análises estruturais com os modelos de dano apresentassem eficiência e custo computacional baixo. Daí a opção pela transformação dos modelos escritos em "tensão-deformação" para outros escritos em "momento-curvatura". O efeito principal dessa mudança está na discretização em elementos finitos para estruturas de barras. No modelo em "momento-curvatura" a discretização é feita ao longo do comprimento das barras, ao contrário do modelo em tensões em que a discretização é feita ao longo do comprimento e da altura das barras, resultando elementos de chapa.

O procedimento iterativo de busca da linha neutra das seções de concreto armado utilizando-se integração por quadratura de Gauss pode apresentar falhas se o número de pontos de Gauss não for grande o suficiente. A situação ideal seria a técnica da divisão das seções em sub-elementos ao longo da altura e a cada um desses sub-elementos associar um número elevado de pontos de Gauss. Esse técnica de sub-divisão não foi utilizada no trabalho, mas pode ser facilmente incorporada. 
Os exemplos numéricos mostraram a característica mais importante dos modelos de dano que é a identificação paramétrica. Essa deve ser feita com base em resultados experimentais obtidos em laboratório. Deve-se atentar que essa identificação varia com a classe de resistência do concreto e a aplicabilidade de um determinado modelo de dano pode modificar-se de acordo com a variação da classe de resistência do concreto.

Os modelos de dano devem permitir que a identificação paramétrica possa ser feita em ensaios simples, como de compressão ou tração uniaxiais e que, com os parâmetros daí obtidos, possa ser previsto o comportamento do material sob solicitações multiaxiais.

A análise do pavimento do exemplo 2 do capítulo 5 foi satisfatória. Mesmo sem parâmetros para comparações, observa-se que a distribuição de esforços e os deslocamentos seguem uma coerência comum aos modelos não-lineares. A consideração da contribuição das lajes na rigidez do pavimento, com modelos de dano, constitui tema de interesse para prosseguimento do trabalho iniciado.

Quanto ao aspecto computacional, a utilização de elementos finitos de barra com discretização apenas ao longo do comprimento reduz a ordem do sistema linear, e os ganhos de tempo de processamento são maiores que aqueles da discretização das barras em elementos de chapa. Em contrapartida, há a inconveniência das integrações para busca da linha neutra em cada extremidade de barra a cada iteração do procedimento.

Os temas de trabalho dentro da linha de pesquisa são muitos. A começar, não foi considerado um modelo de dano que leve em conta a anisotropia evidenciada no concreto. A aplicação de um modelo desse tipo levaria a respostas mais confiáveis. Um tema atual é o da aplicação de modelos de dano em conjunto com modelos de mecânica da fratura. Problemas como localização de tensões e formação de fissuras podem ser utilizados na análise de estruturas de concreto.

Dentro do campo da análise numérica, pode-se trabalhar com outros tipos de elementos finitos, ou utilizar o método dos elementos de contorno para análise estrutural de pavimentos de concreto armado. Vê-se que a mecânica do dano e suas aplicações constituem amplo campo de pesquisa a ser ainda explorado. 


\section{CAPÍTULO 7}

\section{BIBLIOGRAFIA}

[1]ALVES, B.K.; LUBLINER, J. A damage mechanics model for beams. Application to reinforced concrete beams. Congreso Int. Metodos Numericos en Ingenieria y Ciencias Aplicadas, Barcelona, 277-286, 1992.

[2]ÁLVARES, M.S. Estudo de um modelo de dano para o concreto: formulação, identificação paramétrica e aplicação com o emprego do método dos elementos finitos. Dissertação (mestrado), Escola de Engenharia de São Carlos - USP, 1993.

[3]BATHE, K.J. Finite Element Procedures. Prentice Hall, New Jersey, 1996.

[4]BREBBIA, C.A .; DOMINGUEZ, J. Boundary elements: An Introductory Course. Second Edition, Computational Mechanics Publications, Southampton, McGraw-Hill Book Company, 1992.

[5]BURR, A.; HILD, F.; LECKIE, F.A. Micro-mechanics and continuum damage mechanics. Archive of Applied Mechanics 65, 437-456, 1995.

[6]BUSSAMRA, F.L.S. Equações constitutivas do concreto baseadas na mecânica do dano contínuo. Dissertação (mestrado), Escola Politécnica - USP, 1993. 
[7]CERVERA, M.; OLIVER, J.; MANZOLI, O. A rate-dependent isotropic damage model for the seismic analysis of concrete dams. Earthquake Engineering and Structural Dynamics, vol. 25, pgs. 987-1010, 1996.

[8]CERVERA, M.; OLIVER, J.; MANZOLI, O. Seismic evaluation of concrete dams via continuum damage models. Earthquake Engineering and Structural Dynamics, vol. 24, pgs. 1225-1245, 1995.

[9]CHABOCHE, J.L. Continuum Damage Mechanics. Part I - General Concepts and Part II - Damage Growth, Crack Initiation, and Crack Growth. Journal of Applied Mechanics, Vol. 55, págs. 59-72, 1988.

[10]CHEN, E. P. Continuum damage response of a center-cracked plain concrete panel in tension. Engineering Fracture Mechanics, Vol. 39, No. 3, pp. 553$560,1991$.

[11]CHEN, W.F. Concrete plasticity: macro- and microapproaches. Int. J. Mech. Sci., Vol. 35, No. 12, pp. 1097-1109, 1993.

[12]CHEN, W.F.; SALEEB, A .F. Constitutive equations for engineering materials. John Wiley, N. York, 1982.

[13]CILONI, A.D. Sobre o comportamento em serviço de estruturas planas de concreto armado. Tese (doutorado), Escola de Engenharia de São Carlos USP, 1993.

[14]CORRÊA, M.R.S. Aperfeiçoamento de modelos usualmente empregados no projeto de sistemas estruturais de edifícios. Tese (doutorado), Escola de Engenharia de São Carlos - USP, 1991.

[15]DIAO, X. A statistical equation of damage evolution. Engineering Fracture Mechanics, Vol. 52, No. 1, pp. 33-42, 1995. 
[16]DRIEMEIER, L. Considerações sobre a fadiga em metais e o comportamento do concreto sob solicitação cíclica. Dissertação (mestrado), Escola de Engenharia de São Carlos - USP, 1995.

[17]GERE, J.M.; WEAVER, W.Jr. Análisis de Estructuras Reticulares. Segunda impresión en español, Compañia Editorial Continental S.A ., Mexico-España, 1970.

[18]HULT, J. Introduction and general overview, in: D. Krajcinovic and J. Lemaitre, eds., Continuum Damage Mechanics Theory and Applications, Springer, Wien, p. 1.

[19]KACHANOV, L.M. On the Time to Failure under Creep Conditions. Izv. Akad. Nauk. SSR, Otd. Tekhn. N.8, 26-31, 1958.

[20]KRAJCINOVIC, D. Constitutive Equations for Damaging Materials. Journal of Applied Mechanics, Vol. 50, págs 355-360, 1983.

[21]KRAJCINOVIC, D. Damage Mechanics. Mechanics of Materials 8, 117-197, 1989.

[22]LEMAITRE, J.; CHABOCHE, J.L. Mecanique des Materiaux Solids. Paris, Dunod, 1985.

[23]MACHADO, C.P. Tensões, deformações e deslocamentos em estruturas de concreto armado e protendido. Dissertação (mestrado), Escola Politécnica USP, 1989.

[24]MASUERO, J.R.; CREUS, G.J. Finite element analysis of viscoelastic fracture. International Journal of Fracture 60: 267-282, 1993. 
[25]MAZARS, J. Application de la mécanique de l'endommagement au comportement non lineaire et à la rupture du béton de structure. Thése de Doctorat d'État, Université Paris 6, 1984.

[26]MAZARS, J.; PIJAUDIER-CABOT, G. Continuum Damage Theory Application to Concrete. Journal of Engineering Mechanics, Vol. 115, No. 2, pp. 345-365, 1989.

[27]OWEN, D.R.J.; HINTON, E. Finite elements in plasticity: theory and practice. Swansea, U.K., Pineridge Press, 1980.

[28]PAAS, M.H.J.W. et al. A continuum approach to brittle and fatigue damage: theory and numerical procedures. Int. J. Solids Structures. Vol. 30, No. 4, pp. 579-599, 1993.

[29]PROENÇA, S.P.B. Sobre modelos matemáticos do comportamento não-linear do concreto: análise crítica e contribuições. Tese (doutorado), Escola de Engenharia de São Carlos - USP, 1988.

[30] RAMALHO, M. A. Sistema para análise de estruturas considerando interação com o meio elástico. Tese (doutorado), Escola de Engenharia de São Carlos USP, 1990.

[31] ZIENKIEWICZ, O. C. The Finite Element Method in Engineering Science. McGraw-Hill, London, 1971. 


\begin{abstract}
ANEXO
TABELA 5 - Coordenadas dos nós do pavimento do exemplo 02
\end{abstract}

\begin{tabular}{|r|r|r|}
\hline Nó & \multicolumn{1}{|c|}{$X(\mathrm{~cm})$} & \multicolumn{1}{c|}{$Y(\mathrm{~cm})$} \\
\hline 1 & 100 & 100 \\
\hline 2 & 203,75 & 203,75 \\
\hline 3 & 307,5 & 307,5 \\
\hline 4 & 1012 & 1012 \\
\hline 5 & 1117,875 & 1117,875 \\
\hline 6 & 1223,75 & 1223,75 \\
\hline 7 & 1329,625 & 1329,625 \\
\hline 8 & 1435,5 & 1435,5 \\
\hline 9 & 100 & 100 \\
\hline 10 & 203,75 & 203,75 \\
\hline 11 & 307,5 & 307,5 \\
\hline 12 & 419,75 & 419,75 \\
\hline 13 & 532 & 532 \\
\hline 14 & 659,75 & 659,75 \\
\hline 15 & 787,5 & 787,5 \\
\hline 16 & 899,75 & 899,75 \\
\hline 17 & 1012 & 1012 \\
\hline 18 & 1117,875 & 1117,875 \\
\hline 19 & 1223,75 & 1223,75 \\
\hline 20 & 1329,625 & 1329,625 \\
\hline 21 & 1435,5 & 1435,5 \\
\hline 22 & 1547,75 & 1547,75 \\
\hline 23 & 1660 & 1660 \\
\hline 24 & 1787,75 & 1787,75 \\
\hline 25 & 100 & 100 \\
\hline 26 & 176,9375 & 176,9375 \\
\hline 27 & 253,875 & 253,875 \\
\hline 28 & 330,8125 & 330,8125 \\
\hline 29 & 407,75 & 407,75 \\
\hline 30 & 533,75 & 533,75 \\
\hline 31 & 659,75 & 659,75 \\
\hline 32 & 785,75 & 785,75 \\
\hline 33 & 911,75 & 911,75 \\
\hline 34 & 989,75 & 989,75 \\
\hline 35 & 1067,75 & 1067,75 \\
\hline & & \\
\hline & &
\end{tabular}


continuação da tabela 5

\begin{tabular}{|r|r|r|}
\hline Nó & \multicolumn{1}{|c|}{$X(\mathrm{~cm})$} & \multicolumn{1}{c|}{$Y(\mathrm{~cm})$} \\
\hline 36 & 1145,75 & 1145,75 \\
\hline 37 & 1223,75 & 1223,75 \\
\hline 38 & 1301,75 & 1301,75 \\
\hline 39 & 1379,75 & 1379,75 \\
\hline 40 & 1457,75 & 1457,75 \\
\hline 41 & 1535,75 & 1535,75 \\
\hline 42 & 1661,75 & 1661,75 \\
\hline 43 & 1787,75 & 1787,75 \\
\hline 44 & 100 & 100 \\
\hline 45 & 100 & 100 \\
\hline 46 & 100 & 100 \\
\hline 47 & 100 & 100 \\
\hline 48 & 100 & 100 \\
\hline 49 & 100 & 100 \\
\hline 50 & 100 & 100 \\
\hline 51 & 100 & 100 \\
\hline 52 & 100 & 100 \\
\hline 53 & 307,5 & 307,5 \\
\hline 54 & 307,5 & 307,5 \\
\hline 55 & 307,5 & 307,5 \\
\hline 56 & 307,5 & 307,5 \\
\hline 57 & 307,5 & 307,5 \\
\hline 58 & 307,5 & 307,5 \\
\hline 59 & 307,5 & 307,5 \\
\hline 60 & 407,75 & 407,75 \\
\hline 61 & 407,75 & 407,75 \\
\hline 62 & 407,75 & 407,75 \\
\hline 63 & 407,75 & 407,75 \\
\hline 64 & 659,75 & 659,75 \\
\hline 65 & 659,75 & 659,75 \\
\hline 66 & 659,75 & 659,75 \\
\hline 67 & 659,75 & 659,75 \\
\hline 68 & 659,75 & 659,75 \\
\hline 69 & 659,75 & 659,75 \\
\hline 70 & 659,75 & 659,75 \\
\hline 71 & 659,75 & 659,75 \\
\hline 72 & 659,75 & 659,75 \\
\hline 73 & 659,75 & 659,75 \\
\hline 74 & 1012 & 1012 \\
\hline 75 & 1012 & 1012 \\
\hline 76 & 1012 & 1012 \\
\hline 77 & 1012 & 1012 \\
\hline 78 & 1012 & 1012 \\
\hline 79 & 1012 & 1012 \\
\hline 80 & 1012 & 1012 \\
\hline 81 & 911,75 & 911,75 \\
\hline 82 & 911,75 & 911,75 \\
\hline & & \\
\hline 5 & & \\
\hline 5 & &
\end{tabular}


continuação da tabela 5

\begin{tabular}{|c|c|c|}
\hline Nó & $X(\mathrm{~cm})$ & $Y(\mathrm{~cm})$ \\
\hline 83 & 911,75 & 911,75 \\
\hline 84 & 911,75 & 911,75 \\
\hline 85 & 1223,75 & 1223,75 \\
\hline 86 & 1223,75 & 1223,75 \\
\hline 87 & 1223,75 & 1223,75 \\
\hline 88 & 1223,75 & 1223,75 \\
\hline 89 & 1223,75 & 1223,75 \\
\hline 90 & 1223,75 & 1223,75 \\
\hline 91 & 1223,75 & 1223,75 \\
\hline 92 & 1223,75 & 1223,75 \\
\hline 93 & 1223,75 & 1223,75 \\
\hline 94 & 1223,75 & 1223,75 \\
\hline 95 & 1223,75 & 1223,75 \\
\hline 96 & 1435,5 & 1435,5 \\
\hline 97 & 1435,5 & 1435,5 \\
\hline 98 & 1435,5 & 1435,5 \\
\hline 99 & 1435,5 & 1435,5 \\
\hline 100 & 1435,5 & 1435,5 \\
\hline 101 & 1435,5 & 1435,5 \\
\hline 102 & 1435,5 & 1435,5 \\
\hline 103 & 1535,75 & 1535,75 \\
\hline 104 & 1535,75 & 1535,75 \\
\hline 105 & 1535,75 & 1535,75 \\
\hline 106 & 1535,75 & 1535,75 \\
\hline 107 & 1787,75 & 1787,75 \\
\hline 108 & 1787,75 & 1787,75 \\
\hline 109 & 1787,75 & 1787,75 \\
\hline 110 & 1787,75 & 1787,75 \\
\hline 111 & 1787,75 & 1787,75 \\
\hline 112 & 1787,75 & 1787,75 \\
\hline 113 & 1787,75 & 1787,75 \\
\hline 114 & 1787,75 & 1787,75 \\
\hline 115 & 1787,75 & 1787,75 \\
\hline 116 & 1787,75 & 1787,75 \\
\hline 117 & 169,1 & 169,1 \\
\hline 118 & 238,3 & 238,3 \\
\hline 119 & 169,1 & 169,1 \\
\hline 120 & 238,3 & 238,3 \\
\hline 121 & 1085,35 & 1085,35 \\
\hline 122 & 1154,55 & 1154,55 \\
\hline 123 & 1297,1 & 1297,1 \\
\hline 124 & 1366,3 & 1366,3 \\
\hline 125 & 1085,35 & 1085,35 \\
\hline 126 & 1154,5 & 1154,5 \\
\hline 127 & 1297,1 & 1297,1 \\
\hline 128 & 1366,3 & 1366,3 \\
\hline
\end{tabular}


TABELA 6 - Características geométricas dos elementos do pavimento do exemplo 02

\begin{tabular}{|c|c|c|c|c|c|c|}
\hline Elemento & $\mathrm{B}(\mathrm{cm})$ & $\mathrm{H}(\mathrm{cm})$ & As2 (cm2) & $\mathrm{d}^{\prime}(\mathrm{cm})$ & As1 (cm2) & $\mathrm{d}(\mathrm{cm})$ \\
\hline 1 & 20 & 50 & 1,6 & 3 & 1,6 & 47 \\
\hline 2 & 20 & 50 & 1,6 & 3 & 1,6 & 47 \\
\hline 3 & 20 & 50 & 2,5 & 3 & 1,6 & 47 \\
\hline 4 & 20 & 50 & 3,75 & 3 & 1,6 & 47 \\
\hline 5 & 20 & 50 & 3,75 & 3 & 1,6 & 47 \\
\hline 6 & 20 & 50 & 2,5 & 3 & 1,6 & 47 \\
\hline 7 & 20 & 60 & 2,5 & 3 & 10 & 57 \\
\hline 8 & 20 & 60 & 2,5 & 3 & 14 & 57 \\
\hline 9 & 20 & 60 & 4 & 3 & 14 & 57 \\
\hline 10 & 20 & 60 & 8 & 3 & 8,5 & 57 \\
\hline 11 & 20 & 60 & 8 & 3 & 2,5 & 57 \\
\hline 12 & 20 & 60 & 5 & 3 & 2,5 & 57 \\
\hline 13 & 20 & 60 & 5 & 3 & 6 & 57 \\
\hline 14 & 20 & 60 & 2,5 & 3 & 10 & 57 \\
\hline 15 & 20 & 60 & 4 & 3 & 10 & 57 \\
\hline 16 & 20 & 60 & 8 & 3 & 6 & 57 \\
\hline 17 & 20 & 60 & 8 & 3 & 6 & 57 \\
\hline 18 & 20 & 50 & 4 & 3 & 10 & 47 \\
\hline 19 & 20 & 50 & 2,5 & 3 & 10 & 47 \\
\hline 20 & 20 & 50 & 5 & 3 & 6 & 47 \\
\hline 21 & 20 & 60 & 5 & 3 & 4 & 57 \\
\hline 22 & 20 & 60 & 1,6 & 3 & 1,6 & 57 \\
\hline 23 & 20 & 60 & 1,6 & 3 & 1,6 & 57 \\
\hline 24 & 20 & 60 & 1,6 & 3 & 1,6 & 57 \\
\hline 25 & 20 & 60 & 6 & 3 & 2,5 & 57 \\
\hline 26 & 20 & 60 & 10 & 3 & 2,5 & 57 \\
\hline 27 & 20 & 50 & 10 & 3 & 2,5 & 47 \\
\hline 28 & 20 & 50 & 10 & 3 & 2,5 & 47 \\
\hline 29 & 20 & 50 & 10 & 3 & 2,5 & 47 \\
\hline 30 & 20 & 50 & 6 & 3 & 2,5 & 47 \\
\hline 31 & 20 & 50 & 1,6 & 3 & 6 & 47 \\
\hline 32 & 20 & 50 & 1,6 & 3 & 6 & 47 \\
\hline 33 & 20 & 50 & 1,6 & 3 & 6 & 47 \\
\hline 34 & 20 & 50 & 1,6 & 3 & 6 & 47 \\
\hline 35 & 20 & 50 & 1,6 & 3 & 6 & 47 \\
\hline 36 & 20 & 50 & 1,6 & 3 & 6 & 47 \\
\hline 37 & 20 & 50 & 1,6 & 3 & 6 & 47 \\
\hline 38 & 20 & 50 & 1,6 & 3 & 4 & 47 \\
\hline 39 & 20 & 50 & 1,6 & 3 & 4 & 47 \\
\hline 40 & 20 & 50 & 1,6 & 3 & 6 & 47 \\
\hline 41 & 20 & 50 & 1,6 & 3 & 6 & 47 \\
\hline 42 & 20 & 50 & 1,6 & 3 & 6 & 47 \\
\hline 43 & 20 & 50 & 1,6 & 3 & 4 & 47 \\
\hline 44 & 20 & 50 & 0,6 & 3 & 8 & 47 \\
\hline 45 & 20 & 50 & 0,6 & 3 & 8 & 47 \\
\hline
\end{tabular}


continuação da tabela 6

\begin{tabular}{|c|c|c|c|c|c|c|}
\hline Elemento & $\mathrm{B}(\mathrm{cm})$ & $\mathrm{H}(\mathrm{cm})$ & As2 (cm2) & $\mathrm{d}^{\prime}(\mathrm{cm})$ & As1 (cm2) & $d(\mathrm{~cm})$ \\
\hline 46 & 20 & 50 & 0,6 & 3 & 8 & 47 \\
\hline 47 & 20 & 50 & 0,6 & 3 & 8 & 47 \\
\hline 48 & 20 & 50 & 8 & 3 & 4 & 47 \\
\hline 49 & 20 & 50 & 8 & 3 & 4 & 47 \\
\hline 50 & 20 & 50 & 0,6 & 3 & 6 & 47 \\
\hline 51 & 20 & 50 & 0,6 & 3 & 6 & 47 \\
\hline 52 & 20 & 50 & 0,6 & 3 & 4 & 47 \\
\hline 53 & 20 & 50 & 6 & 3 & 4 & 47 \\
\hline 54 & 20 & 50 & 6 & 3 & 4 & 47 \\
\hline 55 & 20 & 50 & 6 & 3 & 4 & 47 \\
\hline 56 & 20 & 50 & 6 & 3 & 4 & 47 \\
\hline 57 & 20 & 50 & 0,6 & 3 & 4 & 47 \\
\hline 58 & 20 & 50 & 0,6 & 3 & 8 & 47 \\
\hline 59 & 20 & 50 & 0,6 & 3 & 8 & 47 \\
\hline 60 & 20 & 50 & 6 & 3 & 4 & 47 \\
\hline 61 & 20 & 50 & 3,75 & 3 & 4 & 47 \\
\hline 62 & 20 & 50 & 3,75 & 3 & 4 & 47 \\
\hline 63 & 20 & 50 & 6 & 3 & 6 & 47 \\
\hline 64 & 20 & 50 & 6 & 3 & 6 & 47 \\
\hline 65 & 20 & 50 & 6 & 3 & 4 & 47 \\
\hline 66 & 20 & 50 & 6 & 3 & 2,5 & 47 \\
\hline 67 & 20 & 50 & 6 & 3 & 2,5 & 47 \\
\hline 68 & 20 & 50 & 6 & 3 & 2,5 & 47 \\
\hline 69 & 20 & 50 & 3,75 & 3 & 2,5 & 47 \\
\hline 70 & 20 & 50 & 3,75 & 3 & 2,5 & 47 \\
\hline 71 & 20 & 50 & 3,75 & 3 & 2,5 & 47 \\
\hline 72 & 20 & 50 & 1,6 & 3 & 4 & 47 \\
\hline 73 & 20 & 50 & 1,6 & 3 & 6 & 47 \\
\hline 74 & 20 & 50 & 10 & 3 & 6 & 47 \\
\hline 75 & 20 & 50 & 10 & 3 & 4 & 47 \\
\hline 76 & 20 & 50 & 10 & 3 & 4 & 47 \\
\hline 77 & 20 & 50 & 10 & 3 & 4 & 47 \\
\hline 78 & 20 & 50 & 10 & 3 & 4 & 47 \\
\hline 79 & 20 & 50 & 10 & 3 & 4 & 47 \\
\hline 80 & 20 & 50 & 1,6 & 3 & 5 & 47 \\
\hline 81 & 20 & 50 & 1,6 & 3 & 5 & 47 \\
\hline 82 & 20 & 50 & 2,5 & 3 & 5 & 47 \\
\hline 83 & 20 & 50 & 2,5 & 3 & 2,5 & 47 \\
\hline 84 & 20 & 50 & 10 & 3 & 2,5 & 47 \\
\hline 85 & 20 & 50 & 10 & 3 & 2,5 & 47 \\
\hline 86 & 20 & 50 & 10 & 3 & 2,5 & 47 \\
\hline 87 & 20 & 50 & 10 & 3 & 3,75 & 47 \\
\hline 88 & 20 & 50 & 2,5 & 3 & 3,75 & 47 \\
\hline 89 & 20 & 50 & 5 & 3 & 2,5 & 47 \\
\hline 90 & 20 & 50 & 5 & 3 & 2,5 & 47 \\
\hline
\end{tabular}


continuação da tabela 6

\begin{tabular}{|c|c|c|c|c|c|c|}
\hline Elemento & $\mathrm{B}(\mathrm{cm})$ & $\mathrm{H}(\mathrm{cm})$ & As2 (cm2) & $\mathrm{d}^{\prime}(\mathrm{cm})$ & As1 (cm2) & $\mathrm{d}(\mathrm{cm})$ \\
\hline 91 & 20 & 50 & 5 & 3 & 2,5 & 47 \\
\hline 92 & 20 & 50 & 5 & 3 & 2,5 & 47 \\
\hline 93 & 20 & 50 & 2,5 & 3 & 3,75 & 47 \\
\hline 94 & 20 & 50 & 1,6 & 3 & 3,75 & 47 \\
\hline 95 & 20 & 50 & 1,6 & 3 & 5 & 47 \\
\hline 96 & 20 & 50 & 1,6 & 3 & 5 & 47 \\
\hline 97 & 20 & 50 & 2,5 & 3 & 5 & 47 \\
\hline 98 & 20 & 50 & 2,5 & 3 & 2,5 & 47 \\
\hline 99 & 20 & 50 & 1,6 & 3 & 2,5 & 47 \\
\hline 100 & 20 & 50 & 1,6 & 3 & 3,75 & 47 \\
\hline 101 & 20 & 50 & 4 & 3 & 3,75 & 47 \\
\hline 102 & 20 & 50 & 4 & 3 & 3,75 & 47 \\
\hline 103 & 20 & 50 & 8 & 3 & 2,5 & 47 \\
\hline 104 & 20 & 50 & 8 & 3 & 2,5 & 47 \\
\hline 105 & 20 & 50 & 8 & 3 & 1 & 47 \\
\hline 106 & 20 & 50 & 8 & 3 & 1 & 47 \\
\hline 107 & 20 & 50 & 10 & 3 & 6 & 47 \\
\hline 108 & 20 & 50 & 10 & 3 & 6 & 47 \\
\hline 109 & 20 & 50 & 10 & 3 & 6 & 47 \\
\hline 110 & 20 & 50 & 10 & 3 & 14 & 47 \\
\hline 111 & 20 & 50 & 6 & 3 & 14 & 47 \\
\hline 112 & 20 & 50 & 14 & 3 & 14 & 47 \\
\hline 113 & 20 & 50 & 14 & 3 & 2,5 & 47 \\
\hline 114 & 20 & 50 & 14 & 3 & 2,5 & 47 \\
\hline 115 & 20 & 50 & 14 & 3 & 2,5 & 47 \\
\hline 116 & 20 & 50 & 24 & 3 & 2,5 & 47 \\
\hline 117 & 20 & 50 & 10 & 3 & 3,75 & 47 \\
\hline 118 & 20 & 50 & 10 & 3 & 3,75 & 47 \\
\hline 119 & 20 & 50 & 10 & 3 & 3,75 & 47 \\
\hline 120 & 20 & 50 & 1,6 & 3 & 2,5 & 47 \\
\hline 121 & 20 & 50 & 1,6 & 3 & 3,75 & 47 \\
\hline 122 & 20 & 50 & 4 & 3 & 3,75 & 47 \\
\hline 123 & 20 & 50 & 4 & 3 & 3,75 & 47 \\
\hline 124 & 20 & 50 & 8 & 3 & 2,5 & 47 \\
\hline 125 & 20 & 50 & 8 & 3 & 2,5 & 47 \\
\hline 126 & 20 & 50 & 8 & 3 & 1 & 47 \\
\hline 127 & 20 & 50 & 8 & 3 & 1 & 47 \\
\hline 128 & 20 & 50 & 1,6 & 3 & 5 & 47 \\
\hline 129 & 20 & 50 & 1,6 & 3 & 5 & 47 \\
\hline 130 & 20 & 50 & 2,5 & 3 & 5 & 47 \\
\hline 131 & 20 & 50 & 2,5 & 3 & 2,5 & 47 \\
\hline 132 & 20 & 50 & 8 & 3 & 4 & 47 \\
\hline 133 & 20 & 50 & 8 & 3 & 4 & 47 \\
\hline 134 & 20 & 50 & 8 & 3 & 4 & 47 \\
\hline 135 & 20 & 50 & 4 & 3 & 4 & 47 \\
\hline
\end{tabular}


continuação da tabela 6

\begin{tabular}{|c|c|c|c|c|c|c|}
\hline Elemento & $\mathrm{B}(\mathrm{cm})$ & $\mathrm{H}(\mathrm{cm})$ & As2 $(\mathrm{cm} 2)$ & $\mathrm{d}^{\prime}(\mathrm{cm})$ & As1 $(\mathrm{cm} 2)$ & $\mathrm{d}(\mathrm{cm})$ \\
\hline 136 & 20 & 50 & 2,5 & 3 & 4 & 47 \\
\hline 137 & 20 & 50 & 5 & 3 & 4 & 47 \\
\hline 138 & 20 & 50 & 5 & 3 & 4 & 47 \\
\hline 139 & 20 & 50 & 5 & 3 & 2,5 & 47 \\
\hline 140 & 20 & 50 & 5 & 3 & 2,5 & 47 \\
\hline 141 & 20 & 50 & 1,6 & 3 & 3,75 & 47 \\
\hline 142 & 20 & 50 & 1,6 & 3 & 3,75 & 47 \\
\hline
\end{tabular}

